\title{
A synthesis of Martian aqueous mineralogy after 1 Mars year of observations from the Mars Reconnaissance Orbiter
}

\author{
Scott L. Murchie, ${ }^{1}$ John F. Mustard, ${ }^{2}$ Bethany L. Ehlmann, ${ }^{2}$ Ralph E. Milliken, ${ }^{3}$ \\ Janice L. Bishop, ${ }^{4}$ Nancy K. McKeown, ${ }^{5}$ Eldar Z. Noe Dobrea, ${ }^{3}$ Frank P. Seelos, ${ }^{1}$ \\ Debra L. Buczkowski, ${ }^{1}$ Sandra M. Wiseman, ${ }^{6}$ Raymond E. Arvidson, ${ }^{6}$ James J. Wray, ${ }^{7}$ \\ Gregg Swayze, ${ }^{8}$ Roger N. Clark, ${ }^{8}$ David J. Des Marais, ${ }^{9}$ Alfred S. McEwen, ${ }^{10}$ \\ and Jean-Pierre Bibring ${ }^{11}$
}

Received 24 January 2009; revised 8 May 2009; accepted 11 June 2009; published 22 September 2009.

[1] Martian aqueous mineral deposits have been examined and characterized using data acquired during Mars Reconnaissance Orbiter's (MRO) primary science phase, including Compact Reconnaissance Imaging Spectrometer for Mars hyperspectral images covering the $0.4-3.9 \mu \mathrm{m}$ wavelength range, coordinated with higher-spatial resolution HiRISE and Context Imager images. MRO's new high-resolution measurements, combined with earlier data from Thermal Emission Spectrometer; Thermal Emission Imaging System; and Observatoire pour la Minéralogie, L'Eau, les Glaces et l'Activitié on Mars Express, indicate that aqueous minerals are both diverse and widespread on the Martian surface. The aqueous minerals occur in 9-10 classes of deposits characterized by distinct mineral assemblages, morphologies, and geologic settings. Phyllosilicates occur in several settings: in compositionally layered blankets hundreds of meters thick, superposed on eroded Noachian terrains; in lower layers of intracrater depositional fans; in layers with potential chlorides in sediments on intercrater plains; and as thousands of deep exposures in craters and escarpments. Carbonate-bearing rocks form a thin unit surrounding the Isidis basin. Hydrated silica occurs with hydrated sulfates in thin stratified deposits surrounding Valles Marineris. Hydrated sulfates also occur together with crystalline ferric minerals in thick, layered deposits in Terra Meridiani and in Valles Marineris and together with kaolinite in deposits that partially infill some highland craters. In this paper we describe each of the classes of deposits, review hypotheses for their origins, identify new questions posed by existing measurements, and consider their implications for ancient habitable environments. On the basis of current data, two to five classes of Noachian-aged deposits containing phyllosilicates and carbonates may have formed in aqueous environments with $\mathrm{pH}$ and water activities suitable for life.

Citation: Murchie, S. L., et al. (2009), A synthesis of Martian aqueous mineralogy after 1 Mars year of observations from the Mars Reconnaissance Orbiter, J. Geophys. Res., 114, E00D06, doi:10.1029/2009JE003342.

\section{Introduction}

[2] Central scientific questions about Mars are whether any past environments were habitable, when and where they existed, and which geologic deposits could have preserved evidence of past life that developed in these environments. On Earth, the preservation of a record of life or prebiotic chemistry generally requires that biotic materials be

\footnotetext{
${ }^{1}$ Applied Physics Laboratory, Laurel, Maryland, USA.

${ }^{2}$ Department of Geological Sciences, Brown University, Providence, Rhode Island, USA.

${ }^{3}$ Jet Propulsion Laboratory, Caltech, Pasadena, California, USA.

${ }^{4}$ SETI Institute, Mountain View, California, USA.

${ }^{5}$ Department of Earth and Planetary Sciences, University of California, Santa Cruz, California, USA.

Copyright 2009 by the American Geophysical Union. 0148-0227/09/2009JE003342
}

entombed by chemical precipitates or fine-grained clastic sediments, especially clays [Farmer and Des Marais, 1999]. Decades of analysis of imaging data from the Mariner 9 and Viking Orbiters, together with studies of terrestrial analogs, indicate that the Martian environments most likely to have harbored life or prebiotic chemistry and to have preserved a fossil record are pedogenic layers, paleolakes, paleoseas, and springs [Farmer and Des Marais, 1999].

\footnotetext{
${ }^{6}$ Department of Earth and Planetary Sciences, Washington University, St. Louis, Missouri, USA. USA.

${ }^{7}$ Department of Astronomy, Cornell University, Ithaca, New York,

${ }^{8}$ U.S. Geological Survey, Denver, Colorado, USA

${ }^{9}$ NASA Ames Research Center, Moffett Field, California, USA

${ }^{10}$ Institut d'Astrophysique Spatiale, Université Paris Sud, Orsay, France.

${ }^{11}$ Lunar and Planetary Laboratory, University of Arizona, Tucson, Arizona, USA.
} 
From the perspective of Mars orbit, two major types of evidence can indicate the existence of these past environments: (1) morphology and bed forms indicative of past liquid water, such as depositional fans and point bars, and (2) remotely detected minerals indicative of persistent water activity. Minerals expected to form in these liquid water environments, commonly called "aqueous minerals," include iron oxides and oxyhydroxides, zeolites, carbonates, sulfates, hydrated silica, and phyllosilicates [e.g., Allen and Conca, 1991; Banfield et al., 1991; Robert and Goffé, 1993; Bishop et al., 2004]. Deposits that exhibit both morphology and minerals indicative of past water are of special interest. For example, structures characteristic of marine, lacustrine, or fluvial sediments provide information on physical processes in their depositional environments, whereas mineralogy provides information on chemical conditions and sediment source regions.

[3] During the period 1997-2005, morphological and mineralogical evidence for past water was sought using the Thermal Emission Spectrometer (TES) and Mars Orbiter Camera (MOC) on Mars Global Surveyor (MGS) [Christensen and Moore, 1992; Malin et al., 1992], the Thermal Emission Imaging System (THEMIS) on Mars Odyssey (MO) [Christensen et al., 2004], and Observatoire pour la Minéralogie, L'Eau, les Glaces et l'Activitié (OMEGA) on Mars Express [Bibring et al., 2005]. Among the most important morphologic evidence are valley networks indicating Noachian era surface flow [Baker et al., 1992]; widespread, subhorizontally layered rocks of Noachian to Hesperian age in Valles Marineris, Meridiani Planum, and western Arabia [Malin and Edgett, 2001]; and Noachian age intracrater fans consistent with fluvial or alluvial deposition [Malin and Edgett, 2003]. Mineralogic evidence includes phyllosilicates in Noachian rocks, which suggest the prolonged presence of liquid water during Mars' oldest geologic period [Bibring et al., 2005; Poulet et al., 2005; Bibring et al., 2006]. Aqueous minerals in younger Hesperian rocks include hydrated sulfates and ferric oxides [Arvidson et al., 2005; Gendrin et al., 2005a, 2005b; Mangold et al., 2008]. This ancient temporal change in Mars' aqueous mineralogy has been interpreted as evidence for changes in the surface environment, from earlier, wetter conditions with near-neutral $\mathrm{pH}$ to later drier, more acidic conditions. Acidity might have increased over time because of $\mathrm{SO}_{2}$ emissions from the Tharsis volcanoes [Bibring et al., 2006], or because of dissolution of buried sulfide deposits by oxidizing groundwater [Burns, 1986, 1987, 1993; Burns and Fisher, 1990].

[4] Two investigations on the Mars Reconnaissance Orbiter (MRO) have dramatically improved the spatial resolutions of both mineralogic and morphologic evidence for past aqueous environments. Through the completion of MRO's primary science phase in December 2008, Compact Reconnaissance Imaging Spectrometer for Mars (CRISM) [Murchie et al., 2007a, 2009a] acquired a spectral map of $55 \%$ of Mars's surface in 72 selected wavelengths at $200 \mathrm{~m} /$ pixel (5 times higher average spatial resolution than OMEGA). Targeted observations were taken covering about 9500 sites in 544 spectral bands with $6.55 \mathrm{~nm}$ sampling, at 18-36 m/pixel (20 times higher spatial resolution than OMEGA's highest resolution). CRISM's spectral range of 0.4-3.9 $\mu \mathrm{m}$ covers electronic transition absorptions due to olivine and pyroxene (dominant phases in Mars' basaltic crust) and their ferric alteration products, and vibrational absorptions due to $\mathrm{H}_{2} \mathrm{O}, \mathrm{OH}, \mathrm{CO}_{3}$, and $\mathrm{SO}_{4}$ in alteration products including phyllosilicates, hydrated silica, sulfates, oxyhydroxides, and carbonates. The High-Resolution Imaging Science Experiment (HiRISE) has acquired $\sim 30 \mathrm{~cm} /$ pixel images, 5 times finer than MOC, covering $\sim 0.55 \%$ of the Martian surface [McEwen et al., 2007, 2009]. The resulting $1-\mathrm{m}$ spatial resolution is shown from terrestrial analog studies to resolve bed forms and structures diagnostic of important surface processes [McEwen et al., 2007]. A portion of each HiRISE image is acquired in three-band color, enabling mapping of distinct surface compositions at meter scales. CRISM and HiRISE observations are typically coordinated with each other, and often with the Context Imager (CTX) [Malin et al., 2007] acquiring $6 \mathrm{~m} /$ pixel panchromatic images to provide local context.

[5] In this paper we summarize the state of knowledge, at the conclusion of MRO's primary science phase, of the types and distributions of deposits that exhibit evidence for aqueous minerals. The spatial extent, number of exposures, and diversity of these deposits are far greater than had been expected on the basis of previous orbital surveys [e.g., Christensen et al., 2001b]. However, among these exposures, there are recurring combinations of morphologies and mineral assemblages that characterize distinct "classes" of aqueous deposits. We describe 10 such classes, which are distributed across the planet in geologic units ranging from Noachian through Amazonian ages. Part of this description is synthesized from recent papers describing results from the THEMIS [Osterloo et al., 2008] and MRO CRISM and HiRISE investigations [Mustard et al., 2008; Bishop et al., 2008; Milliken et al., 2008; Ehlmann et al., 2008a, 2008b], and from new studies published in this issue [Mustard et al., 2009; Ehlmann et al., 2009; McKeown et al., 2009; Wiseman et al., 2009; Bishop et al., 2009; Roach et al., 2009; Murchie et al., 2009b; Calvin et al., 2009; E. Z. Noe Dobrea et al., Mineralogy and stratigraphy of phyllosilicatebearing and dark mantling units in the greater Mawrth Vallis/West Arabia Terra area: Constraints on geological origin, submitted to Journal of Geophysical Research, 2009; K. Lichtenberg et al., Stratigraphy of hydrated sulfates in the sedimentary deposits of Aram Chaos, Mars, submitted to Journal of Geophysical Research, 2009]. In addition we present original results on deep exposures of phyllosilicate in Valles Marineris, and on assemblages of phyllosilicates and potential chlorides in "plains sediments." The occurrence of distinct classes of aqueous deposits has not previously been recognized or documented, yet they have implications for the range of past environments that might have supported habitable conditions. We review hypotheses for the origins of these deposits and, on the basis of the mineral assemblages present, make a preliminary assessment of which of the deposits may have formed in environments having water activities consistent with habitable conditions.

\section{Orbital and Landed Investigation of Mars' Aqueous Mineralogy}

[6] Recent orbital observations of Mars have revealed increasingly widespread and diverse aqueous mineral- 
Table 1. Timeline Showing Detection of Aqueous Minerals by Different Mars Orbital Spectroscopic Investigations ${ }^{\mathrm{a}}$

\begin{tabular}{|c|c|c|c|c|}
\hline & MGS TES & MEx/OMEGA & Odyssey THEMIS & MRO/CRISM, MRO/HiRISE \\
\hline Spatial resolution & $6 \mathrm{~km} /$ pixel & $0.3-2 \mathrm{~km} /$ pixel & $\begin{array}{l}18 \mathrm{~m} / \text { pixel VIS, } \\
100 \mathrm{~m} / \text { pixel IR }\end{array}$ & $\begin{array}{l}18 \mathrm{~m} / \text { pixel CRISM } \\
\text { VISIR, } 0.3 \mathrm{~m} / \text { pixel } \\
\text { HiRISE VIS }\end{array}$ \\
\hline Wavelength & $6-50 \mu \mathrm{m}$ & $0.4-5.1 \mu \mathrm{m}$ & $\begin{array}{l}0.4-1.0 \\
6-15 \mu \mathrm{m}\end{array}$ & $0.4-3.9 \mu \mathrm{m}$ \\
\hline Layered phyllosilicates & & $\begin{array}{c}\mathrm{Al} \text { and } \mathrm{Fe} / \mathrm{Mg} \\
\text { clays at Nili and } \\
\text { Mawrth }\end{array}$ & - & $\begin{array}{c}\text { Stratification of } \\
\text { different compositions; } \\
\text { detailed stratigraphy }\end{array}$ \\
\hline Phyllosilicates in intercrater fans & & & & $\begin{array}{c}\text { Highland crater } \\
\text { fans/deltas contain } \\
\text { phyllosilicate-bearing } \\
\text { layers }\end{array}$ \\
\hline Plains sediments & & & $\begin{array}{l}\text { Chloride } \\
\text { detection }\end{array}$ & $\begin{array}{c}\text { Cooccurrence with } \\
\text { phyllosilicates in layers }\end{array}$ \\
\hline Deep phyllosilicates & & $\begin{array}{c}\text { Unknown } \\
\text { hydrated mineral } \\
\text { in dozens } \\
\text { of highland craters }\end{array}$ & - & $\begin{array}{c}>5000 \text { outcrops } \\
\text { in craters, chasmata; } \\
\text { chlorite }+ \text { other } \\
\text { hydrated silicates }\end{array}$ \\
\hline Intracrater clay-sulfate deposits & & & & $\begin{array}{l}\text { Sulfates and } \\
\text { interbedded clays in } \\
\text { highland craters }\end{array}$ \\
\hline Carbonate deposits & & & & $\begin{array}{l}\text { Thin layers of hydrous } \\
\text { carbonates on olivine-rich } \\
\text { rocks }\end{array}$ \\
\hline Meridiani-type layered deposits & $\begin{array}{l}\text { Deposits of } \\
\text { gray hematite }\end{array}$ & $\begin{array}{c}\text { Adjacent } \\
\text { occurrences of } \\
\text { monohydrated } \\
\text { and polyhydrated } \\
\text { sulfates }\end{array}$ & - & $\begin{array}{l}\text { Improved resolution of } \\
\text { largely undeformed } \\
\text { vertical stratification }\end{array}$ \\
\hline Valles-type layered deposits & $\begin{array}{l}\text { Deposits of } \\
\text { gray hematite }\end{array}$ & $\begin{array}{c}\text { Adjacent } \\
\text { occurrences of } \\
\text { monohydrated } \\
\text { and polyhydrated } \\
\text { sulfates }\end{array}$ & - & $\begin{array}{l}\text { Intricate vertical } \\
\text { layering of sulfate } \\
\text { types and Fe oxides; } \\
\text { folding; alteration } \\
\text { zones }\end{array}$ \\
\hline Siliceous layered deposits & & & & $\begin{array}{c}\text { Widespread hydrated } \\
\text { silica in layered } \\
\text { deposits on Hesperian plains }\end{array}$ \\
\hline Gypsum plains & & $\begin{array}{l}\text { Gypsum-rich } \\
\text { optical surface }\end{array}$ & - & Relationship to basal unit \\
\hline
\end{tabular}

\footnotetext{
${ }^{\mathrm{a}}$ As spatial resolution and wavelength coverage of the data have improved, the diversity of recognized deposits and their known spatial distributions have increased. Data are given for the time during which a class of deposits' existence was known. Hyphens mean there are no new mineral identifications.
}

bearing deposits, as spatial resolution of the measurements has increased. A history of the discovery of these deposits is summarized in Table 1. At the few-kilometer resolution of TES and OMEGA, four to five types of deposits were resolved. The first of these was concentrations of coarsegrained, gray hematite [Christensen et al., 2000, 2001a] exposed from one or more strata of an etched mantling deposit in Meridiani Planum [Arvidson et al., 2003]. Subsequent orbital investigation showed that the etched materials also contain large amounts of hydrated sulfate minerals [Arvidson et al., 2005; Griffes et al., 2007]. This hematitebearing material was chosen as the target for the Mars Exploration Rover/Opportunity, whose landed investigations are discussed below. Deposits of similar morphology compose much if not all of the interior layered deposits of Valles Marineris [Lucchitta et al., 1992], and were found to contain spatially segregated polyhydrated sulfates and monohydrated sulfate (probably the $\mathrm{Mg}$ phase kieserite) in close spatial association with ferric oxides [Gendrin et al., 2005a, 2005b; Bibring et al., 2007; Mangold et al., 2008]. $\mathrm{Fe} / \mathrm{Mg}$ phyllosilicates were found in regions surrounding Mawrth Vallis and Nili Fossae and in scattered outcrops in other regions of the Noachian-aged highlands. Bedrock units with smectite clays, Fe-rich nontronite in Nili Fossae and both nontronite and Al-rich montmorillonite surrounding Mawrth Vallis, were identified beneath units of unaltered rock [Bibring et al., 2005; Poulet et al., 2005; Bibring et al., 2006; Loizeau et al., 2007]. Finally, parts of the north polar erg (sand sea) were found to be rich in gypsum, at up to $>30 \mathrm{wt} \%$ abundance at the optical surface [Langevin et al., 2005; Fishbaugh et al., 2007].

[7] With the improved spatial resolution of THEMIS, one additional probable aqueous mineral was recognized, in socalled "glowing terrain." At thermal infrared wavelengths this terrain exhibits evidence for a phase that lacks diagnostic emission features, but has emissivity $<1.0$ throughout the THEMIS wavelength range. Chloride minerals exhibit these properties and also are the geologically most reasonable candidates, but they would have to be present in excess of $25 \%$ by weight. The presence of chloride or some other evaporite mineral is consistent with the glowing terrain's location typically in shallow closed basins, sometimes at the terminus of inflowing channels [Osterloo et al., 2008].

[8] The first Mars year of MRO observations caused a paradigm change in recognition of the diversity and abundance of aqueous deposits on Mars. Four new classes of aqueous mineral deposits have been discovered: phyllosilicates occurring within previously recognized intracrater 
depositional fans and deltaic deposits, most conspicuously in the lowermost strata [Grant et al., 2007; Ehlmann et al., 2008a]; widespread hydrated silica in thin, light-toned layers on Hesperian age plains [Milliken et al., 2008]; carbonates in Noachian age terrains [Ehlmann et al., 2008b]; and intracrater deposits in the Noachian highlands that contain assemblages of sulfates and kaolinite [Swayze et al., 2008; Wray et al., 2008b, 2009]. Many new details about the previously recognized aqueous deposits (as summarized in section 4) have also been discovered. The most significant new finding is the widespread distribution and diversity of hydrated silicates in the highlands. Whereas OMEGA global mapping uncovered a few dozen occurrences, the higher spatial resolution of CRISM global mapping has revealed between several thousand and a few tens of thousands of outcrops hundreds of meters or larger in size, mostly in the central peaks, walls, and ejecta of craters [Mustard et al., 2008]. The probable phases present include hydrated glass and silica, zeolite, the Mg smectite saponite, the $\mathrm{Fe}$ smectite nontronite, chlorite, prehnite, and one or more micaceous phases such as illite or muscovite [Ehlmann et al., 2007, 2008c, 2009; Clark et al., 2008; Mustard et al., 2008].

[9] Finding these materials from orbit is an important achievement. However, results from MER/Opportunity provide lessons on the importance of landed investigations to interpreting the orbital data, and on limitations on testing hypotheses for the origin of these deposits in lieu of landed measurements [Squyres et al., 2004, 2006; Arvidson et al., 2006]. Prior to the MER landings, models for deposition of gray hematite exposed at the landing site included precipitation from surface waters, precipitation from hydrothermal fluids, and in situ alteration of basaltic materials [Christensen et al., 2000, 2001a]. To test these hypotheses at the Meridiani site, Opportunity performed several measurements, including (1) panoramic imaging with sufficient spectral capability to distinguish among materials having different gross iron mineralogies and sufficient spatial resolution to characterize structures and bed forms, such as bedding in the Burns Formation and hematite concretions; (2) microscopic imaging to characterize diagnostic textures and small structures, such as cross-bedding, ripples, desiccation cracks, and molds of evaporite crystals; and (3) elemental and mineralogic composition measurements at multiple locations within a section, to estimate normative mineralogy and to reveal any geochemical trends in the concentrations of sulfates, halides, and other indicators of aqueous activity.

[10] These findings led to a model for the formation of these deposits that is distinct from all three hypotheses inferred from orbital data, yet incorporates aspects of all of them. The interpreted sequence of events, namely the deposition of detrital clastics and chemical precipitates that were later reworked, lithified, and diagenetically altered by groundwater, could not have been inferred from orbital measurements alone.

[11] These results from landed science help to clarify both the strengths and the limitations of orbital observations. Orbital reconnaissance can identify an aqueous deposit and support multiple working hypotheses for its origin, but landed investigation has proven necessary to distinguish among these hypotheses and to decipher the environment that it records. Landed investigation also shows that orbital reconnaissance provides a "lower limit" on the mineralogic diversity at a given site, with much of that record not being detectable from orbit because of dust cover or limitations in spatial resolution. For example, at the MER/Spirit landing site at the Columbia Hills in Gusev crater, in situ investigation has revealed hydrated phases including goethite, opaline silica, and several phases of hydrated sulfates. The exposures of these materials are at scales too small to be seen from orbit, even once they are exposed from beneath dust cover by the rover's wheels [Arvidson et al., 2008]. To the extent that the Columbia Hills are representative of the Hesperian to Noachian rock record, Mars' aqueous deposits can be expected to contain a more detailed mineralogic record diagnostic of past environments than can be seen from orbit.

\section{Data Reduction and Analysis}

[12] This paper is focused on Mars' aqueous mineralogy. Therefore we emphasize data from CRISM, and consider its mineralogic evidence together with morphologic observations from HiRISE and CTX images. CRISM data shown in this paper were converted to apparent $\mathrm{I} / \mathrm{F}$ using procedures described by Murchie et al. [2007a, 2009a], which include three core steps. First, the data were corrected for detector background by subtracting dark measurements that accompany Mars scene measurements. Second, they were converted to radiance by dividing by similarly processed measurements of an onboard integrating sphere, and multiplied by a spectral model of the integrating sphere derived from ground calibrations. Finally they were divided by a solar spectrum convolved through CRISM's band passes measured on ground, scaled to Mars' solar distance. In addition, propagated detector noise was reduced using a filtering algorithm [Parente, 2008].

[13] Three methods have been used to correct surface measurements for effects of illumination and atmospheric scattering and attenuation. The first method, the "volcano scan correction," is the correction typically applied to single targeted observations. The data are divided by the cosine of the solar incidence angle and by a scaled atmospheric transmission spectrum obtained during an observation crossing Olympus Mons [Bibring et al., 2005; Mustard et al., 2008]. This corrects for atmospheric gases but not aerosols. The second method, the "Lambert albedo correction," is applied during standard processing to mosaics of multispectral data acquired over a range of atmospheric and illumination conditions. Mars climatology is used to predict atmospheric conditions, and the radiative transfer algorithm DISORT [Stamnes et al., 1988] is used to compute and remove the estimated atmospheric contribution to radiance resulting from both gases and aerosols [McGuire et al., 2008]. The retrieved surface value, Lambert albedo, represents I/F of a Lambertian surface free of atmospheric effects illuminated and observed at normal angles. The third method is applied to selected targeted observations [e.g., Arvidson et al., 2008]. Using climatological values of atmospheric gas and aerosol abundances as a starting guess, DISORT is run iteratively to model both surface and atmospheric radiances to minimize atmospheric gas bands, and Lambert albedo is retrieved. In each of the three cases, 
Table 2. Spectral Parameters Used to Represent CRISM Data in This Paper

\begin{tabular}{|c|c|c|c|}
\hline Name & Parameter & Formulation $^{\mathrm{a}}$ & Rationale \\
\hline R770 & Corrected $0.77-\mu \mathrm{m} \mathrm{I} / \mathrm{F}$ & $\mathrm{R} 770$ & Reference surface reflectance \\
\hline BD530 & $0.53-\mu \mathrm{m}$ band depth & $1-(\mathrm{R} 530 /(\mathrm{a} * \mathrm{R} 709+\mathrm{b} * \mathrm{R} 440))$ & $\begin{array}{l}\text { Ferric minerals, especial nanophase } \\
\text { ferric oxide and hematite }\end{array}$ \\
\hline SH600 & Inflection at $0.6 \mu \mathrm{m}$ & $\mathrm{R} 600 /(\mathrm{a} * \mathrm{R} 530+\mathrm{b} * \mathrm{R} 709)$ & $\begin{array}{l}\text { Dust coatings on dark substrate or } \\
\text { compacted dust [Fischer and Pieters, 1993] }\end{array}$ \\
\hline BDI1000VIS & $\begin{array}{c}1-\mu \mathrm{m} \text { integrated } \\
\text { band depth } \\
\text { measured at }<1.0 \mu \mathrm{m}\end{array}$ & $\begin{array}{l}\text { divide } \mathrm{R} 830, \mathrm{R} 860, \mathrm{R} 890, \mathrm{R} 915 \\
\text { by peak } \mathrm{R} \text { between } 0.60 \text { and } 0.83 \mu \mathrm{m} \text {, } \\
\text { then integrate over }(1-\text { normalized } \\
\text { radiances) to get integrated band depth }\end{array}$ & $\begin{array}{l}1-\mu \mathrm{m} \text { absorption due to olivine or pyroxene } \\
\text { also sensitive to crystalline ferric minerals }\end{array}$ \\
\hline BDI1000IR & $\begin{array}{c}1-\mu \mathrm{m} \text { integrated } \\
\text { band depth } \\
\text { measured at }>1.0 \mu \mathrm{m}\end{array}$ & $\begin{array}{l}\text { divide R1030, R1050, R1080, R } 1150 \\
\text { by linear continuum fit between } 1.3 \\
\text { and } 1.87 \mu \mathrm{m} \text { and } \mathrm{R} 2530 \text {, then integrate } \\
\text { over ( } 1 \text { - normalized radiances) to get } \\
\text { integrated band depth }\end{array}$ & $\begin{array}{l}1-\mu \mathrm{m} \text { absorption due to olivine or pyroxene } \\
\text { also weakly sensitive to dust }\end{array}$ \\
\hline IRA & Corrected $1.33-\mu \mathrm{m} \mathrm{I} / \mathrm{F}$ & $\mathrm{R} 1330$ & Reference surface reflectance \\
\hline OLINDEX & Olivine index & $\begin{array}{l}(\mathrm{R} 1695 /(0.1 * \mathrm{R} 1050+0.1 * \mathrm{R} 1210 \\
+0.4 * \mathrm{R} 1330+0.4 * \mathrm{R} 1470))-1\end{array}$ & Olivine and Fe-containing phyllosilicate \\
\hline LCPINDEX & $\begin{array}{l}\text { Low-Ca pyroxene } \\
\text { index }\end{array}$ & $\begin{array}{l}((\mathrm{R} 1330-\mathrm{R} 1050) /(\mathrm{R} 1330+\mathrm{R} 1050)) \\
((\mathrm{R} 1330-\mathrm{R} 1815) /(\mathrm{R} 1330+\mathrm{R} 1815)\end{array}$ & Pyroxene, favoring low-Ca pyroxene \\
\hline HCPINDEX & $\begin{array}{l}\text { High-Ca pyroxene } \\
\text { index }\end{array}$ & $\begin{array}{c}((\mathrm{R} 1470-\mathrm{R} 1050) /(\mathrm{R} 1470+\mathrm{R} 1050)) \\
((\mathrm{R} 1470-\mathrm{R} 2067) /(\mathrm{R} 1470+\mathrm{R} 2067)\end{array}$ & Pyroxene, favoring high-Ca pyroxene \\
\hline ISLOPE1 & IR spectral slope & $(\mathrm{R} 1815-\mathrm{R} 2530) /(2530-\mathrm{R} 1815)$ & Same as SH600 \\
\hline BD1900 & $\begin{array}{l}1.9 \text { micron } \mathrm{H}_{2} \mathrm{O} \\
\text { band depth }\end{array}$ & $\begin{array}{c}1-(((\mathrm{R} 1930+\mathrm{R} 1985) * 0.5) / \\
(\mathrm{a} * \mathrm{R} 1875+\mathrm{b} * \mathrm{R} 2067)\end{array}$ & Bound $\mathrm{H}_{2} \mathrm{O}$ in most minerals \\
\hline BD2100 & $\begin{array}{l}2.1 \text { micron shifted } \\
\mathrm{H}_{2} \mathrm{O} \text { band depth }\end{array}$ & $\begin{array}{c}1-(((\mathrm{R} 2120+\mathrm{R} 2140) * 0.5) / \\
(\mathrm{a} \text { R } 1930+\mathrm{b} * \mathrm{R} 2250))\end{array}$ & Bound $\mathrm{H}_{2} \mathrm{O}$ in monohydrated sulfates \\
\hline BD2210 & $\begin{array}{l}2.21 \text { micron } \mathrm{Al}-\mathrm{OH} \\
\text { band depth }\end{array}$ & $1-(\mathrm{R} 2210 /(\mathrm{a} * \mathrm{R} 2140+\mathrm{b} * \mathrm{R} 2250))$ & $\begin{array}{l}\mathrm{Al}-\mathrm{OH} \text { and } \mathrm{Si}-\mathrm{OH} \text { bonds } \\
\text { in glass and phyllosilicate }\end{array}$ \\
\hline D2300 & 2.3 micron dropoff & $\begin{array}{c}1-(\mathrm{R} 2290+\mathrm{R} 2330+\mathrm{R} 2330) / \\
(\mathrm{R} 2140+\mathrm{R} 2170+\mathrm{R} 2210)\end{array}$ & $\mathrm{Mg}-\mathrm{OH}$ and $\mathrm{Fe}-\mathrm{OH}$ bonds in phyllosilicate \\
\hline SINDEX & $\begin{array}{l}\text { Detects convexity at } \\
2.29 \mu \mathrm{m} \text { due } \\
\text { to absorptions at } \\
1.9-2.1,2.4 \mu \mathrm{m}\end{array}$ & $1-(\mathrm{R} 2100+\mathrm{R} 2400) /(2 * \mathrm{R} 2290)$ & Hydrated minerals \\
\hline IRR2 & IR ratio 2 & $\mathrm{R} 2530 / \mathrm{R} 2210$ & Spectral slope at $2.2-2.5 \mu \mathrm{m}$ \\
\hline BD3000 & 3- $\mu \mathrm{m} \mathrm{H}_{2} \mathrm{O}$ band depth & $1-(\mathrm{R} 3000 /(\mathrm{R} 2530 *(\mathrm{R} 2530 / \mathrm{R} 2210)))$ & Bound $\mathrm{H}_{2} \mathrm{O}$ and $\mathrm{OH}$ \\
\hline
\end{tabular}

${ }^{\mathrm{a}}$ Values beginning with $\mathrm{R}$ are used to represent atmospherically and photometrically corrected $\mathrm{I} / \mathrm{F}$ at a given wavelength in nanometers.

data are map projected using the line-of-sight intercept of each detector element with the MOLA shape model of Mars.

[14] To show variations in key mineralogic absorptions in image form, we use spectral parameters or "summary products" [Pelkey et al., 2007], standardized representations of absorption band depths using wavelengths included in both targeted and multispectral mapping data. Summary products are shown here overlain on reference corrected I/F, at $0.77 \mu \mathrm{m}$ for parameters calculated from wavelengths $0.44-1.02 \mu \mathrm{m}$ and at $1.33 \mu \mathrm{m}$ for parameters calculated from wavelengths $1.02-3.92 \mu \mathrm{m}$. The full set of summary products is described by S. Murchie et al. (CRISM data product software interface specification, 2007; available at $\mathrm{ftp}: / /$ pds-geosciences.wustl.edu/mro-crism/mro-m-crism-2edr-v1/mrocr_0001/document/crism_avsis.pdf), and those utilized in this paper are described in Table 2.

[15] The results presented here focus on the detection of mineral phases and their correlations with morphologic features, their stratigraphic relationships, and their spatial distributions. For these purposes CRISM data were analyzed in conjunction with HiRISE and CTX images that were processed to the standard levels delivered to the Planetary Data System [McEwen et al., 2007; Malin et al., 2007]. HiRISE color images, which sample CRISM's
$0.4-1.0 \mu \mathrm{m}$ wavelength range in three broad bands, were autostretched to enhance subtle color variations.

\section{Classes of Aqueous Mineral-Bearing Deposits}

[16] We define classes of aqueous deposits as deposits which (1) exhibit common spectral signatures indicative of a characteristic set of minerals or mineral groups, (2) exhibit the spectral signatures over different geographic areas in materials having comparable morphology and geologic settings, and (3) exhibit consistent stratigraphic relationships with other major geologic units defined by Tanaka et al. [1992], as well as they can be determined. Nine to ten classes of deposits have been recognized to date, depending on whether layered materials in Meridiani Planum and Valles Marineris are considered to be the same or different (section 4.8). We recognize that choices of lumping and splitting classes can be somewhat arbitrary and that further distinctions are likely to be realized in the future. In addition, MRO data are so new that more classes of deposits may yet be discovered.

[17] Table 3 lists the 10 classes of deposits and their characteristic aqueous mineralogy, associated morphology and geologic setting, and geographic distribution, on the basis of analyses conducted through the end of 2008. For each class a type area is given, along with identifiers of the 
Table 3. Characteristics of Major Classes of Aqueous Mineral-Bearing Deposits Known Through Late 2008

\begin{tabular}{|c|c|c|c|c|}
\hline Short Name & Aqueous Minerals Present & Morphology & Distribution & $\begin{array}{c}\text { Type Area With CRISM/ } \\
\text { HiRISE Image IDs }\end{array}$ \\
\hline Layered phyllosilicate & $\begin{array}{l}\text { Al smectite, } \\
\text { kaolinite group, } \\
\text { Fe/Mg smectite, } \\
\text { hydrated silica, } \\
\text { Fe oxides }\end{array}$ & $\begin{array}{c}\text { 10s-m thick blanket of } \mathrm{Al} \\
\text { phyllosilicate and } \\
\text { hydrated silica overlying } \\
\mathrm{Fe} / \mathrm{Mg} \text { smectite, } \\
\text { commonly polygonally } \\
\text { fractured; exposed where } \\
\text { protective caprock has } \\
\text { been removed }\end{array}$ & $\begin{array}{l}\text { Mawrth Valles } \\
\text { and surrounding } \\
\text { regions, Nili } \\
\text { Fossae; small } \\
\text { exposures elsewhere }\end{array}$ & $\begin{array}{c}\text { Plains surrounding Mawrth Valles, } \\
\text { 24.7N, 339.1E, HRL000043EC, } \\
\text { PSP_005819_2050 }\end{array}$ \\
\hline $\begin{array}{l}\text { Phyllosilicates in } \\
\text { intracrater fans }\end{array}$ & $\begin{array}{c}\mathrm{Fe} / \mathrm{Mg} \text { smectites } \\
\text { from drainage basins }\end{array}$ & $\begin{array}{l}\text { Fan-shaped deposit where } \\
\text { channel debouches into } \\
\text { crater; phyllosilicate } \\
\text { typically in lower, tabular strata }\end{array}$ & $\begin{array}{l}\text { Holden, Eberswalde, } \\
\text { Jezero, Terby craters }\end{array}$ & $\begin{array}{c}\text { Jezero Crater, } 18.5 \mathrm{~N}, 77.4 \mathrm{E}, \\
\text { HRL000040FF, } \\
\text { PSP_002387_1985 }\end{array}$ \\
\hline Plains sediments & $\begin{array}{c}\text { Chlorides and } \\
\mathrm{Fe} / \mathrm{Mg} \text { smectites }\end{array}$ & $\begin{array}{l}\text { Eroded remnants of } \\
\text { phyllosilicate-rich } \\
\text { deposits in topographic low, } \\
\text { sometimes forming piedmont; } \\
\text { may be embayed by chloride }\end{array}$ & $\begin{array}{l}\text { Scattered throughout } \\
\text { highland plains in crater } \\
\text { floors and intercrater } \\
\text { plains }\end{array}$ & $\begin{array}{l}\text { Terra Sirenum, 32.7S, } \\
\text { 205.5E, HRL0000860C, } \\
\text { PSP_005811_1470 }\end{array}$ \\
\hline Deep phyllosilicates & $\begin{array}{l}\text { Various phyllosilicates, } \\
\text { dominated by prehnite, } \\
\text { chlorite, Fe/Mg smectite }\end{array}$ & $\begin{array}{l}\text { Massive or bouldery to } \\
\text { layered outcrops in crater } \\
\text { walls and central peaks, } \\
\text { massifs, and chasma walls } \\
\text { and escarpments }\end{array}$ & $\begin{array}{l}\text { Craters walls and central } \\
\text { peaks in highland plains, } \\
\text { walls of Valles Marineris }\end{array}$ & $\begin{array}{c}\text { Wall of Valles Marineris, 14.0S, } \\
\text { 304.4E, FRT00009804, } \\
\text { PSP_006928_1660 }\end{array}$ \\
\hline Carbonate deposits & $\begin{array}{c}\text { Magnesium carbonate, } \\
\text { possibly other } \\
\text { hydrated phases }\end{array}$ & $\begin{array}{l}\text { Thin bed overlying or } \\
\text { grading into olivine-rich } \\
\text { rock; superposed by } \\
\text { resistant caprock }\end{array}$ & $\begin{array}{l}\text { Thin outcrops surrounding } \\
\text { Isidis basin }\end{array}$ & $\begin{array}{c}\text { Nili Fossae, 21.9N, 78.4E, } \\
\text { FRT0000B072, } \\
\text { PSP_002176_2025 }\end{array}$ \\
\hline $\begin{array}{l}\text { Intracrater clay-sulfate } \\
\text { deposits }\end{array}$ & $\begin{array}{l}\text { Kaolinite, hydrated } \\
\text { sulfates including alunite } \\
\text { and maybe jarosite }\end{array}$ & $\begin{array}{l}\text { Interbedded phyllosilicate } \\
\text { and sulfate layers on } \\
\text { crater walls forming } \\
\text { "bathtub ring" pattern }\end{array}$ & Craters in Terra Sirenum & $\begin{array}{c}\text { Columbus crater, 28.5S, 194.0E, } \\
\text { FRT00007D87, } \\
\text { PSP_005429_1510 }\end{array}$ \\
\hline $\begin{array}{l}\text { Meridiani-type layered } \\
\text { deposits }\end{array}$ & $\begin{array}{l}\text { Hydrated sulfates, } \\
\text { jarosite, hematite }\end{array}$ & $\begin{array}{l}\text { Undeformed layers } \\
\text { superposed on cratered } \\
\text { terrain; monohydrated or } \\
\text { polyhydrated sulfates in } \\
\text { various layers; extensive } \\
\text { eolian erosion; some } \\
\text { strata rich in hematite }\end{array}$ & $\begin{array}{l}\text { Terra Meridiani and } \\
\text { Aram Chaos }\end{array}$ & $\begin{array}{c}\text { Terra Meridiani, } 2.3 \mathrm{~N}, 359.7 \mathrm{E}, \\
\text { FRT00004616, } \\
\text { PSP_002680_1825 }\end{array}$ \\
\hline $\begin{array}{l}\text { Valles-type layered } \\
\text { deposits }\end{array}$ & $\begin{array}{c}\text { Hydrated sulfates, } \\
\text { Fe oxides and sulfates }\end{array}$ & $\begin{array}{l}\text { Thick stack of layers } \\
\text { infilling chasmata; mostly } \\
\text { horizontal bedding } \\
\text { deformed by folding and } \\
\text { faulting; monohydrated or } \\
\text { polyhydrated sulfates in } \\
\text { discrete layers; extensive } \\
\text { eolian erosion; some } \\
\text { strata rich in Fe oxide }\end{array}$ & $\begin{array}{l}\text { Valles Marineris including } \\
\text { Candor, Melas, Juventae, } \\
\text { Tithonium, and } \\
\text { Eos Chasmata }\end{array}$ & $\begin{array}{c}\text { Candor Chasma, 5.8S, 286.1E, } \\
\text { FRT00009CB6, } \\
\text { PSP_007166_1740 }\end{array}$ \\
\hline $\begin{array}{l}\text { Siliceous layered } \\
\text { deposits }\end{array}$ & $\begin{array}{l}\text { Hydrated silica } \\
\text { including opal, } \\
\text { also jarosite }\end{array}$ & $\begin{array}{l}\text { Thin, light-toned, layered } \\
\text { deposits; extensive eolian } \\
\text { stripping, inverted stream } \\
\text { channels }\end{array}$ & $\begin{array}{l}\text { Plains surrounding } \\
\text { Valles Marineris }\end{array}$ & $\begin{array}{c}\text { Plains west of Juventae Chasma, } \\
\text { 4.6S, 296.4E, FRT00005814, } \\
\text { PSP_005429_1510 }\end{array}$ \\
\hline Gypsum plains & $\begin{array}{l}\text { Gypsum, probably } \\
\text { other hydrated minerals }\end{array}$ & $\begin{array}{l}\text { Dark, sandy material in } \\
\text { part of polar basal unit } \\
\text { reworked into dunes }\end{array}$ & $\begin{array}{l}\text { Dark sediments in north } \\
\text { polar erg and north polar } \\
\text { layered deposits }\end{array}$ & $\begin{array}{c}\text { Olympia Undae, } 80.0 \mathrm{~N}, 240.7 \mathrm{E}, \\
\text { FRT0000285F, } \\
\text { PSP 001432 2610 }\end{array}$ \\
\hline
\end{tabular}

CRISM and HiRISE observations covering it. Approximate relative ages according to stratigraphic conventions summarized by Tanaka et al. [1992] are shown in Figure 1. For most of the classes, the age ranges are cited from published literature; for plains sediments and intracrater clay-sulfate deposits, they are inferred from stratigraphic relationships evident in MRO data.

[18] In sections 4.1-4.10 we describe the classes of deposits as seen from orbit, and summarize hypotheses for their origins that are consistent with available data. In most cases multiple working hypotheses appear viable and addi- tional, probably landed, measurements are required to further evaluate those hypotheses.

\subsection{Layered Phyllosilicates}

[19] The phyllosilicates detected by OMEGA surrounding Nili Fossae and Mawrth Vallis [Michalski and Noe Dobrea, 2007; Loizeau et al., 2007] form discrete, commonly polygonally fractured layers having a distinctive, stratified composition [Mustard et al., 2008]. At Mawrth Vallis (Figures 2 and 3 ) the layers have a total thickness of $>150 \mathrm{~m}$ and form a sequence of (1) a lower layer of Fe/Mgrich clay, typically nontronite; (2) a middle layer of Al-rich 


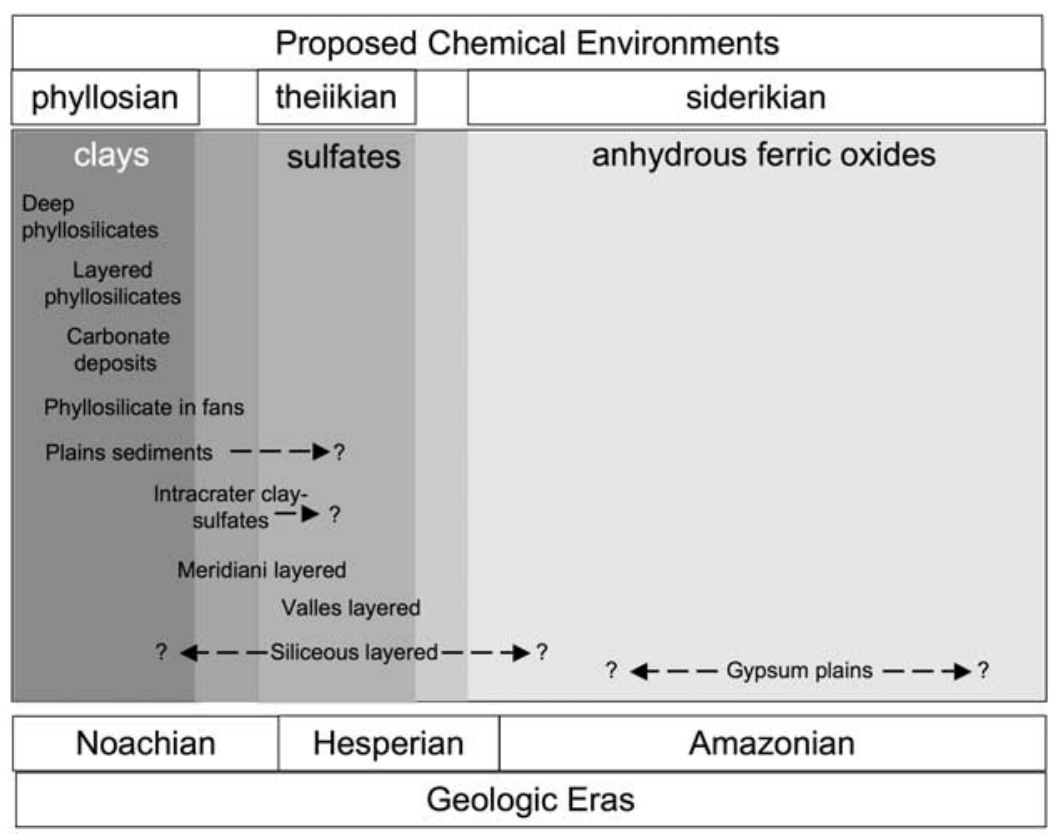

Figure 1. Interpreted relative ages of the 10 classes of aqueous deposits described in Table 1 and sections 2 and 4, given both in the Mars stratigraphic timeframe and relative to the chemical environments proposed by Bibring et al. [2006].

smectite, possibly montmorillonite, or hydrated silica and sometimes (3) a thin upper layer containing an Al phyllosilicate of the kaolinite group and probably hydrated silica. The lower beds contain a strong spectral signature indicating alteration to ferric phases, but ferrous phases are present both above and below the contact of the Fe/Mg- and Al-rich clays [Bishop et al., 2008]. The phyllosilicate-bearing sequence is overlain by a darker-toned caprock that exhibits little to no evidence of altered phases and has weak pyroxene absorptions. Morphologies of the phyllosilicatebearing layers vary, with the Fe/Mg clays exhibiting coarse polygonal fractures tens of meters apart, the Al smectite clays exhibiting more closely spaced fractures, and the kaolinite-group- and silica-bearing layers exhibiting a smooth texture at meters scale [Wray et al., 2007, 2008a; Bishop et al., 2008; McKeown et al., 2009].

[20] MRO results indicate that the deposits in the Mawrth Vallis region are late Noachian in age and once covered much of western Arabia. Studies using Mars Express data suggested that the phyllosilicates are incised by and predate erosion of the Mawrth Vallis outflow channel [Loizeau et al., 2007]. However, using bedding dips extracted from HRSC and HiRISE digital elevation models of selected outcrops, Wray et al. [2008a] showed that the aluminum phyllosilicates are draped on the topography of the channel and that selected outcrops occur within the channel, suggesting that the $\mathrm{Al}$ phyllosilicates postdate channel formation and thus are upper Noachian in age. CRISM multispectral mapping has identified eroded remnants of this stratigraphy over a region at least $700 \times 900 \mathrm{~km}$ in size, suggesting a formerly much greater spatial extent [Noe Dobrea et al., 2008a, also submitted manuscript, 2009].

[21] Phyllosilicate exposures in the eastern and western areas of Nili Fossae [Mangold et al., 2007] are distinctly different. Exposures west of Nili Fossae are classified as deep phyllosilicates, and are discussed in section 4.4. Exposures east of the fossae exhibit commonalities with the material around Mawrth Vallis, including a sequence of $\mathrm{Al}$ phyllosilicates overlying Fe-Mg phyllosilicates, and metersto tens-of-meters-scale polygonal fracturing [Ehlmann et al., 2007, 2008c, 2009]. However, in contrast with Mawrth Vallis, Fe/Mg-rich clays are much more dominant [Ehlmann et al., 2007, 2009]. A dominantly Fe/Mg smectite-bearing, brecciated, $>500 \mathrm{~m}$ thick lower unit [Mustard et al., 2009] and layered sedimentary $\mathrm{Fe} / \mathrm{Mg}$ smectites are frequently capped by a thin kaolinite layer that is no more than tens of meters thick [Ehlmann et al., 2009]. The kaolinite-bearing material is overlain by a capping unit with no distinctive mineralogic signature.

[22] Other occurrences of this sequence of Al-bearing clays overlying $\mathrm{Fe} / \mathrm{Mg}$-bearing clays have been recognized in widely separated locations including Eridania basin [Noe Dobrea et al., 2008b], Noachis [Wray et al., 2009], and in the walls of Valles Marineris (section 4.4), possibly indicating a globally widespread distribution.

[23] Previously proposed origins of layered phyllosilicates include marine sedimentation of sorted, transported clays, alteration of volcanic ash, hydrothermal alteration driven by caprock deposited as an overlying impact melt sheet, and pedogenesis of basaltic regolith [Loizeau et al., 2007; McKeown et al., 2009; Ehlmann et al., 2009]. Marine sedimentation would require late Noachian standing water, which is difficult to envision as blanketing all of the regions where the sequence is observed. Alteration of volcanic ash has less demanding environmental requirements because it could occur in precipitation-fed groundwater as well as in standing water, but the ash must have been regionally extensive. Impact-driven hydrothermal circulation does not require extensive near-surface liquid water [McKeown et al., 2009], but at least at Mawrth Vallis there is no 


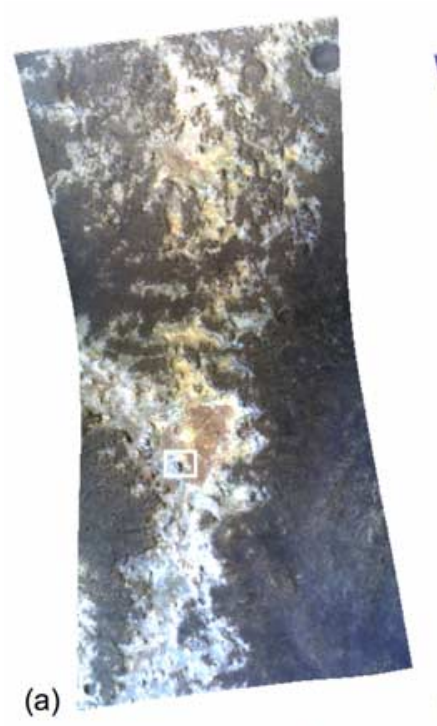

$$
\begin{aligned}
& \text { Enhanced visible color } \\
& R=0.59 \mu \mathrm{m} \\
& G=0.53 \mu \mathrm{m} \\
& B=0.44 \mu \mathrm{m}
\end{aligned}
$$

(d)

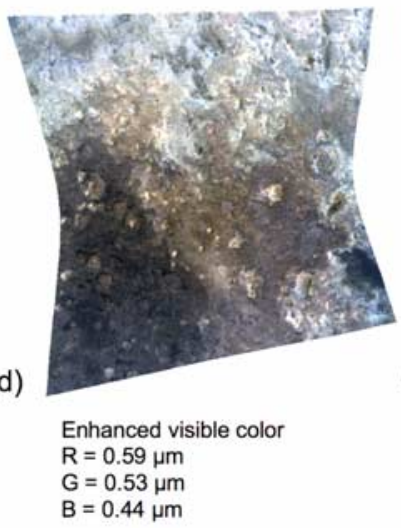

(b)

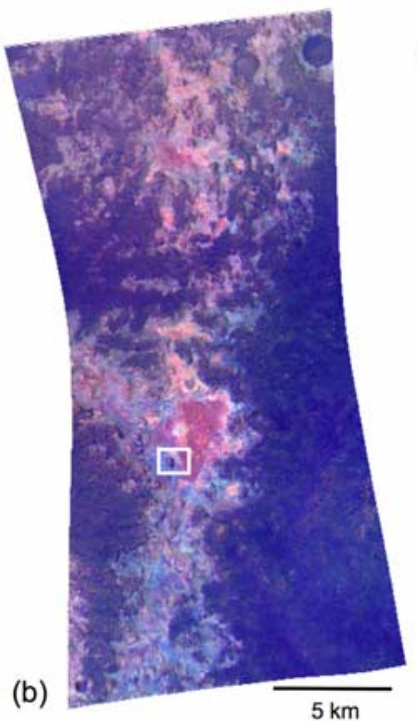

$\mathrm{R}=0.53-\mu \mathrm{m}$ band depth $\mathrm{G}=0.6-\mu \mathrm{m}$ inflection $\mathrm{B}=1-\mu \mathrm{m}$ band index Overlain on $1.3-\mu \mathrm{m} \mathrm{I/F}$

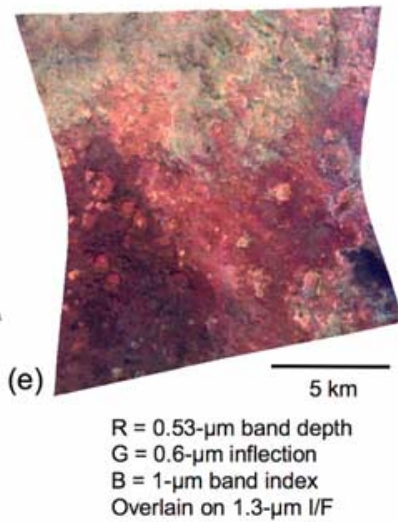

(e) (c)

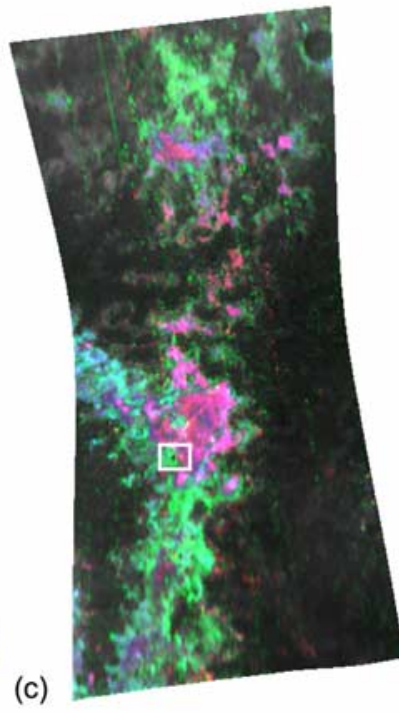

$\mathrm{R}=2.3-\mu \mathrm{m}$ band depth $\mathrm{G}=2.2-\mu \mathrm{m}$ band depth $\mathrm{B}=1.9-\mu \mathrm{m}$ band depth Overlain on 1.3- $\mu \mathrm{m} \mathrm{I/F}$

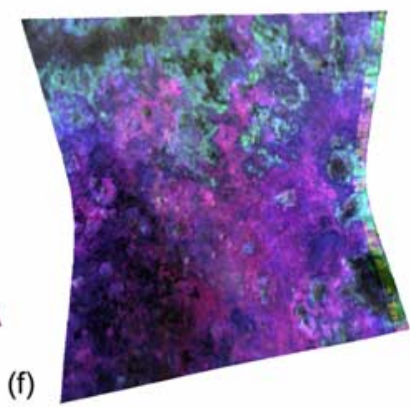

$\mathrm{R}=2.3-\mu \mathrm{m}$ band depth $\mathrm{G}=2.2-\mu \mathrm{m}$ band depth $\mathrm{B}=1.9-\mu \mathrm{m}$ band depth Overlain on 1.3- $\mu \mathrm{m} \mathrm{I/F}$

Figure 2. False color representations of two CRISM observations showing compositional differences in layered phyllosilicates in Mawrth Vallis. (a-c) HRL000043EC is located at $24.7^{\circ} \mathrm{N}, 339.1^{\circ} \mathrm{E}$, and $(\mathrm{d}-\mathrm{f})$ FRT0000AA7D is located at $24.4^{\circ} \mathrm{N}, 339.9^{\circ} \mathrm{E}$. The white boxes in Figures $2 \mathrm{a}-2 \mathrm{c}$ show the location of the HiRISE image in Figure 3. Figures $2 \mathrm{a}$ and $2 \mathrm{~d}$ represent enhanced visible color. Figures $2 \mathrm{~b}$ and $2 \mathrm{e}$ show spectral parameters related to Fe mineralogy (red, BD5300; green, SH600; blue, BDI1000VIS). Materials appearing redder have a stronger spectral signature of nanophase ferric oxides, and materials appearing bluer have a stronger $1-\mu \mathrm{m}$ absorption due to olivine, pyroxene, or other ferrous phases. The green image plane (which makes some areas appear yellowish or aqua) indicates an inflection near $0.6 \mu \mathrm{m}$ in mixtures or coatings of dust on dark materials [Fischer and Pieters, 1993]. Figures $2 \mathrm{c}$ and $2 \mathrm{f}$ show spectral parameters related to bound water or hydroxyl (red, D2300; green, BD2210; blue, BD1900). Red to magenta areas contain $\mathrm{Fe} / \mathrm{Mg}$ phyllosilicate, green and blue-green areas contain Al phyllosilicate or hydrated silica, and grayish areas have low contents of these phases. Note that both $\mathrm{Fe} / \mathrm{Mg}$ and $\mathrm{Al}$ phyllosilicates occur in regions having an enhanced signature of Fe oxide.

evidence for a suitably located, large basin whose impact melt would cover the original extent of the deposits, and that has the required late Noachian age [e.g., Frey, 2006]. Pedogenic weathering of a basaltic regolith to the observed thickness implies at least a temporary late Noachian environment that involved a substantial throughput of water [McKeown et al., 2009]. Among previously proposed hypotheses, alteration of volcanic ash and pedogenic weathering of basalt are, overall, most consistent with the deposits' geologic settings and with constraints from MRO data. In addition the brecciated nature of the lower
$\mathrm{Fe} / \mathrm{Mg}$ phyllosilicates east of Nili Fossae strongly suggests the excavation of deep phyllosilicates and their emplacement as basin ejecta is an important mechanism in forming some strata of the layered phyllosilicates.

\subsection{Phyllosilicates in Intracrater Fans/Deltas}

[24] MOC images revealed the existence of fans, possibly originating in part as deltaic deposits, where large channels debouch into a number of highland craters thought to have hosted open basin lakes [Fassett and Head, 2008]. The craters include Holden [Grant et al., 2007, 2008], Ebers- 


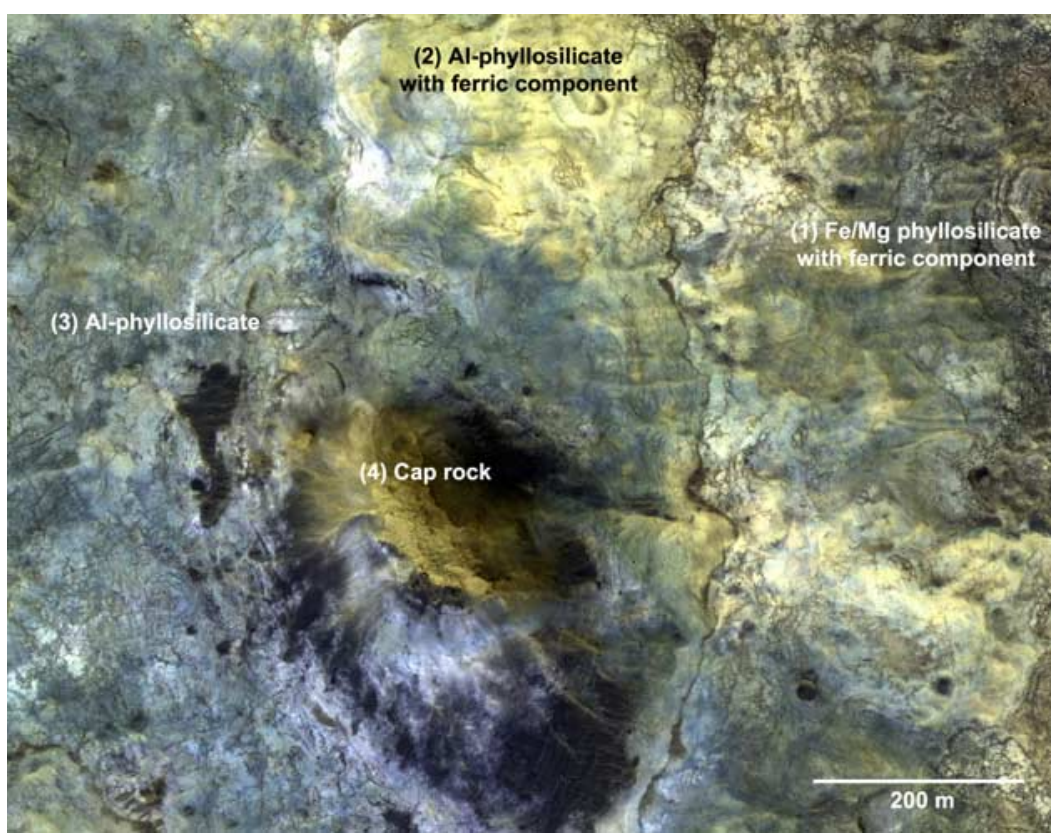

Figure 3. Part of HiRISE image PSP 005819_2050_COLOR showing layering within the white boxes in Figure 2. The numbering of the materials present in the image represents the sequence of their deposition.

walde [Malin and Edgett, 2003; Lewis and Aharonson, 2006], and Jezero [Fassett and Head, 2005; Ehlmann et al., 2008a]. Systematic targeting of these features by HiRISE, CRISM, and CTX has revealed that the lower units of the fans exhibit subhorizontal bedding and a stronger spectral signature of Fe/Mg phyllosilicates (Figure 4). The phyllosilicates are spectrally similar to those located elsewhere in the drainage basins. They are generally found in the lower portions of the fans in bright sediments with planar beds that lack resolvable blocks, consistent with the presence of fine-grained materials deposited in a quiescent depositional environment. The $\mathrm{Fe} / \mathrm{Mg}$ phyllosilicate-bearing layers are typically overlain by a more lithified, and commonly bouldery, caprock unit with no mineralogically distinct spectral signatures. The caprock may represent a later fluvial deposit or a capping volcanic deposit [Grant et al., 2007, 2008; Ehlmann et al., 2008a].

[25] The occurrence of phyllosilicates in the fans' lower, perhaps bottom-set deltaic beds and their resemblance spectrally to phyllosilicate-bearing outcrops within the drainage basin are strong evidence for erosion, transport, and depositional sorting in a quiescent, lacustrine environment. The phyllosilicate-bearing strata thus have substantial exobiological importance because their clays could have entombed and preserved organics formed in persistent standing water [Farmer and Des Marais, 1999; Ehlmann et al., 2008a].

\subsection{Plains Sediments}

[26] Plains sediments are an assemblage of phyllosilicates and sometimes chlorides that occur in relatively flat areas of intercrater plains and on some crater floors, without obvious relations to depositional fans. The evidence for chlorides is glowing terrain in THEMIS data, characterized by an unusually high apparent emissivity at shorter wavelengths of processed data [Osterloo et al., 2008]. This appearance of high emissivity is an artifact of THEMIS ground processing methods, which assume that unit emissivity occurs at least at one wavelength. In fact, the glowing terrain actually has much less than unit emissivity throughout the wavelength range of THEMIS. Chloride minerals exhibit this property and are the most reasonable phases geologically, but chloride must be present in excess of $25 \%$ mass fraction in order to account for the observed spectral properties [Osterloo et al., 2008]. Several hundred occurrences of glowing terrain have been identified in the Noachian highlands, typically in shallow closed basins of intercrater plains, and occasionally at the terminus of channels.

[27] Although chlorides lack diagnostic absorption features at visible and near-infrared wavelengths, new CRISM images reveal the existence of associated phyllosilicates and provide constraints on chloride composition. One of the largest clusters of glowing terrain deposits lies within a relatively flat-bottomed basin in Terra Sirenum (Figure 5). Multispectral mapping by CRISM shows that the densest part of the cluster overlaps a region containing Fe-bearing phases and phyllosilicates several tens of kilometers in lateral extent. CRISM's targeted observations have sampled several occurrences within this region. Glowing terrain appears brighter at infrared wavelengths than typical background soils (Figure 6), it is redder (it lacks the negative infrared continuum slope characteristic of dusty basaltic materials), and it has a much weaker $3-\mu \mathrm{m} \mathrm{H}_{2} \mathrm{O}$ absorption feature. These spectral properties are consistent with a significant content of a high-albedo, anhydrous phase such as chlorides. The red spectral slope and weak $3-\mu \mathrm{m}$ absorption are characteristic of glowing terrain and can be mapped at near-infrared wavelengths (Figure 7). The spectrum of the adjacent phyllosilicates resembles that of $\mathrm{Fe} / \mathrm{Mg}$ smectites observed elsewhere and discussed previously. 

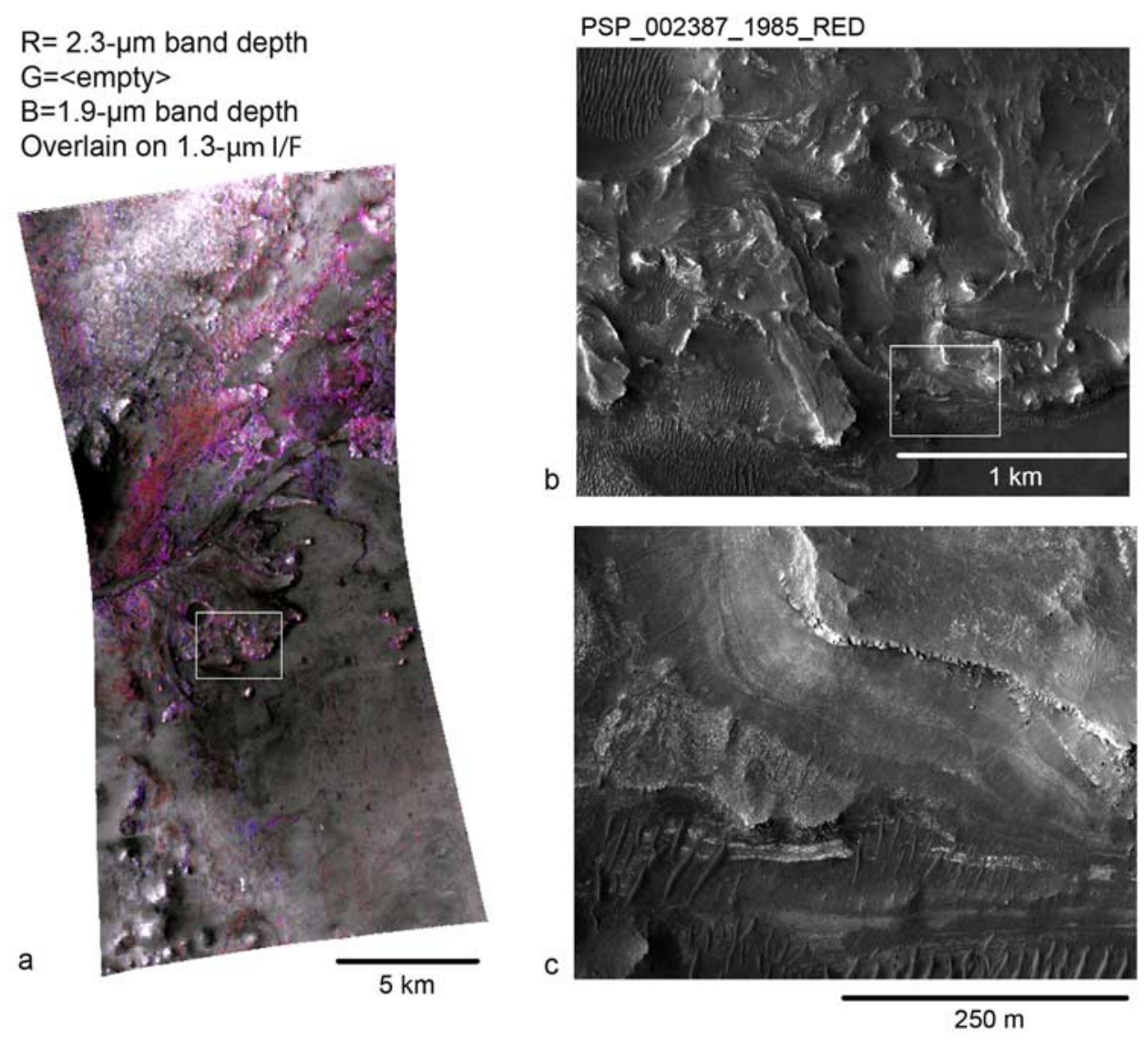

Figure 4. Phyllosilicates and carbonate in the layered bright materials comprising the western delta of Jezero crater. (a) Spectral parameter image of CRISM observation HRL000040FF at $18.5^{\circ} \mathrm{N}, 77.4^{\circ} \mathrm{E}$ related to hydrated materials (red, D2300; green, not applicable; blue, D1900). Red to magenta areas contain a mixture of $\mathrm{Fe} / \mathrm{Mg}$ smectite and carbonate [Ehlmann et al., 2009], and grayish areas have a low content of altered phases. The white box shows the location of Figure 4b. (b) Part of HiRISE image PSP_002387 1985_RED showing the eroded light-toned materials comprising the delta which have the strongest hydrated mineral signature. The white box shows the location of Figure 4c. (c) Zoom of Figure $4 b$ showing horizontally layered materials at the base of the fan.

[28] The relationship between the probable chlorides and the phyllosilicates is shown in Figure 7, located near the center of the basin. High-standing, coarsely fractured, deeply eroded mounds of light-toned phyllosilicate-bearing material are embayed by lower-standing, platy to polygonally fractured, medium-toned glowing terrain. Both are superposed on an eroded basement exhibiting weak pyroxene absorptions consistent with basaltic materials. In other examples of the contact between chloride- and phyllosilicatebearing materials in this region, the chloride is observed to fill channels cut into the phyllosilicate [Wray et al., 2009]. These relationships suggest that although the two phases were deposited at the same location, phyllosilicatebearing material was deposited first and subsequently eroded by fluvial and/or eolian processes prior to deposition of the chloride-bearing material.

[29] Other examples of plains sediments are more dominated by phyllosilicate. One is in the crater Miyamoto, which was fed by a regional drainage network [Newsom et al., 2003]. The crater's floor is partially filled with lighttoned, polygonally fractured deposits containing $\mathrm{Fe} / \mathrm{Mg}$ phyllosilicate, probably smectite clay [Wiseman et al.,
2008]. Wray et al. [2009] note other examples of craters in Terra Sirenum and Noachis having similar fractured, relatively flat-lying floor deposits exhibiting the spectral signature of $\mathrm{Fe} / \mathrm{Mg}$ clay. Numerous craters in Nili Fossae and Mawrth Vallis are filled by $\mathrm{Fe} / \mathrm{Mg}$ smectite and $\mathrm{Al}$ phyllosilicate sediment [Ehlmann et al., 2009; Noe Dobrea et al., submitted manuscript, 2009].

[30] Plausible depositional environments for plains sediments include playas and lacustrine environments, whose history included sedimentation of detritus sorted from the surrounding highlands by fluvial and aeolian processes, deposition of chloride-rich evaporites, and possibly autochthonous (in-place) formation of phyllosilicates by alteration of mafic sediments or regolith. These depositional environments may be comparable to those of the fans and deltas described in section 4.2 , or of the intracrater clay-sulfate deposits discussed in 4.6 (however with lesser acidity).

\subsection{Deep Phyllosilicates}

[31] Numerous outcrops of phyllosilicates in the Noachian highlands are found in crater walls, rims, ejecta, and central peaks [Mustard et al., 2008], and in the walls of Nili Fossae 


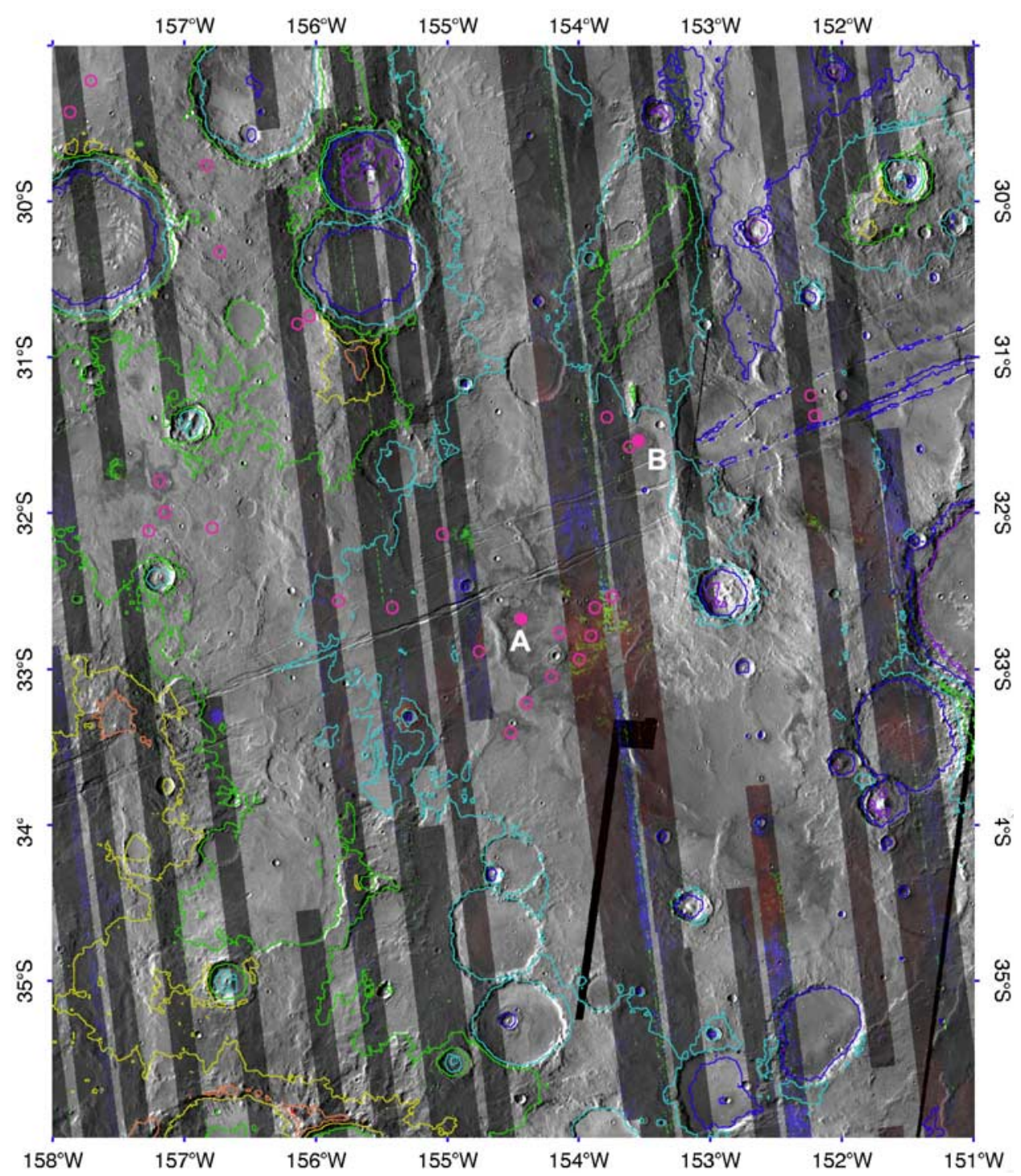

Figure 5. Regional view of intercrater plains in Terra Sirenum that contain both phyllosilicates and outcrops of glowing terrain interpreted as chlorides. The background is a THEMIS day IR mosaic, overlain with color-coded MOLA elevation contours at 500-m increments from 0 to $+3500 \mathrm{~m}$, where blue is low and red is high. The strips are CRISM multispectral mapping data, in which red (OLINDEX, stretched $0.01-0.16$ ) shows $1.0-1.7-\mu \mathrm{m}$ spectral slope due to olivine or, in this case, Fe/Mg phyllosilicate; green (D2300, stretched 0.001-0.03) shows the 2.3- $\mu \mathrm{m}$ absorption due to $\mathrm{Fe} / \mathrm{Mg}$ phyllosilicates; and blue (HCPINDEX, stretched 0.01-0.06) shows 1- and 2- $\mu \mathrm{m}$ absorptions due to pyroxene. Magenta circles are locations of glowing terrain identified by Osterloo et al. [2008]; the filled circles marked B and A show the locations of Figures 6 and 7, respectively.

[Mustard et al., 2009] and Valles Marineris (Figure 8). Their common attribute is their presence in basement rock or in materials exhumed from depth, but their other characteristics vary. We group these materials into a class of "deep phyllosilicates," and as discussed below this class consists of a variety of materials probably formed by multiple mechanisms that may comprise a much more substantial component of the Noachian crust than previously recognized.

[32] A variety of phyllosilicate mineral groups is indicated by spectral signatures of various outcrops (e.g., Figure 9). The shape and center of the $2.2-2.3-\mu \mathrm{m}$ metal-OH absorption and its strength relative to the $1.9-\mu \mathrm{m}$ bound water absorption suggest that chlorite and saponite are common phases. Also observed, but less common, are spectral signatures consistent with nontronite, Al smectite, kaolinite, muscovite or illite, serpentine, hydrated silica, and zeolite [Ehlmann et al., 2008c, 2009; Fraeman et al., 2009]. Prehnite also occurs and may be common in some regions [Clark et al., 2008; Buczkowski et al., 2008, also Investigation of an Argyre basin ring structure using MRO/CRISM, manuscript in preparation, 2009; Ehlmann et al., 2009]. In general, the implied mineral assemblages suggest aqueous alteration at a relatively low temperature and pressure, grading from diagenesis into low-grade metamorphism. On the basis of the number density of outcrops of deep phyllo- 


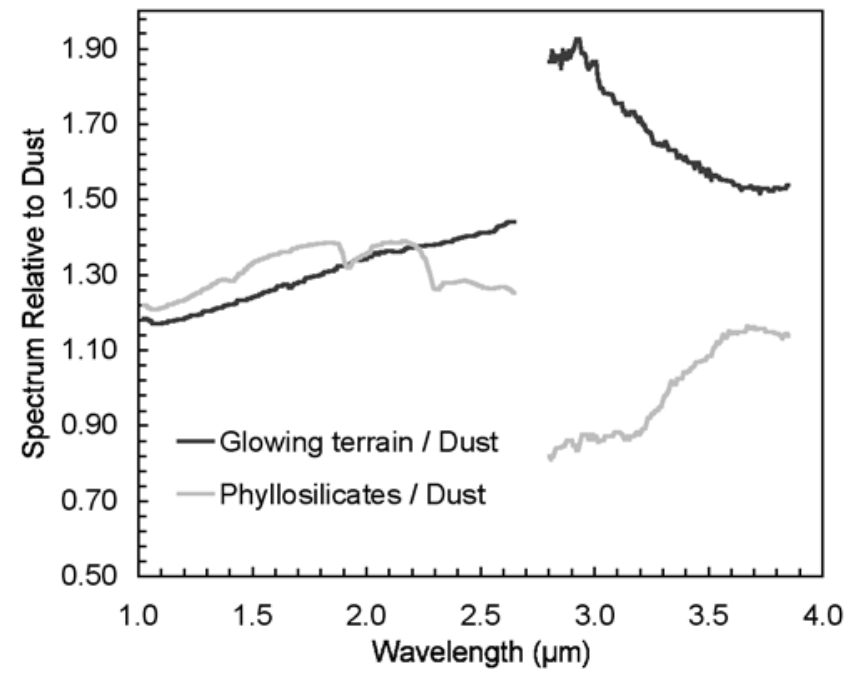

Figure 6. Relative spectra of glowing terrain and phyllosilicates taken from CRISM observation FRT0000AB81 at $31.6^{\circ} \mathrm{S}, 206.4^{\circ} \mathrm{E}$, at the location marked $\mathrm{B}$ in Figure 5. The spectra of both materials have been ratioed to nearby spectrally neutral material to highlight differences. The phyllosilicate resembles the $\mathrm{Fe} / \mathrm{Mg}$ smectite observed in intracrater fans, layered phyllosilicates, and deep phyllosilicates. The glowing terrain exhibits a relatively red spectral slope and weak $3-\mu \mathrm{m}$ band due to bound water, consistent with intermixture of anhydrous, spectrally neutral chloride.

silicates in multispectral mapping coverage examined to date, and extrapolating that density over the Noachian-aged southern highlands, there may be 5000-10,000 locations where deep phyllosilicates are detectable spectrally over regions hundreds of meters or greater in extent [Mustard et al., 2008]. To date, only a fraction of these locations have been sampled at high resolution.

[33] Most deep phyllosilicates are $\mathrm{Fe} / \mathrm{Mg}$ phyllosilicates but there is evidence for considerable regional variation in the specific type and abundance of phyllosilicate and alteration mineral assemblages. Fraeman et al. [2009] probed possible variations in mineralogy with depth by examining the frequency of different phyllosilicate occurrences as a function of crater diameter in Noachian units of Mars' eastern hemisphere. They found a weak relationship between mineral occurrences and crater size (a proxy for depth of excavation). Also, there are regional variations in the mineralogy of exhumed phyllosilicates: chlorite more frequently occurs in Tyrrhena Terra, whereas Fe/Mg smectites are more dominant at Noachis. Zeolite and illite or muscovite occur very infrequently and have so far only been found in a few craters west of Nili Fossae and Terra Tyrrhena [Ehlmann et al., 2009; Fraeman et al., 2009]. A thick $(>500 \mathrm{~m})$ megabreccia that surrounds Isidis basin is dominated spectrally by $\mathrm{Fe} / \mathrm{Mg}$ smectite [Mustard et al., 2009]. Buczkowski et al. [2008, also manuscript in preparation, 2009] found chlorite- and prehnite-bearing exposures surrounding Argyre whose elevations are consistent with a discrete phyllosilicate-bearing layer, occurring within the otherwise pyroxene-dominated and probably basaltic lower Noachian unit of the plateau plains series that forms the southern highlands [Scott and Tanaka, 1986; Tanaka et al.,
1992] (unit $\mathrm{Npl}_{1}$ and its fluvially dissected equivalent Npld). The phyllosilicates are buried by younger Noachian and Hesperian plains units (units $\mathrm{Npl}_{2}$ and $\mathrm{Hpl}_{3}$ ) having spectral signatures of high-calcium pyroxene that indicate a basaltic composition, and they overlie low-Ca pyroxeneand olivine-bearing rocks interpreted previously to originate from lower layers of the plateau plains (units $\mathrm{Nh}$ and $\mathrm{HNu}$ ) [Mustard et al., 2005].

[34] The walls of Valles Marineris expose a relatively continuous section of these units over thousands of kilometers, and provide an opportunity to assess the stratigraphy of deep phyllosilicates. CRISM targeted observations achieved particularly dense coverage of eastern Coprates Chasma (Figure 8) for this purpose. The lowest parts of the chasma walls contain low-Ca pyroxene- and olivine-bearing materials near the $-4 \mathrm{~km}$ elevation. These are comparable to exposures elsewhere in basin massifs (Figures 9a, 9b, and 9e) [Mustard et al., 2005; Buczkowski et al., 2008, also manuscript in preparation, 2009], and the occurrence of olivinebearing materials at comparable elevations in the walls of Ganges and Eos Chasmata to the east was reported previously from THEMIS data [Edwards et al., 2008]. In the middle portions of the wall near $-2 \mathrm{~km}$ elevation, material with a $2.32-\mu \mathrm{m}$ absorption band and lacking a $1.9-\mu \mathrm{m}$ band resembles chlorite or dehydrated saponite; no Al phyllosilicate is evident (Figures 9a, 9b, and 9d). It is overlain by several kilometers of high-Ca pyroxene-bearing material consistent with basalt. The phyllosilicate-bearing material is massive to blocky, resembling impact breccia, and it forms a sharp contact with overlying layered basaltic materials that comprise much of the chasma walls (Figure 10a) [McEwen et al., 1999]. In the uppermost portion of the wall and plateau (elevation $+3 \mathrm{~km}$ ) overlying the layered basalt, a two-layer sequence having spectral signatures consistent with $\mathrm{Al}$ smectite or kaolinite on top of $\mathrm{Fe} / \mathrm{Mg}$ smectite (Figures $9 \mathrm{c}$ and $9 \mathrm{~d}$ ) is exposed where overlying material from unit $\mathrm{Hpl}_{3}$ has been removed. The overlying stripped layer has a spectral signature of high-Ca pyroxene, and its morphology suggests friable, possibly sandy basaltic material eroded by wind (Figure 10b). The Al phyllosilicates are light toned and polygonally fractured, as observed in comparable layered phyllosilicate-bearing material surrounding Mawrth Vallis (Figure 10c). The Fe/Mg phyllosilicates lack this fracturing and outcrop in multiple thinner layers, each perhaps a few meters thick (Figure 10d). A very preliminary, generalized stratigraphic column for eastern Coprates Chasma (Figure 11) shows different types of phyllosilicates that are interbedded with mostly basaltic material [McEwen et al., 1999; Edwards et al., 2008]. The occurrence of a discrete layer of chlorite or dehydrated saponite-like materials within the $\mathrm{Npl}_{1}$ unit is comparable to its occurrence to the southeast near Argyre, and the occurrence of the $\mathrm{Al}$ and $\mathrm{Fe} / \mathrm{Mg}$ smectites high in the section is comparable to their occurrence in layered phyllosilicates to the northeast at Mawrth Valles (section 4.1).

[35] The association of phyllosilicates with breccias and megabreccias of probable impact origin is widespread. West of Isidis basin, in the walls of Nili Fossae and in the regional basement (from -1 to $-2 \mathrm{~km}$ elevation), $\mathrm{Fe} / \mathrm{Mg}$ smectites occur as the matrix in a breccia with blocks consisting of low-calcium pyroxene and phyllosilicates [Mustard et al., 2009]. McEwen et al. [2008] have found over fifty exam- 

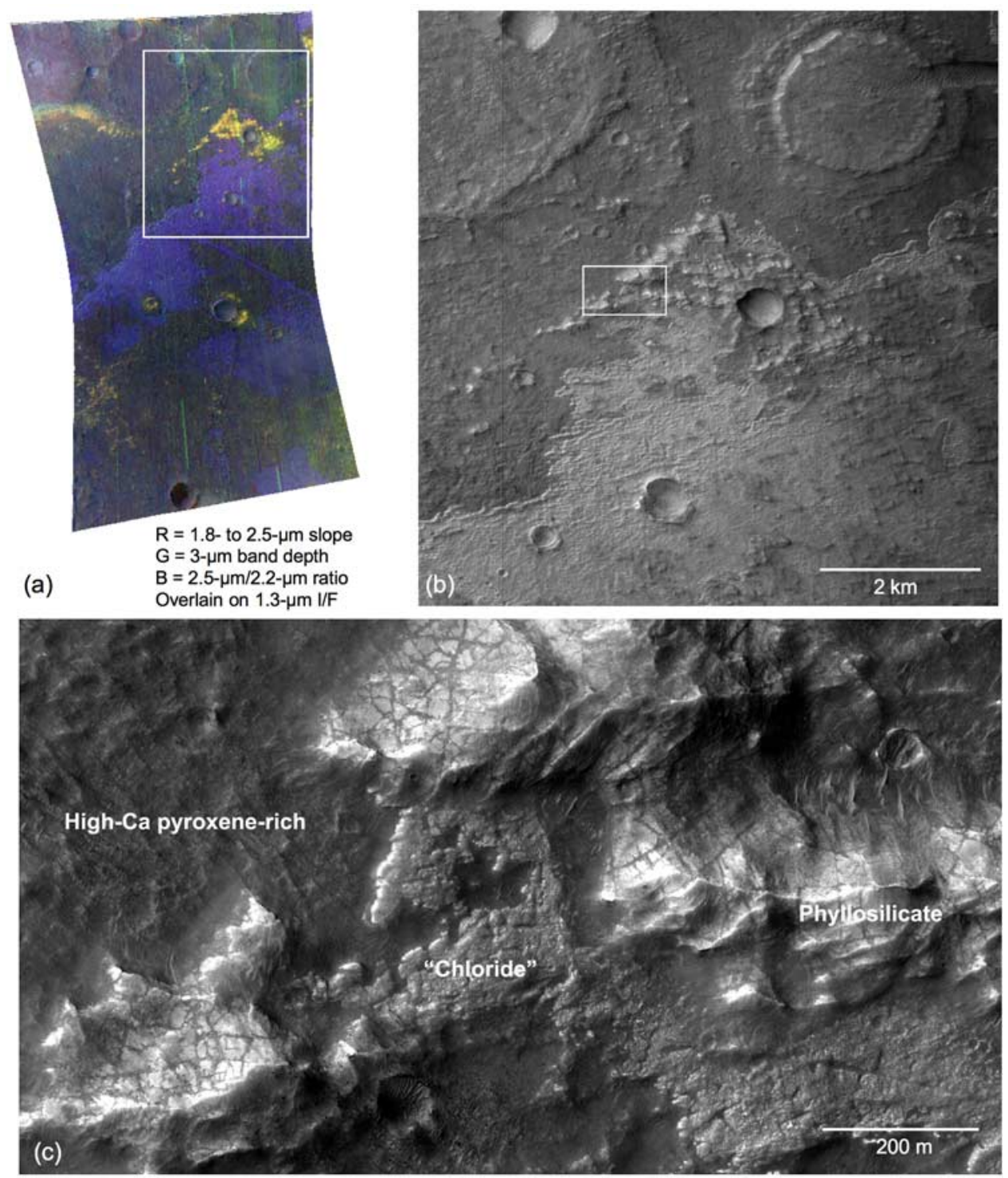

Figure 7. (a) Spectral parameter representation of CRISM observation HRL0000860C located at $32.7^{\circ} \mathrm{S}, 205.5^{\circ} \mathrm{E}$, showing plains sediments with a contact between phyllosilicate- and chloride-bearing materials (red, ISLOPE1; green, BD3000; blue, IRR2). The relatively red continuum of glowing terrain gives it a distinct blue color in this representation, whereas the $3-\mu \mathrm{m}$ absorption in phyllosilicates makes them appear yellow. The background gray areas have weak absorptions due to pyroxene. The white box shows the location of Figure 7b. (b) Context image P12_005811_1476_XI_32S154W showing phyllosilicate-bearing (middle of image) and chloride-bearing (bottom of image) materials superposed on their substrate. The white box shows the location of Figure 7c. (c) HiRISE image PSP_005811_1470_RED showing the stratigraphic relations of different materials.

ples of megabreccia, commonly in central peaks of large craters, and typically they contain a phyllosilicate component in the blocks or matrix.

[36] The diversity of phyllosilicate compositions and geologic settings within this one class of deposits indicates that multiple genetic mechanisms are likely involved. These may include alteration by hydrothermal circulation in the cooling crust, impact-generated hydrothermal alteration, and diagenesis of deposits formed at the surface and buried by volcanic, impact, or sedimentary processes. Parmentier et al. [2008] showed that the Noachian time history of lithospheric thicknesses derived from modeling surface loads of different age is consistent with enhanced heat transfer and cooling of the crust by deep hydrothermal circulation. They suggested that this mechanism could have formed widespread phyllosilicates through the upper $10 \mathrm{~km}$ or more of the Martian crust. Fraeman et al. [2009] showed that mineralogy of phyllosilicates exposed by impact craters varies weakly if at all with impact size, and thus with depth of excavation of the crust. They interpreted this to be consistent with a hydrothermal crustal cooling mechanism that would have maintained a moderate temperature profile in the crust. Most of the observed minerals could have formed at temperatures $<100^{\circ} \mathrm{C}$, implicating only the cool- 


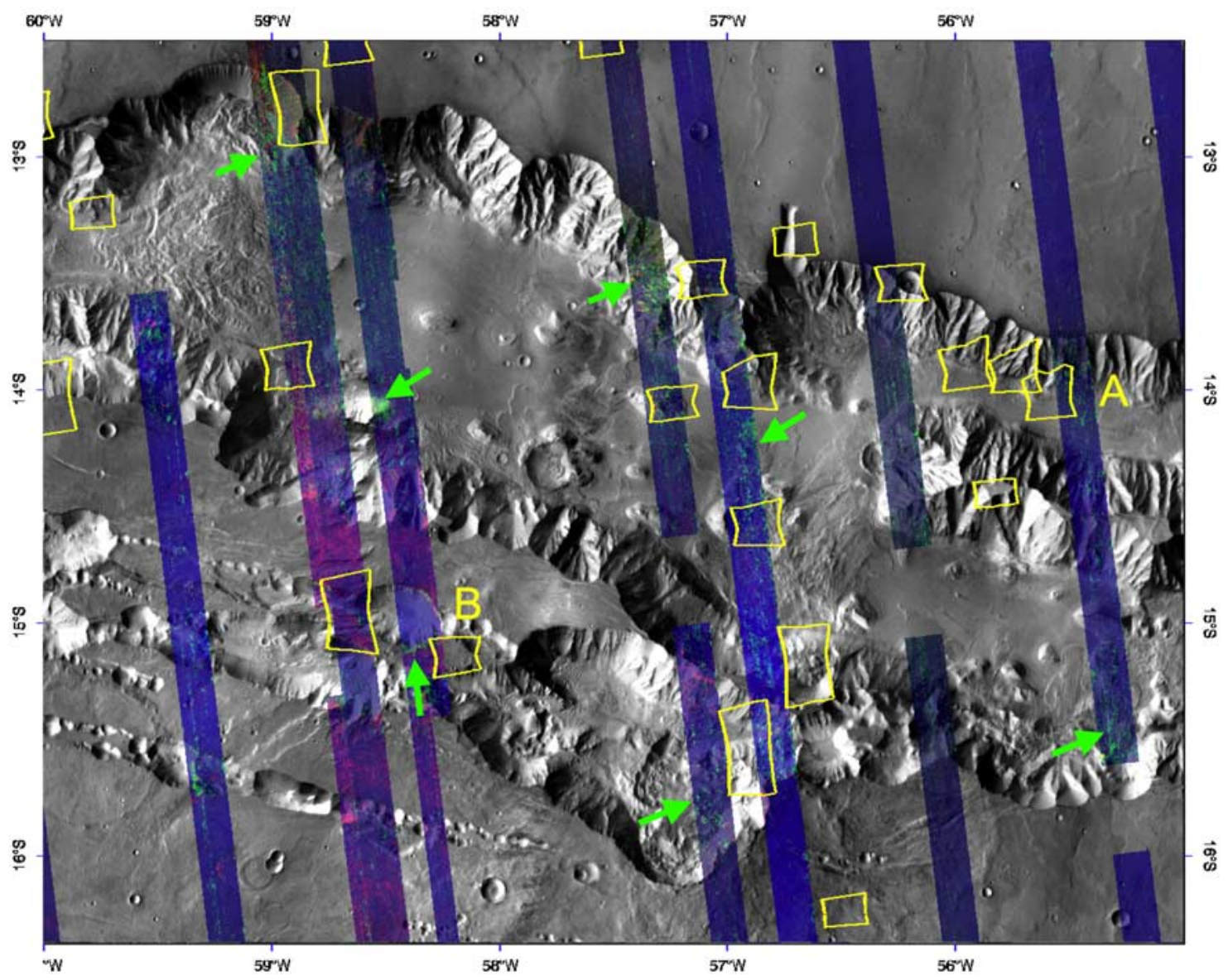

Figure 8. Regional view of eastern Coprates Chasma in Valles Marineris. The background is a THEMIS day IR mosaic, and the overlain strips are CRISM multispectral mapping data represented as spectral parameters (red, BDI1000VIS; green, D2300; blue, BDI1000IR). Blue areas have a 1- $\mu \mathrm{m}$ absorption consistent with olivine and pyroxene, and the magenta areas may be richer in olivine. Green areas (indicated by arrows) are outcrops of phyllosilicates in lower parts of the chasma walls, landslides, and high parts of the wall on the southern side of the chasma. The yellow footprints are CRISM targeted observations; the pair marked A and the one marked B are shown in Figure 9.

est epithermal environments if they were in fact hydrothermal. Detection of prehnite in some outcrops suggests that at least locally alteration temperatures exceeded $200^{\circ} \mathrm{C}$, consistent with some degree of low-grade metamorphism or hydrothermal activity [Ehlmann et al., 2009]. However, the persistence of olivine (which is easily altered) underlying the phyllosilicate in Valles Marineris and Argyre is difficult to reconcile with globally distributed hydrothermal alteration [Hoefen et al., 2003]. Hydrothermal activity may have been more localized, controlled by the availability of water. Tornabene et al. [2007] suggested that some phyllosilicates formed instead by impact heating of water-bearing target materials. Alternatively, the concentration of phyllosilicates in discrete strata in the walls of Valles Marineris, and the resemblance of some strata to surficial occurrences of phyllosilicates elsewhere [Mustard et al., 2009], suggests that phyllosilicates that formed in a near-surface environment may have been buried by impact ejecta and volcanism.

\subsection{Carbonate-Bearing Deposits}

[37] Carbonate-bearing bedrock is exposed in craters and escarpments surrounding the Isidis basin, especially in the Nili Fossae region, although a few occurrences farther south in Tyrrhena Terra have been noted [Ehlmann et al., 2008b]. Spectrally, the wavelength positions of overtone absorptions near 2.3 and $2.5 \mu \mathrm{m}$ and at 3.4 and $3.9 \mu \mathrm{m}$ are consistent with magnesium carbonate either in hydrated form or mixed with hydrated phases. The carbonate-bearing layer is about $20 \mathrm{~m}$ thick, and it lies stratigraphically above local occurrences of layered phyllosilicates (Figure 12). In fact it appears coincident with or just above the regional-scale olivine-rich layer [Hamilton and Christensen, 2005; Mustard et al., 2007] that caps the occurrence of hydrated silicates, indicating that the carbonate is a deposit distinct from the phyllosilicates. Ehlmann et al. [2008b, 2009] suggested that the carbonates are confined to the Isidis region because they formed directly from the olivine-rich regional deposit, and other olivine-rich deposits were not subjected to a comparable degree of aqueous alteration. They suggested that the carbonates formed as an alteration product of the olivine, or as an aqueous sediment in surface waters.

\subsection{Intracrater Phyllosilicate-Sulfate Deposits}

[38] This newly identified class of deposits has been identified by Swayze et al. [2008] and Wray et al. [2008b, 2009] in two closed-basin, highland craters in Terra Sir- 


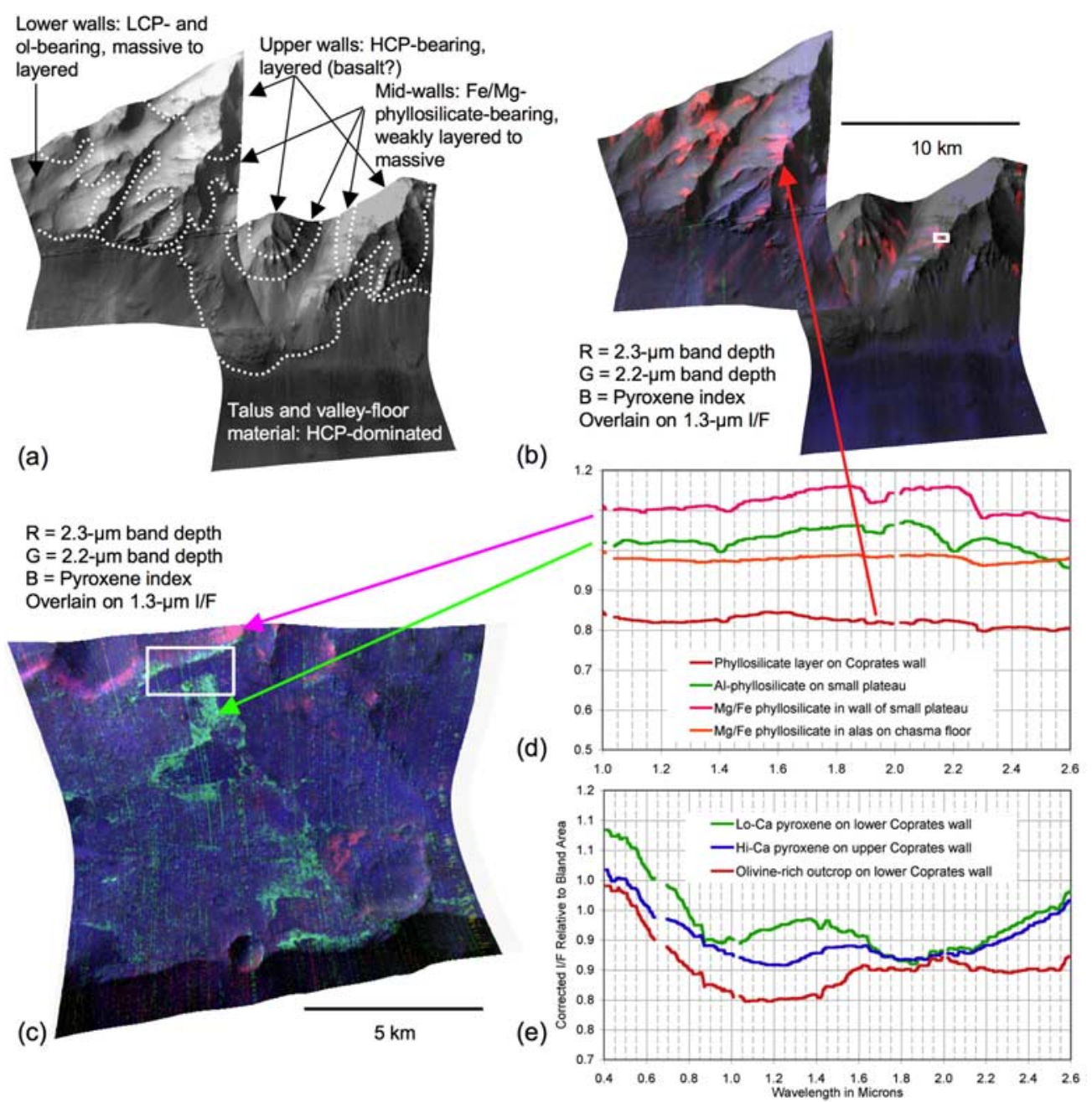

Figure 9. CRISM images of exposures of phyllosilicate on the walls of eastern Coprates Chasma at sites A (FRT00009804 and FRT0000B8E2 near $14.0^{\circ} \mathrm{S}, 304.4^{\circ} \mathrm{E}$ ) and B (FRT0000B6C5 at $15.1^{\circ} \mathrm{S}$, $301.8^{\circ} \mathrm{E}$ ) from Figure 8. (a) Sketch map of the middle and lower portions of the chasma wall covered by site A. (b) Spectral parameter images of the two observations covering site A (red, D2300; green, BD2210; blue, HCPINDEX). Blue colors indicate pyroxene-rich materials, green colors indicate material with $\mathrm{Al}$ phyllosilicate, and red colors indicate material with $\mathrm{Fe} / \mathrm{Mg}$ phyllosilicate. The white box indicates the location of the HiRISE image shown in Figure 10a. (c) Spectral parameter image of the observation covering site $\mathrm{B}$, using the same color scheme. The white box indicates the location of the HiRISE image shown in Figure 10b. (d) Representative spectra of phyllosilicate-bearing outcrops at the locations indicated by the arrows, ratioed to nearby spectrally neutral material. (e) Representative spectra of mafic mineral-bearing outcrops from Figures $9 \mathrm{a}$ and $9 \mathrm{~b}$, ratioed to nearby spectrally neutral material.

enum. This setting contrasts with phyllosilicates in fans and deltaic materials, which occur in open basins connected by large channels. The occurrences are ring shaped in planform along contours of nearly equal elevation, and coincide with locations of high nighttime temperature suggesting that the deposits are indurated. The deposits have a medium to light tone, and at visible wavelengths they resemble dust spectrally and display a strong ferric edge (Figure 13a). Infrared absorptions of parts of the deposits are consistent with the presence of kaolinite and sulfates. Columbus crater contains multiple hydrated $\mathrm{Fe}$ and $\mathrm{Mg}$ sulfates [Wray et al., 2009] while an unnamed $70 \mathrm{~km}$ crater to the west contains the acid sulfate alunite [Swayze et al., 2008] (Figures 13b, and 14). In Columbus crater, HiRISE images indicate that the kaolinite and sulfates occur in discrete, adjacent layers, and suggest that materials bearing these phases are interbedded [Wray et al., 2008b, 2009]. CTX images and CRISM multispectral mapping of other large craters in Terra Sirenum reveal several likely additional examples of deposits in this class. Proposed genetic mechanisms include acid weathering of basaltic substrate and chemical sedimentation from acid-saline lakes. Sulfates and smectites found in other craters, e.g., Gale [Thomson et al., 2008a, 2008b; Milliken et al., 2009], may also have been formed by acidic waters during diagenesis of sediments within a closed basin, although the ring-shaped pattern of mineral deposits is not evident, and whether deposition was autochthonous cannot yet be determined. 

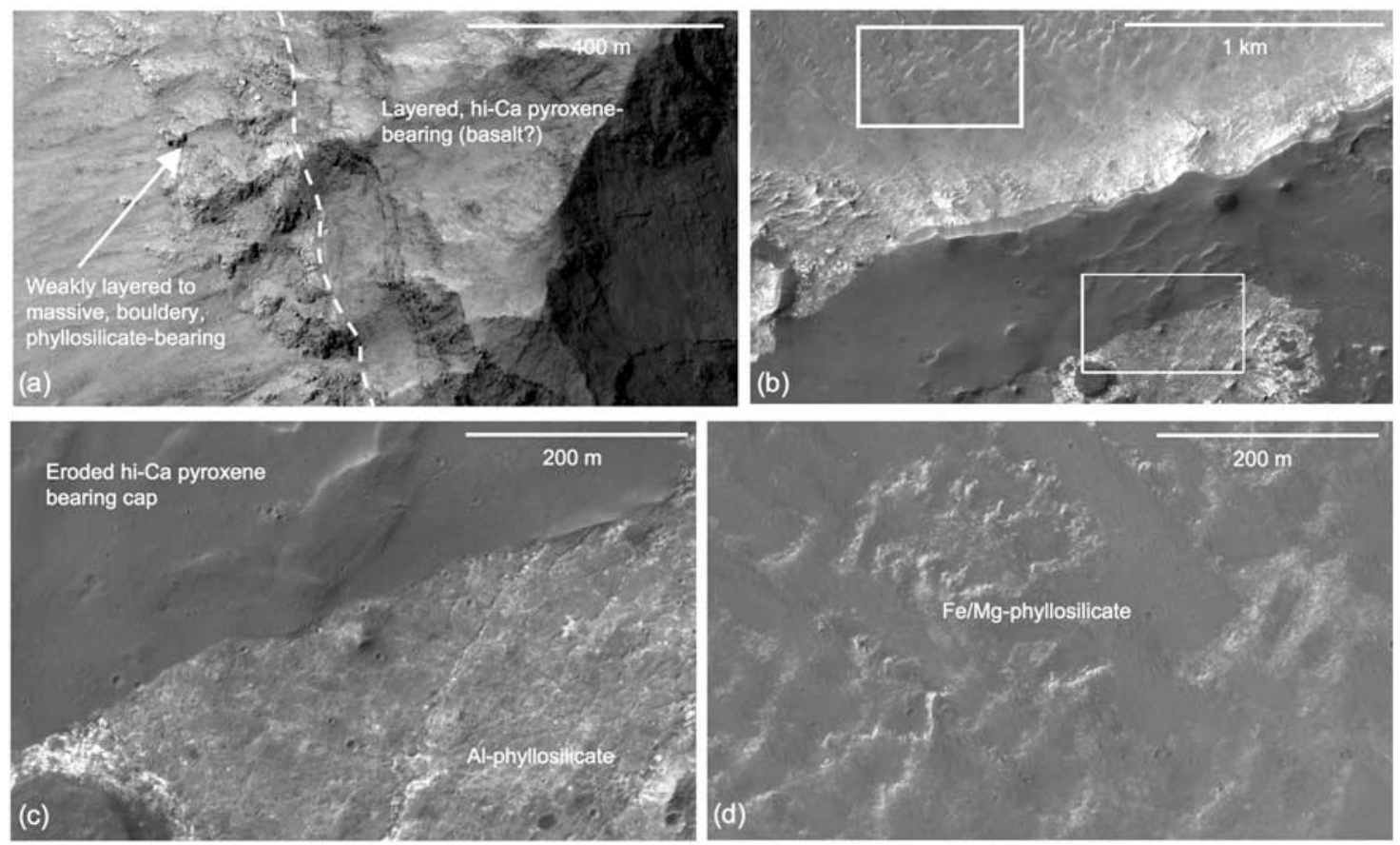

Figure 10. (a) Part of HiRISE image PSP_006928_1660_RED, covering the white box at site A in Figure 9b. (b) Part of HiRISE image PSP $009143 \overline{1} 645 \bar{R} E D$, covering the white box at site $B$ in Figure 9c. (c) Bottom box in Figure 10b, covering Al phyllosilicate and the overlying eroded mafic material. (d) Top box in Figure 10b, covering layered Fe/Mg phyllosilicate. The white boxes in Figure 10b show the locations of Figures $10 \mathrm{c}$ and $10 \mathrm{~d}$.

\subsection{Meridiani-Type Layered Deposits}

[39] The layered, etched, sulfate- and hematite-bearing deposits in Meridiani Planum have been studied intensively from orbit [Christensen et al., 2000, 2001a, 2001b; Arvidson et al., 2003, 2005; Griffes et al., 2007; Wiseman et al., 2007, 2008] and in situ by MER/Opportunity [Squyres et al., 2004, 2006; Arvidson et al., 2006]. Orbital investigation shows that the etched material covers about $300,000 \mathrm{~km}^{2}$, is late Noachian to early Hesperian in age, and was deposited unconformably on early to middle Noachian cratered terrain overlying phyllosilicate-bearing deposits. The deposit is stratified into light- to medium-toned layers of differential erodibility, and is largely undeformed by fracturing or folding. Some of the layers show spectral evidence for monohydrated and polyhydrated, probably Mg-rich sulfates. A lag enriched in coarse-grained hematite blankets parts of the eroded deposit. Figure 15 illustrates a representative example of the deposits as seen by CRISM, showing separate layers containing polyhydrated sulfate (magenta in Figure 15b) and monohydrated sulfate (yellow-green in Figure 15b). An inset HiRISE image (Figure 15c) shows component beds, and cones of dark, sandy material that appear to emanate from discrete layers and to be redistributed by wind.

[40] Landed investigations have provided complementary observations that are required to better understand the origin of the deposits (see section 2). These observations include bed forms such as subaqueous ripples and cross-bedding, rip-up clasts, casts of crystals of soluble minerals that were formed in situ by diagenesis and then redissolved, occurrence of jarosite together with other sulfates, and dark hematite concretions ("blueberries") several $\mathrm{mm}$ across that eroded out of the deposit to form a lag. Elemental abundance measurements show that the deposit has up to several

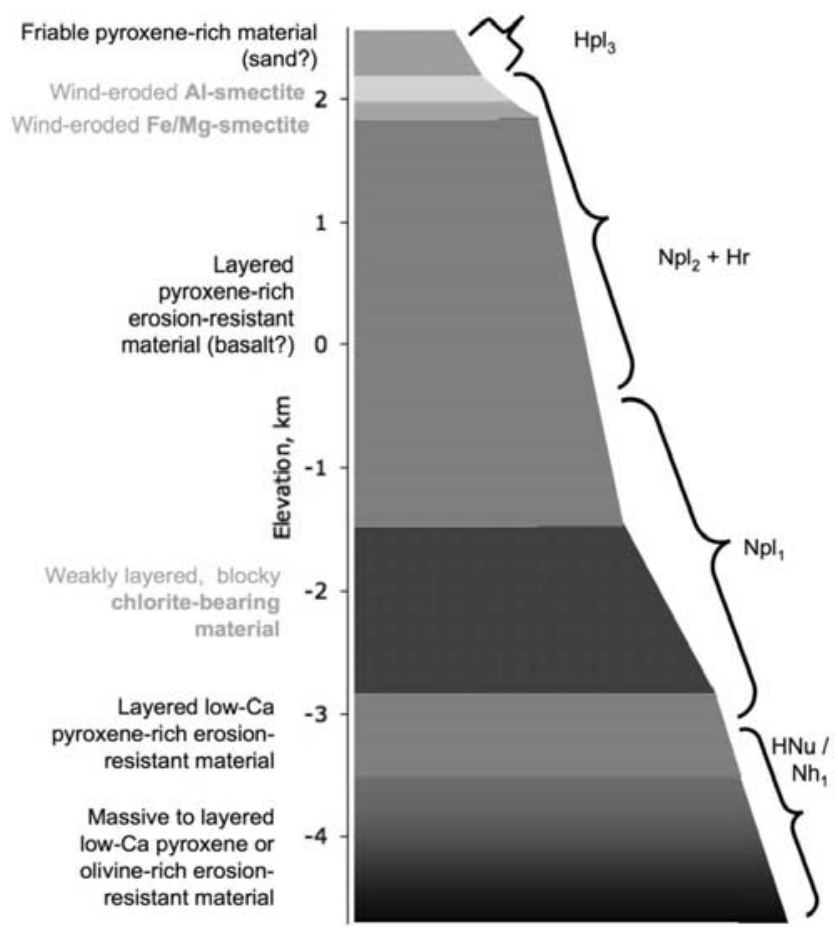

Figure 11. Schematic stratigraphic column of the walls of eastern Coprates Chasma assembled from sites A and B in Figures $8-10$. 

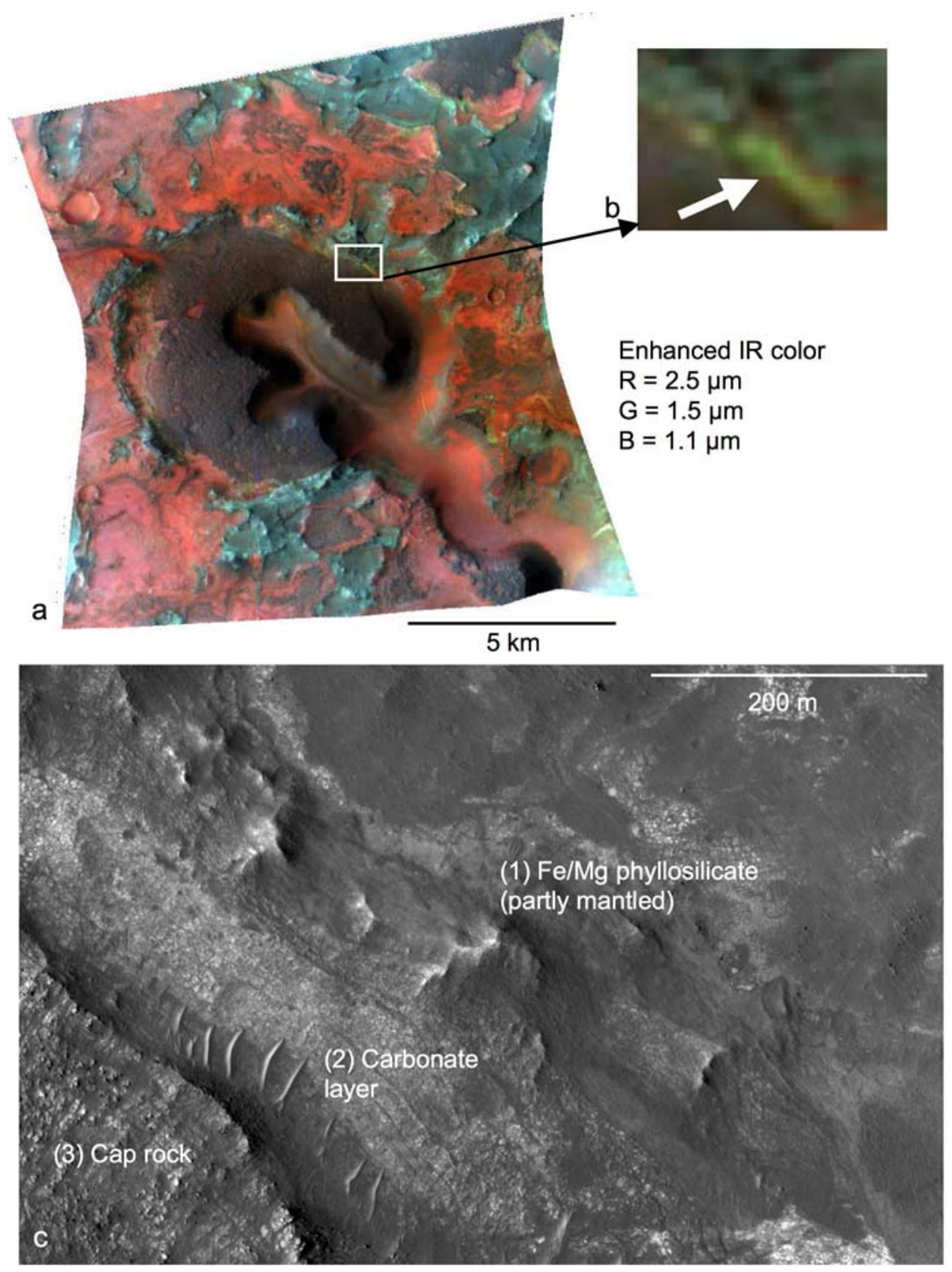

Figure 12. Example outcrop of the layer of carbonate-bearing rock surrounding the Isidis basin. (a) Infrared false color version of CRISM observation FRT00003E12, located at $22.3^{\circ} \mathrm{N}, 77.1^{\circ} \mathrm{E}$. Olivinerich material appears red, phyllosilicate-bearing material appears blue-gray, caprock appears dark gray, and carbonate-bearing rock appears green. (b) Zoomed CRISM view of a carbonate-bearing outcrop in green. (c) Part of HiRISE image PSP_002176_2025_RED showing the stratigraphic position of the carbonate-bearing layer. The numbering of the materials indicates the order of their deposition. The white box in Figure 12a shows the location of Figures $12 \mathrm{~b}$ and $12 \mathrm{c}$.

tens of percent sulfates by weight. Gradients in sulfate abundance and the microtextural evidence for recrystallization of a soluble mineral indicate that the sulfate deposits were subsequently altered by subsurface water.

[41] From these measurements and from geophysical modeling, a sequence of events that formed Meridiani Planum's layered deposits has been proposed [Squyres et al., 2006; Arvidson et al., 2006]. Sulfate-rich eolian sandstone was deposited, and then modified by rising ground- water that produced a range of diagenetic features, notably hematite-rich concretions and sulfate cements. Groundwater reached the surface and ponded in interdune lows, where sulfate-rich sediment was deposited in a shallow lacustrine or playa environment. Subsequently the deposits dried and eolian erosion partially removed them, but the dense hematite concretions preferentially formed a lag that is mappable from orbit. The depositional environment was dominantly arid, acidic, and oxidizing. 

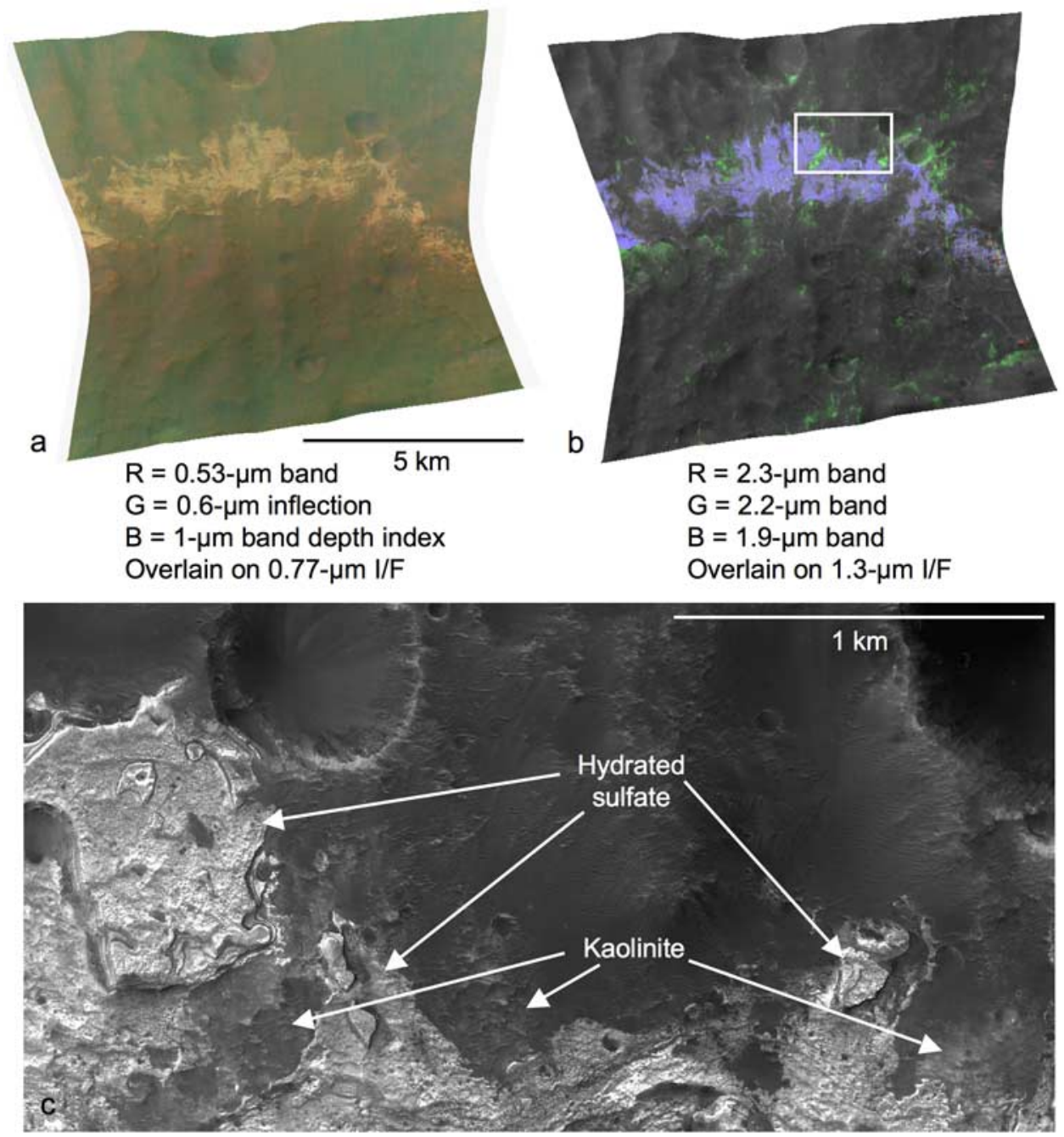

Figure 13. Kaolinite- and hydrated salt- (probably sulfate) bearing material on the wall of Columbus crater. (a) Spectral parameter representation of CRISM observation FRT00007D87, located at $28.5^{\circ} \mathrm{S}$, $194.0^{\circ} \mathrm{E}$, showing variations in iron mineralogy (red, BD530; green, SH600; blue, BDI1000VIS). Materials appearing redder have a stronger spectral signature of nanophase ferric oxides, and materials appearing bluer have a stronger $1-\mu \mathrm{m}$ absorption due to olivine and pyroxene. The green image plane indicates an inflection near $0.6 \mu \mathrm{m}$ in mixtures or coatings of dust on dark materials. (b) Spectral parameters related to bound water or hydroxyl (red, D2300; green, BD2210; blue, BD1900). Green areas contain kaolinite, blue area contains hydrated sulfates, and grayish areas have low contents of altered phases. (c) Part of HiRISE image PSP_005429_1510_RED showing the reflectance and morphology of different mineral outcrops. The white box in Figure $\overline{13 b}$ shows the location of Figure 13c.

[42] Modeling of Mars' Noachian and early Hesperian hydrologic cycle by Andrews-Hanna et al. [2007, 2008] provides an explanation for the source of the groundwater. In their model, precipitation is assumed to have occurred uniformly at latitudes equatorward of $\pm 45^{\circ}$ and to have infiltrated a permeable surface, leaching subsurface rocks and accumulating salinity. Subsurface flow is controlled by topography and by development of Tharsis, which in the model diverts preexisting subsurface water. Discharge occurs in topographically lower regions where the water table intersects the surface and promptly evaporates because of arid conditions, depositing its dissolved load at or near the surface. Only a few regions predicted to have been sites of discharge remain exposed, and are not covered by younger deposits; these include Meridiani Planum and selected other parts of Arabia, parts of the interiors of the Hellas and Argyre basins, Valles Marineris, and Terra Sirenum on the southwestern flank of Tharsis. An unusually high volume of evaporated groundwater is predicted in the Meridiani Planum region, providing a source for the sulfates concentrated in the layered material. The evaporating groundwater discharge is interpreted to have trapped and cemented eolian sediment, and driven diagenetic alteration to form the hematite concretions.

[43] Sulfate-bearing "outlier" deposits resembling those in Meridiani Planum have been recognized recently, for example in Schiaparelli Crater [Wiseman et al., 2009]. Completing the discovery of such outlying sulfate-bearing layered deposits is an important task in relating the Meridiani deposits to those elsewhere, such as in Valles Marineris. 


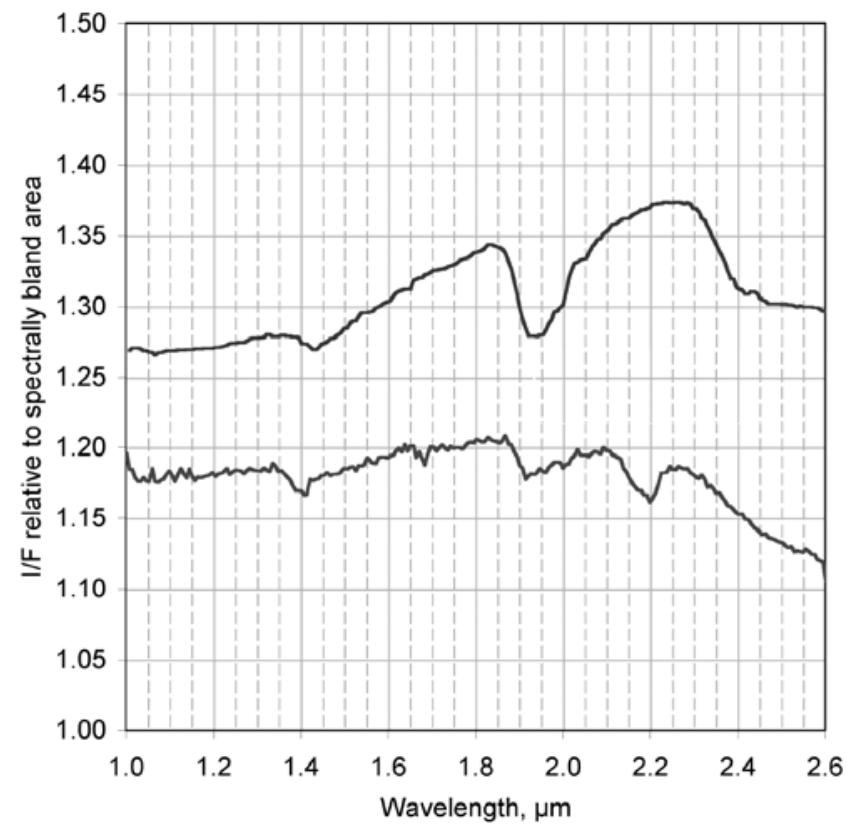

Figure 14. Relative spectra of a hydrated salt, probably sulfate (top line), and kaolinite (bottom line) from Columbus crater. Both are ratioed to nearly spectrally neutral material.

\subsection{Valles-Type Layered Deposits}

[44] The major occurrence of sulfate-bearing layered deposits outside Meridiani Planum is in Valles Marineris. They form deeply eroded plateaus up to several $\mathrm{km}$ in relief, on the floors of Tithonium, Hebes, Ophir, Candor, Melas, Eos, and Ganges Chasmata, whose comparative geology has been reviewed by Nedell et al. [1987], Lucchitta et al. [1992], and Komatsu et al. [1993]. The development and continuity of layers vary from chasma to chasma and are most pronounced in Melas and Candor Chasmata. In contrast to the deposits in Meridiani Planum, some of the deposits in Valles Marineris are highly deformed by folding and exhibit extensive fracturing and possible mineralization along the fractures [Okubo and McEwen, 2007; Okubo et al., 2008].

[45] Spectral data indicate a mineral assemblage resembling that in the Meridiani Planum layered deposits. At wavelengths $<1.0 \mu \mathrm{m}$ the deposits are dust-like and dominated by nanophase ferric oxide. Groups of strata contain dispersed crystalline ferric oxide, which is concentrated in talus [Gendrin et al., 2005b; Bibring et al., 2007; Mangold et al., 2008; Le Deit et al., 2007; Murchie et al., 2009b]. At least locally the talus coincides with concentrations of gray hematite adjacent to the layered deposits [Christensen et al., 2001a]. At infrared wavelengths, signatures of both monohydrated and polyhydrated sulfates occur pervasively in different layers within the layered deposits [Gendrin et al., 2005a; Mangold et al., 2008].

[46] The dominant form of sulfates in the layered deposits is monohydrated [Mangold et al., 2008], but the nature of the monohydrated phase and the relationship between beds containing different sulfate phases varies between the chasmata but with a major shared attribute: sulfates in the stratigraphically lower parts of the deposits tend to be dominated by monohydrated phases, whereas in the stratigraphically higher parts of the deposits they are dominated by polyhydrated phases. In Juventae Chasma, polyhydrated sulfate overlies monohydrated sulfate and is separated by a distinct geologic contact. The shape and position of the $2.1-\mu \mathrm{m}$ absorption in the monohydrated sulfate is most consistent with the Fe phase szomolnokite [Bishop et al., 2007, 2009]. In western Candor Chasma, the lower and middle parts of the section are dominated spectrally by monohydrated sulfate, most consistent with the Mg phase kieserite. However, as in Juventae Chasma, the upper beds are more dominated by polyhydrated sulfates [Murchie et al., 2007b, 2009b]. Discrete, dark strata shed dune-forming debris that contains both monohydrated sulfate and pyroxene like that observed in the chasma walls and surrounding plateau. The sequence in Aram Chaos is similar, with polyhydrated sulfate overlying monohydrated sulfate resembling kieserite, but unlike in the other chasmata these units are underlain by material with hydroxylated iron sulfate (Lichtenberg et al., submitted manuscript, 2009). In eastern Candor Chasma, multiple layers of polyhydrated and monohydrated sulfates are intercalated, and the monohydrated phase is consistent with kieserite [Roach et al., 2008, 2009].

[47] Ferric minerals are closely associated spatially with the sulfates in the Valles Marineris ILDs and the Aram Chaos deposits. TES data [Christensen et al., 2001a] show patches of gray hematite, typically at the base of slopes. Higher-spatial resolution data from OMEGA showed that finer-grained, red ferric minerals (possibly oxides) occur in the ILDs and are concentrated, probably by mass wasting, in aprons around the eroded plateaus [Gendrin et al., 2005b; Bibring et al., 2007; Mangold et al., 2008]. The highestspatial resolution data, from CRISM, show concentrations of ferric minerals not only in aprons but also in dunes and other sediment patches scattered throughout the ILDs. Materials in western Candor Chasma exhibit 0.53- and $0.88-\mu \mathrm{m}$ absorptions due to hematite [Murchie et al., $2009 \mathrm{~b}$ ], but other occurrences have less well defined ferric absorptions as well as absorptions near 1.9 and $2.2 \mu \mathrm{m}$. Minerals that might explain these features include the hydrated ferric sulfate copiapite, the hydrated ferric oxyhydroxide ferrihydrite, or the oxide hematite in combination with one or more other hydrated sulfates [Roach et al., 2007a; Bishop et al., 2009].

[48] Figure 16 illustrates a representative example of Valles Marineris' layered deposits, in western Candor Chasma, as seen by CRISM and HiRISE and using the same representations of the data as for Meridiani Planum in Figure 15. Separate layers contain polyhydrated sulfate (magenta in Figure 16b) and monohydrated sulfate (yellowgreen in Figure 16b). An inset HiRISE image (Figure 16c) shows component beds and dark, sandy material that appears to emanate from discrete layers. The layered deposits in Valles Marineris very closely resemble those in Meridiani Planum with respect to their remotely measured composition and their meters-scale morphology.

[49] Previously proposed genetic mechanisms for the Valles Marineris interior layered deposits include subaerial fluvial deposition or volcanism [Lucchitta et al., 1992], accumulation of eolian dust or sand [Peterson, 1981], evaporite precipitation [McKay and Nedell, 1988], subaque- 

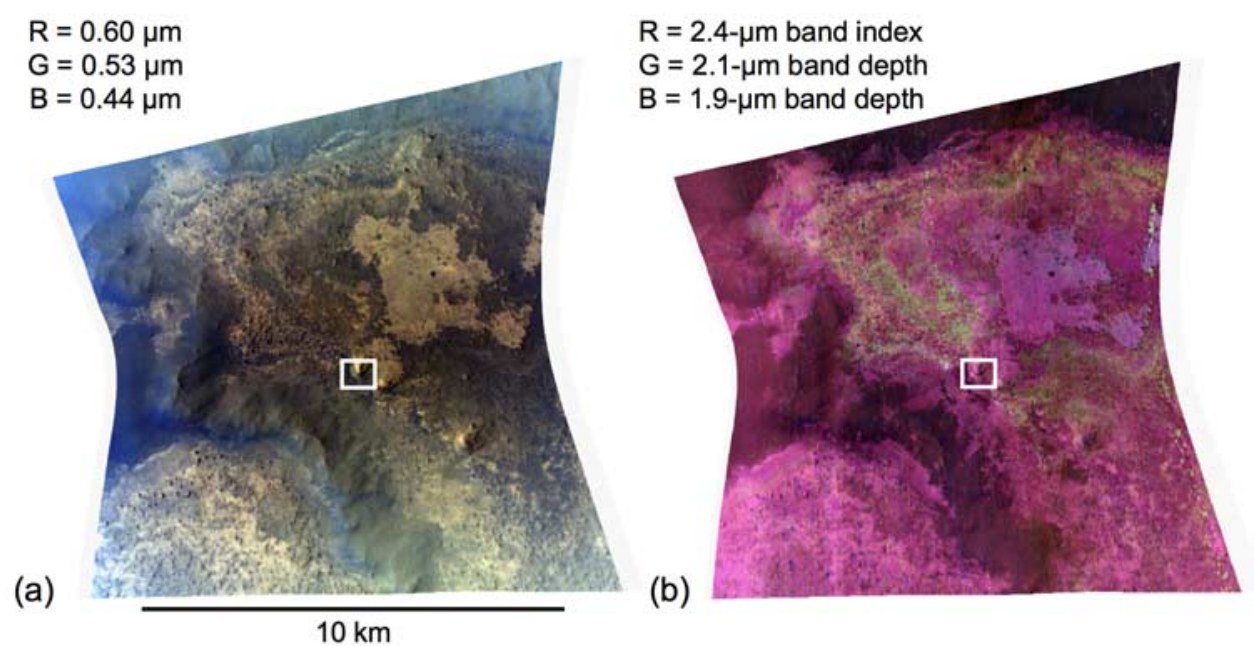

a)

$10 \mathrm{~km}$

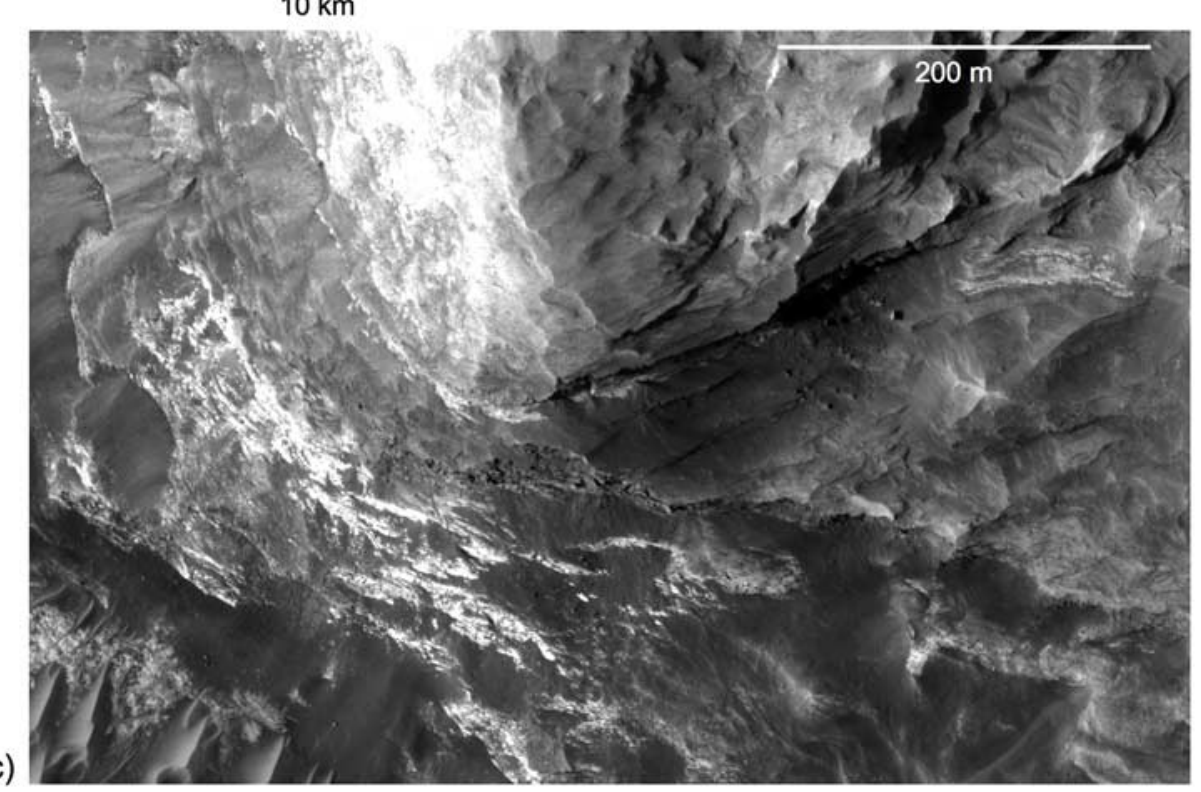

Figure 15. Meridiani-type layered deposits as seen by CRISM and HiRISE. (a) Enhanced visible color representation of CRISM observation FRT00004616 located at $2.3^{\circ} \mathrm{N}, 359.7^{\circ} \mathrm{E}$, showing highly winderoded light- and medium-toned layers. (b) Spectral parameter representation of the same observations (red, SINDEX; green, BD2100; blue, DB1900). Yellow and green tones represent occurrences of monohydrated sulfates, and magenta tones represent occurrences of polyhydrated sulfates or other hydrated phases. (c) Part of HiRISE image PSP_002680_1825_RED showing the contact between upper, polyhydrated sulfate-bearing beds and lower, monohydrated sulfate-bearing beds. Dark, sandy material appears to emanate from discrete layers and is redistributed by wind. The white boxes in Figures 15a and $15 \mathrm{~b}$ show the location of Figure 15c.

ous volcanism [Nedell et al., 1987], or deep erosion exposing preexisting layered chasma wall materials [Malin and Edgett, 2003]. The compositional evidence from spectroscopy effectively rules out eroded wall material and a volcanic origin, while supporting a contribution of evaporites. Furthermore, the similar sulfate stratigraphy between chasmata suggests some level of regional control of sulfate mineralogy.

[50] A potentially unifying hypothesis that would explain Valles Marineris' layered deposits as accumulations of evaporite-cemented eolian sediment was proposed by Murchie et al. [2009b]. They showed that groundwater flow modeling (following the methods of Andrews-Hanna et al. [2007]) predicts the interior of Valles Marineris to have experienced large amounts of discharge similarly to in Meridiani Planum, which could have formed evaporite-rich layered deposits analogously to the layered deposits in Meridiani Planum. That is, interbedded eolian sand and dust accumulated on chasmata floors where groundwater intersected the surface, evaporated, and created saline conditions in which sulfates precipitated and lithified advected eolian sediments. Even as cemented eolian sediments filled the chasmata, the elevated water table in the surrounding highlands maintained discharge sufficient to continue accumulating kilometers of sediments. Crystalline ferric oxide formed during diagenesis, and subsequently, erosion and mass wasting formed superposed sulfate-bearing dunes and coarse-grained hematitic debris. 

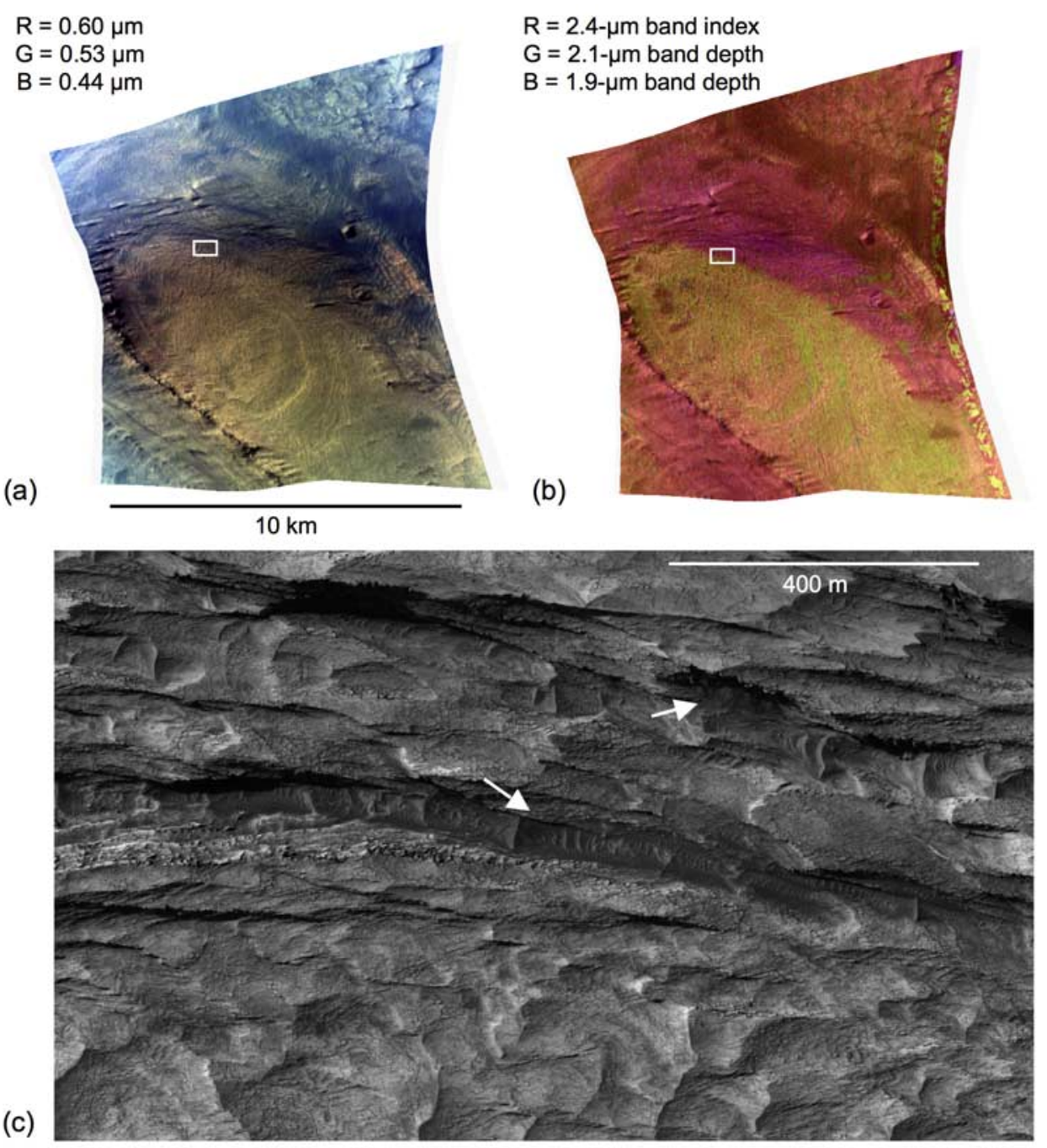

Figure 16. Valles-type layered deposits in Candor Chasma as seen by CRISM and HiRISE, using the same types of representations of CRISM data as in Figure 15. (a) Enhanced visible color representation of CRISM observation FRT0000BE37 located at $5.5^{\circ} \mathrm{S}, 284.1^{\circ} \mathrm{E}$, showing highly eroded light- and medium-toned layers. (b) Spectral parameter representation of the same observations (red, SINDEX; green, BD2100; blue, DB1900). Yellow and green tones represent occurrences of monohydrated sulfates, and magenta tones represent occurrences of polyhydrated sulfates or other hydrated phases. (c) Part of HiRISE image PSP 0094601745 RED showing the contact between upper, polyhydrated sulfatebearing beds (top part of image) and lower, monohydrated sulfate-bearing beds (bottom part of image). Dark, sandy material (arrows) appears to emanate from discrete layers, including the layer across the middle of the image which lies at the contact of the monohydrated and polyhydrated sulfate-bearing materials. The white boxes in Figures 16a and 16b show the location of Figure 16c.

[51] The folding and fracturing of the deposits in Valles Marineris are the major differences from the Meridiani deposits as seen from orbit, and these could be caused principally by gravity-driven deformation due to greater topographic relief and the greater thickness of the Valles Marineris deposits [Okubo et al., 2008]. Thus Hesperian age discharge of saline groundwater is potentially a globally important mechanism that could explain deposition of sulfate-bearing layered deposits in widely separated locations.

\subsection{Hydrated Silica-Bearing Deposits}

[52] A new discovery by MRO is the occurrence of hydrated silica (opal) in thinly bedded deposits that are superposed on the Hesperian plains surrounding Valles Marineris, including southwest of Melas Chasma, south of Ius Chasma, between Melas and Candor Chasma, west of Ganges Chasma, and west of Juventae Chasma (Figure 17) [Milliken et al., 2008; Weitz et al., 2008, 2009]. Several occurrences of opaline silica have also been observed within Melas Chasma and associated with pits in Noctis Labyrinthus [Milliken et al., 2008]. Individual beds are on the order of $<1 \mathrm{~m}$ to $\sim 10 \mathrm{~m}$ thick, exhibit polygonal fractures several meters in diameter, and are differentially eroded, presenting a morphology distinct from layered deposits within the chasmata. In some places the deposits are eroded into yardangs, and in others they display inverted channels 


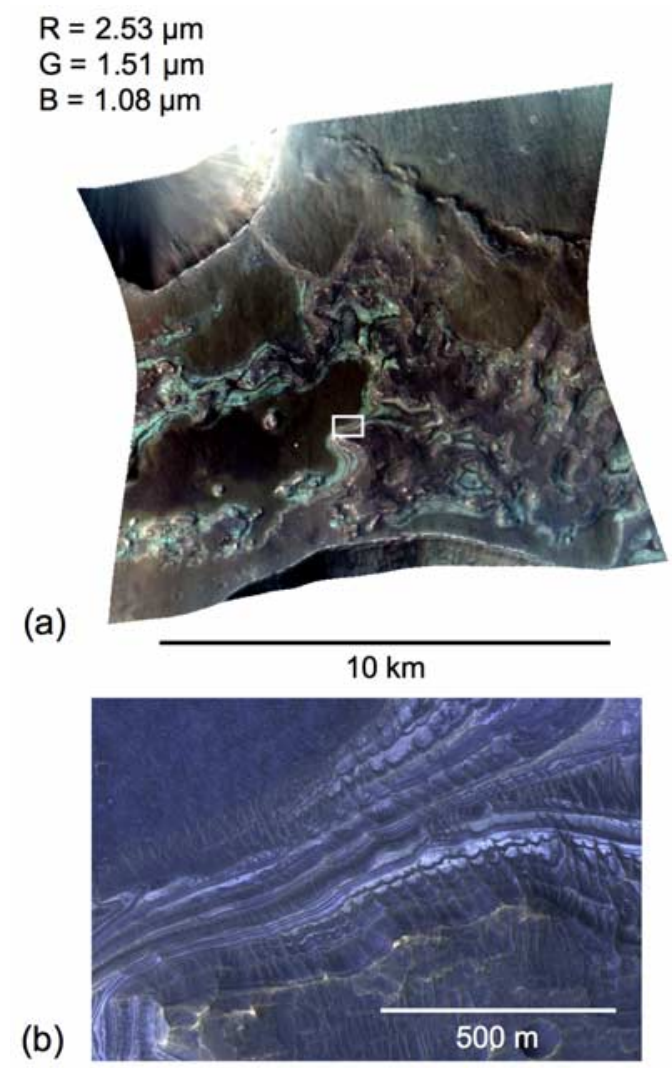

Figure 17. Hydrated silica-bearing, light-toned layered deposit on the plains west of Juventae Chasma. (a) Infrared false color version of CRISM observation FRT0005814_07, located at $4.6^{\circ} \mathrm{S}, 296.4^{\circ} \mathrm{E}$. The silica- and sulfate-bearing beds appear in light blue and pink tones, respectively. (b) HiRISE color image PSP_003434_1755_COLOR, showing an exposed section of silica- and sulfate-containing deposits. The white box in Figure 17a shows the location of Figure $17 \mathrm{~b}$.

indicating the importance of past fluvial processes followed by eolian erosion [Malin and Edgett, 2003; Mangold et al., 2004; Williams et al., 2005; Weitz et al., 2008, 2009]. They are the highest stratigraphic units in their locations adjacent to Valles Marineris, occurring on top of the Hesperian lava flows and thus have ages at least as young as Hesperian and possibly Amazonian.

[53] Hydrated silica is present in some layers of the deposits as evidenced in CRISM spectra by a very broad absorption at $2.2 \mu \mathrm{m}$ that is distinct from phyllosilicate spectra [e.g., Milliken et al., 2008; Bishop et al., 2009]. The shape and center of the band, as well as the strengths and position of accompanying bands at 1.39 and $1.9 \mu \mathrm{m}$, indicate a variety of forms including altered glass, opal, and/or chalcedony. Other layers exhibit a suite of absorptions consistent with jarosite, indicating alteration under acidic conditions [Milliken et al., 2008; Weitz et al., 2009]. In the plains west of Juventae Chasma, opaline silica is found in thin layers superposed by partially dehydrated sulfate [Milliken et al., 2008; Bishop et al., 2009].

[54] The spectral features of the opal/altered glass materials described here resemble the features in some beds within the layered phyllosilicate deposit in Mawrth Vallis, which include silica in light-toned layers [Bishop et al., 2008]. In particular, the presence of an $\mathrm{OH}$ overtone near $1.38 \mu \mathrm{m}$, an $\mathrm{H}_{2} \mathrm{O}$ combination band near $1.93 \mu \mathrm{m}$, and an $\mathrm{OH}$ combination band centered at $2.21 \mu \mathrm{m}$ with a shoulder toward longer wavelengths is characteristic of hydrated silica in both types of deposits. The relationship between hydrated silica and high-Si deposits found by MER/Spirit [Squyres et al., 2008] is currently unknown. Possible origins of the hydrated silica include acid weathering of volcanic ash or lava flows, precipitation from hydrothermal discharge, or some combination of chemical precipitation and detrital sedimentation in a fluvial or lacustrine environment [Milliken et al., 2008; Weitz et al., 2008, 2009].

\subsection{Gypsum Plains}

[55] Gypsum is enriched in Amazonian-aged deposits surrounding the north polar region, as indicated by characteristic absorptions at $1.45,1.75,1.9$ and $2.2 \mu \mathrm{m}$ discovered in OMEGA data. This gypsum forms the youngest known large deposit of aqueous minerals on Mars [Langevin et al., 2005]. The strongest absorptions coincide with dark dunes in the north polar sand sea, or erg, which form part of the Olympia Undae unit of Tanaka et al. [2008]. The gypsumbearing dunes have been interpreted previously as a windmodified part of the north polar basal unit (Planum Boreum cavi unit [Tanaka et al., 2008]), which consists of irregular, platy strata of sand intercalated with thin, light-toned, erosion-resistant strata [Byrne and Murray, 2002; Fishbaugh and Head, 2005]. The dunes are stabilized or indurated at their surfaces, as evidenced by the presence of surface cracks, absence of dry flow on avalanche faces [Feldman et al., 2008], yardangs, and craters [Schatz et al., 2006].

[56] Spectral data from OMEGA indicate a relatively large fraction of gypsum at the optical surface and the presence of hydrated minerals in surrounding areas. The nongypsum component of the Olympia Undae dunes is relatively featureless spectrally and resembles TES "type II" surface material [Bandfield et al., 2000; Rogers and Christensen, 2007]. Modeling of spectra of the dunes as mixtures of gypsum with a dark, spectrally neutral component like the type II material suggests a gypsum mass fraction at the optical surface as high as 30-45\% depending on the assumptions made [Fishbaugh et al., 2007; Horgan et al., 2009]. Outside of the dunes, a weaker $1.9-\mu \mathrm{m}$ absorption indicative of hydrated minerals occurs throughout the remainder of the Olympia Undae unit, as well as in others parts of the north polar layered deposits (cavi and member 2 of the Planum Boreum Formation and Rupes Tenuis unit). Horgan et al. [2009] identified the source of some of the hydrated material as member 2 of the Planum Boreum formation of Tanaka et al. [2008], which occurs at the upper contact of the basal unit. The identity of the hydrated phase is uncertain; it could also be gypsum or an additional hydrated sulfate or ferric mineral [Horgan et al., 2009].

[57] MRO's main contribution to understanding this class of deposit is high-resolution observations, most of which have only recently been acquired. Figure 18 shows the region having the strongest spectral signature of gypsum. CRISM data show that highest concentration of gypsum occurs near the dune crests [Roach et al., 2007b]. Horgan et 


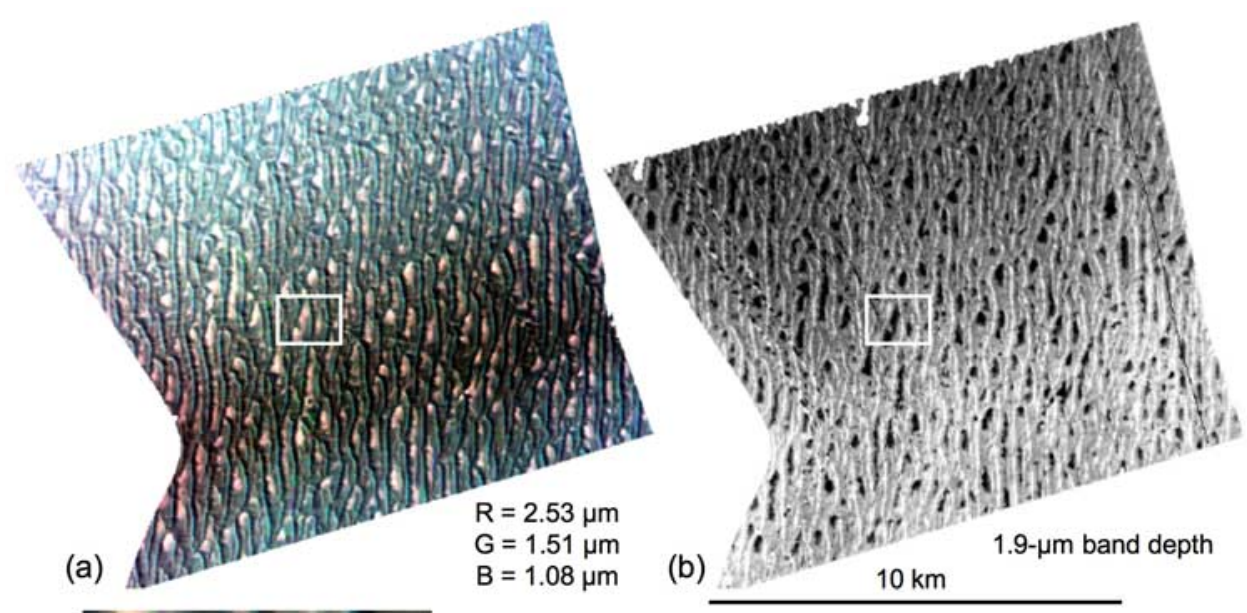

(c)

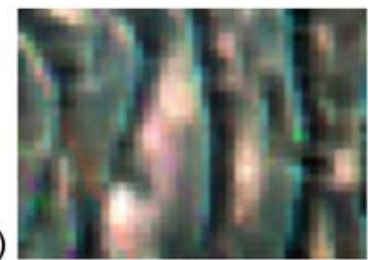

(d)
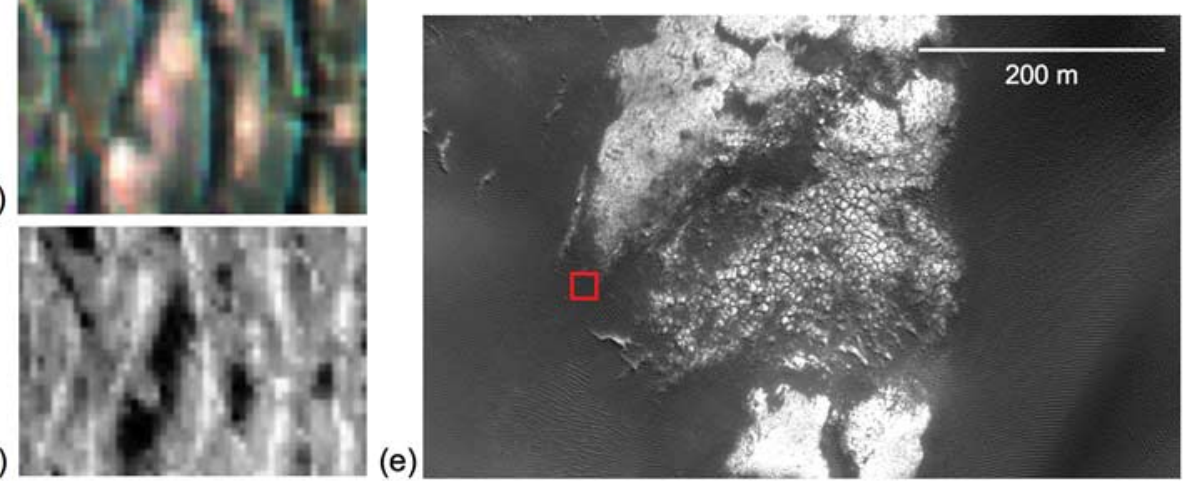

Figure 18. Gypsum-bearing plains in the north circumpolar erg. (a) Infrared false color representation of CRISM observation FRT0000285F located at $80.0^{\circ} \mathrm{N}, 240.7^{\circ} \mathrm{E}$, showing dunes in the region having the strongest spectral signature of gypsum measured by OMEGA. (b) Strength of the 1900-nm absorption in gypsum (BD1900). Low values occur in the light-colored interdune material, and higher values occur in the dunes. (c) Zoomed view of Figure 18a, showing dark dunes and light-colored interdune areas. (d) BD1900 for the same region. High values occur on dark dune crests, and lower values occur in lightcolored interdune areas. (e) Part of HiRISE image PSP_001432_2610_RED covering an interdune area and resolving polygonal fracturing like that in resistant strata of the north polar basal unit. The red box shows the relative size of a full-resolution CRISM pixel. Note that few comparably sized footprints in the interdune area would be free of a dark, gypsum-bearing component. The white box in Figure 18a is the location of the magnified view in Figure 18c.

al. [2009] argue that this most likely results from an enhanced content of gypsum at the crest rather than from a particle size variation due to eolian sorting, although the mechanism to concentrate the gypsum is unclear. Lightcolored interdune plains have much weaker gypsum absorptions (Figure 18a and 18b). It is unclear whether this means that the light-toned interdune plains lacks gypsum, because regions of it the size of a CRISM pixel footprint (red box in Figure 18e) typically also have a subpixel dark component. HiRISE images (Figure 18c) support a relationship to the basal unit members, because the light-toned plains exhibit the same characteristic polygonal fracture pattern present in the light strata of the Boreum Planum unit 3 and Rupes Tenuis unit [Herkenhoff et al., 2007; Tanaka et al., 2008].

[58] Proposed origins of the gypsum include weathering of iron sulfides in the sand, the interaction of pyroxene in the sand with acidic snow following past volcanic activity, or precipitation from sulfate-rich groundwater from basal melting of the layered deposits or from polar outflows [Langevin et al., 2005; Fishbaugh et al., 2007]. Existing analyses do not provide compelling evidence for one or the other mechanism, but the mechanical weakness of gypsum suggests that the phase was precipitated close to its present location [Horgan et al., 2009]. Perhaps gypsum has been concentrated from underlying material near the optical surface during by wicking of intergranular films of water, stabilizing the dunes in the process. The similarity of the erg to the north polar basal unit and the apparent presence of hydrated minerals in the Planum Boreum cavi and Rupes Tenuis members of the basal unit suggest that the source of the gypsum was likely related to formation of the basal unit itself. Further analyses of MRO data covering this enigmatic deposit are required to better constrain the history of this late phase of Martian aqueous activity, and to pose welldefined questions for landed investigation.

\section{Discussion}

[59] New data described here from MRO, considered together with earlier results from MOC, TES, THEMIS, 
and OMEGA, change the paradigm for the nature, occurrence, and distribution of aqueous mineral-bearing deposits on Mars. Although the view that the Martian crust is dominantly basaltic appears unchanged, evidence now indicates that a far greater variety of alteration products occur in far more diverse geologic settings than was believed prior to MRO. Rather than viewing these alteration products only as so many thousands of outcrops, as described above they also represent at least 9-10 distinct classes of deposits having characteristic mineral assemblages that occur in rocks with characteristic morphologies in distinct geologic settings. These classes of deposits record periods of Martian history during which liquid water persisted long enough to leave a mineral record, and they represent diverse aqueous environments with differing $\mathrm{pH}$, cation chemistry and water activity levels. As such, they include a record of those regions on Mars that possibly were habitable and sustained conditions necessary to preserve a fossil record of biotic or prebiotic evolution.

[60] The discovery and orbital characterization of these deposits are the first step in understanding the information they contain about past Martian environments. Continued analysis of new and existing orbital measurements, modeling studies, and especially (as described in section 2) landed, in situ investigation will all be needed to understand that record. In this section we identify several major questions raised by these new data. To help focus future investigation of the significance of the different classes of deposits for past environmental conditions, we also propose four hypotheses that could provide links between the deposit classes and the environmental conditions in which they formed, and we examine implications of the existing data for Mars' past habitability.

\subsection{Were There Phyllosian, Theiikian, and Siderikian Time Periods Characterized by Distinct Aqueous Deposits?}

[61] These periods were named by Bibring et al. [2006] to describe environments that formed alteration products of different ages. In this framework, the phyllosian period was dominated by relatively wet, neutral $\mathrm{pH}$ conditions conducive to the formation of clays, and the theiikian by drier acidic conditions in which sulfates formed. The siderikian period represents the more recent part of Mars' history during which liquid water was too rare and transient to leave a widespread mineralogic record observable from orbit. A leading hypothesis for the phyllosian-theiikian transition is shutdown of Mars' dynamo and weakening of the magnetic field, which allowed solar wind to erode the early atmosphere, cooling and drying the climate. Contemporaneously, $\mathrm{SO}_{2}$ emissions from Tharsis provided a source of sulfur to create an acidic and oxidizing environment and sulfate-rich deposits [Solomon et al., 2005].

[62] The diversity of aqueous deposits as known after new discoveries by MRO still falls neatly in Bibring et al.'s [2006] framework. With little exception, phyllosilicate- and carbonate-bearing deposits fall stratigraphically into the early to late Noachian phyllosian environment. The sulfateand silica-bearing deposits that suggest acidic conditions correspond to the late Noachian and Hesperian theiikian environment. However, two new major qualifications to Bibring et al.'s paradigm have become inescapable. First, formation of sulfates and phyllosilicates overlapped in space and time, at least in the highland craters containing kaolinite-sulfate assemblages; both could have formed together in acidic conditions. Second and more significantly, acidic theiikian conditions did not everywhere pervade the crust. At least some locations, for example certain regions surrounding the Isidis basin, still contain older carbonate deposits that could not have survived exposure to acidic conditions of the theiikian environment.

\subsection{How Were Layered Phyllosilicates Emplaced, and How Are They Related to Hydrated Silica Deposits?}

[63] The layered phyllosilicates and the compositionally distinct hydrated silica-bearing layered deposits share attributes of their layered morphologies and overlapping geologic settings, but they differ in mineralogic composition and age. Both classes of deposits are superposed on older cratered, eroded terrains. Both contain multiple thin beds; however, the fracturing of the beds tends to differ, with those containing $\mathrm{Fe} / \mathrm{Mg}$ or $\mathrm{Al}$ smectite being pervasively polygonally fractured, and those containing kaolinite group minerals or silica tending to be smoother at a tens-of-meters scale. Their geographic distributions are both restricted but overlap at eastern Valles Marineris and possibly in western Arabia. The leading proposed genetic mechanisms for weathering processes that produced layered phyllosilicates, weathering of vast ash deposits or extensive pedogenesis, both point to important late Noachian environmental conditions that are currently not understood but apparently included mildly acidic to neutral $\mathrm{pH}$ waters. In contrast, the compositions of the silica-bearing deposits and their occasional association with Fe sulfates, including jarosite, suggest that they formed during alteration under acidic conditions.

[64] On the basis of these relationships, we propose a hypothesis (hypothesis \#1) linking these two classes: that they both represent altered volcanic and impact glass with similar primary mineralogy, deposits with similar layering. However, they weathered under different environments and differences in $\mathrm{pH}$ were an underlying factor in producing different alteration assemblages. In this case, these two classes of deposits would provide a record of the effects of changing Martian environmental conditions on comparable primary compositions, from wetter conditions and neutral $\mathrm{pH}$ (phyllosian conditions) to drier, acidic (theiikian) conditions.

\subsection{Is There a Continuum of Lacustrine Deposits With Different Proportions of Evaporites and Detritus?}

[65] Three classes of aqueous mineral-containing deposits, phyllosilicates in intracrater fans, plains sediments, and intracrater clay-sulfate deposits, exhibit the strongest evidence for having formed in lake or playa environments. This includes occurrence in topographic basins, the presence of depositional fans, subhorizontal parallel bedding, concentrations of phyllosilicates, and/or concentrations of evaporite minerals. In intracrater fans, phyllosilicates are probably dominated by a detrital component eroded and redeposited from the watershed [Grant et al., 2008; Ehlmann et al., 2008a]; there is little evidence for an authigenic component in the fans or for sulfates or other evaporite deposits. Indeed, carbonate is a component in deltaic materials in Jezero 
crater, indicating neutral to alkaline waters [Ehlmann et al., 2009]. In contrast, in plains sediments and intracrater claysulfate deposits, evaporitic minerals are present, the probable chlorides and hydrated sulfates.

[66] On the basis of these results, we propose (hypothesis \#2) that there is a continuum of lacustrine deposits whose dominant mineralogy results from variations between sediment supply and evaporation in these environments. The recognized examples of phyllosilicates in fans (section 4.2) all occur in basins fed by large systems of valley networks [Fassett and Head, 2008], providing an obvious source of detritus while flushing the lake basins to maintain salinity at relatively low levels. In contrast, plains sediments containing probable chlorides (for example in Figures 5 and 7) occur outside of these valley network-fed basins. The lack of development of integrated drainage in their basins is evidence for low rates of flushing, and greater loss by evaporation of any standing water that accumulated in the basins. The two currently recognized examples of intracrater clay-sulfate deposits also both occur outside the valley network-fed basins, within craters with minimal evidence for inflow, and they have been proposed to represent deposits emplaced in spring-fed lakes [Swayze et al., 2008; Wray et al., 2008b, 2009]. With a decreased input of detritus, the dominant phases in water-filled basins would likely be salts formed during evaporation.

\subsection{What Were the Roles Played by Different Processes in Forming Deep Phyllosilicates?}

[67] Deep phyllosilicates represent a widespread component of the Noachian crust, with widespread geographic distribution in the highlands where materials have been exhumed from depth. At present there are conflicting indications of what these deposits may reveal about early Martian history. Some of the deposits are layered suggesting deposition in a near-surface environment, whereas theoretical considerations of hydrothermal circulation in the crust and association with megabreccia would suggest a less stratified and more chaotic configuration. At Valles Marineris and Argyre, phyllosilicates appear to be concentrated in discrete layers within an otherwise mafic-rich upper crust. At least some of those layers, for example in the upper walls of Valles Marineris, resemble fine-grained, layered, $\mathrm{Al}$ and $\mathrm{Fe} / \mathrm{Mg}$ phyllosilicates such as those exposed around Mawrth Vallis, suggesting that at least a component of the deep phyllosilicates was formed at or near the surface and later buried. Other examples, for instance at Nili Fossae and lower in the walls of Valles Marineris, are brecciated suggesting a different emplacement mechanism, for example as impact ejecta. Both the fine-grained and brecciated layered materials are buried by younger, mafic mineraldominated deposits. In contrast, the history of lithospheric thickening [Parmentier et al., 2008] suggests that throughgoing hydrothermal alteration of the crust may have been an important process. This process is not expected to have produced such strong stratification of mineral composition. Locally, there are exposures containing minerals that could have formed from a relatively high degree of hydrothermal alteration [Ehlmann et al., 2008c, 2009], but regionally, minerals formed by higher-temperature alteration sometimes occur at shallower depths than minerals expected to form by lower-temperature alteration [Fraeman et al.,
2009]. Finally, the brecciated nature of deep phyllosilicates in Nili Fossae [Mustard et al., 2009] and the occurrence of phyllosilicates in impact breccias [McEwen et al., 2008] suggest that impact processes may also have played an important role in forming phyllosilicates as well.

[68] One way to reconcile these observations is hypothesis \#3, that deep phyllosilicates were formed by multiple processes, with near-surface formation and subsequent burial dominating at shallower depths, and with localized formation by hydrothermal processes penetrating throughout the crust. More specifically, shallower phyllosilicates may have formed originally as layered phyllosilicates, and others as plains sediments. Others deposits may have been formed at depth by localized low-temperature metamorphism or hydrothermal activity, and then exhumed by impacts and redeposited as ejecta blankets, contributing to the stratified configuration of phyllosilicates at shallow depths. This hypothesis can reconcile some seemingly contradictory observations: that minerals formed by higher-temperature alteration sometimes occur at shallow depths (where they are part of overturned stratigraphy in ejecta blankets), and that although phyllosilicates are exposed from up to about $6 \mathrm{~km}$ depth, the deepest crustal exposures, for example the basin rings of Argyre, and the lower walls of Valles Marineris, are dominated by unaltered mafic rocks without obvious evidence for hydrothermal alteration. This hypothesis implies that deep hydrothermal alteration of the crust was not a globally pervasive phenomenon, and may have been controlled by the availability of subsurface water or ice on ancient Mars.

\subsection{Was Emplacement of Sulfate-Containing Deposits Related by a Common Process?}

[69] The modeling of Mars' hydrologic cycle by AndrewsHanna et al. [Andrews-Hanna et al., 2007, 2008; Murchie et al., 2009b] provides a possible mechanism that relates the two major occurrences of late Noachian- to Hesperianaged sulfate-bearing materials, the Meridiani- and Vallestype layered deposits. In both cases, the deposits are located where the water table is predicted to have intersected the planet's surface during that part of Mars' history. Sulfate-rich evaporites deposited by the evaporating groundwater would have formed sedimentary deposits themselves, as well as trapped eolian sediment, building up a thick stack of evaporite-cemented eolian materials. On the basis of the success of groundwater discharge models in linking the geographically separated deposits of the two regions, we propose (hypothesis \#4) that other theiikian sulfate-rich materials were also deposited where saline groundwater reached the surface during late Noachian to early Hesperian times. This hypothesis predicts that outlying sulfate-bearing deposits such as in Gale crater and Columbus crater will be found to occur within predicted areas of early Hesperian groundwater discharge. The global, low-resolution map of predicted groundwater discharge [Andrews-Hanna et al., 2007] in fact shows regions of high discharge at or near these regions.

\subsection{Which Classes of Deposits Might Preserve a Record of a Habitable Environment?}

[70] Assemblages of minerals formed in ancient environments frequently can indicate whether an environment provided the essential nutrients, biochemically useful energy, 
and liquid water required to sustain life. Essential nutrient elements apparently have been widely available in most Martian crustal environments, as evidenced by the pervasive distribution of basalts, basaltic sands, and their alteration products. Elemental compositions of Martian basalts broadly resemble those of olivine basalts beneath the seabed on Earth, whose overall nutrient balance has been shown to be adequate to support microorganisms living there today [Fisk and Giovannoni, 1999].

[71] Habitable environments must also provide, at least intermittently, sources of energy to fuel metabolism, selfreplication, and repair of cellular constituents, as well as sufficiently abundant liquid water. Solar radiation is the most obvious example of an energy source, but microorganisms also can exploit oxidation-reduction reactions to obtain energy in the absence of light. For example, the oxidation of $\mathrm{Fe}^{2+}, \mathrm{Mn}^{2+}$ and $\mathrm{S}$ species provides energy and reducing power for metabolism and organic synthesis [Fenchel and Blackburn, 1979]. Liquid water must be available at a water activity $\left(\mathrm{a}_{\mathrm{H} 2 \mathrm{O}}\right)$ sufficient to sustain metabolic processes. The $\mathrm{a}_{\mathrm{H} 2 \mathrm{O}}$ scale ranges from 0 to 1 , where pure water has an activity of 1 and saline waters have lower values. The minimum water activity that is necessary to sustain microbial processes on Earth is $\sim 0.75$ for haloarchea in $\mathrm{NaCl}$ brines and $\sim 0.61$ for fungi in high sugar media [Grant, 2004]. Providing both energy and adequately fresh water can be problematic. For example, sunlight could sustain photosynthesis at the Martian surface, however "where the surface and shallow subsurface of Mars are at or close to thermodynamic equilibrium with the [present-day] atmosphere, [the] temperature and water activity ... are considerably below the threshold conditions for propagation of terrestrial life" [MEPAG Special Regions-Science Analysis Group, 2006, p. 4].

[72] The minerals detected in the 9 to 10 classes of deposits identified in this paper indicate a range of soluble cations, $\mathrm{pH}, \mathrm{Eh}$, and water activities. These mineral detections constrain the presence of habitable environments at the Martian surface as well as in the subsurface, in the distant past, at the time the deposits containing them were emplaced. The formation of different mineral phases and the sequence of precipitation of salts from evaporating solutions are controlled by the parent lithology of the weathering products that provided the solutes. Tosca et al. [2005] modeled weathering of the dominantly basaltic Martian crustal lithology assuming a Nakhlite-type assemblage, and showed that the sequence of weathering products and the chemistry of the water in which they form should differ from those of terrestrial environments having dominantly granitic lithologies [Tosca et al., 2005]. That and other studies cited below provide a basis for using minerals detected on Mars to help constrain the $\mathrm{pH}$ and $\mathrm{a}_{\mathrm{H} 2 \mathrm{O}}$ of the environments where they formed. Most smectite clays form in near-neutral waters, whereas kaolinite and hydrated silica can also form under weakly acidic conditions [e.g., Chamley, 1989; Nagy, 1995]. Carbonates typically form in weakly alkaline environments [Fairén et al., 2004] and precipitate at $\mathrm{a}_{\mathrm{H} 2 \mathrm{O}}$ values of $0.83-0.88$ (for magnesite formed by weathering of Nakhlite-like primary mineralogy) [Tosca et al., 2008]. As the $\mathrm{pH}$ drops below neutrality, different Fecontaining assemblages formed in more acidic (but overlapping) $\mathrm{pH}$ ranges: ferric oxyhydroxides such as goethite

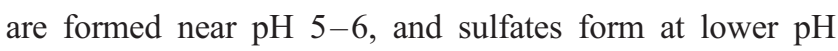
including schwertmannite near $\mathrm{pH} 3-5$ and jarosite near pH 1-3 [Bigham et al., 1996].

[73] The relationship between $\mathrm{pH}$ and mineralogy for the $\mathrm{Fe}-\mathrm{OH}-\mathrm{SO}_{4}$ system also depends on redox potential, or Eh, as described by King and McSween [2005]. Tosca et al. [2005] report $\mathrm{a}_{\mathrm{H} 2 \mathrm{O}}$ values of 0.86 for jarosite plus epsomite. At even lower $\mathrm{pH}$ hydrated iron sulfates such as copiapite and rhomboclase are formed [e.g., Majzlan et al., 2006], whereas hydrated ferrous sulfates such as melanterite form under $\mathrm{pH} 0-4$ at lower Eh values. Salinity values for mineral precipitation increase from polyhydrated to monohydrated sulfates, with $\mathrm{a}_{\mathrm{H} 2 \mathrm{O}}$ near 0.78 for epsomite, 0.62 for hexahydrite, and 0.51 for kieserite [Tosca et al., 2008]. Modeling of solution chemistry suggests that acidic Fe-Mg(Ca)- $\mathrm{SO}_{4}-\mathrm{Cl}$ solutions will precipitate $\mathrm{Fe}$ sulfates with low $\mathrm{OH} /\left(\mathrm{OH}+\mathrm{SO}_{4}\right)$ levels such as copiapite and bilinite, Fe (hydr)oxides, Fe phosphates, $\mathrm{Ca}-\mathrm{Mg}-\mathrm{Na}$ sulfates, Si-rich phases, and possibly $\mathrm{Mg}-\mathrm{Na}+\mathrm{K}-\mathrm{Ca}$ halides [King and $M c S w e e n, 2005]$. In contrast, ferric $\mathrm{Fe}$ is insoluble in nearneutral solutions, thus $\mathrm{Mg}-\mathrm{Na}-(\mathrm{Ca})-\mathrm{SO}_{4}-\mathrm{Cl}$ solutions would likely result in $\mathrm{Fe}$ (hydr)oxides, $\mathrm{Ca}$ phosphates, $\mathrm{Fe}-\mathrm{Mg}-\mathrm{Ca}$ carbonates, Si-rich phases, Fe sulfates with high $\mathrm{OH} /(\mathrm{OH}+$ $\mathrm{SO}_{4}$ ) levels such as schwertmannite, $\mathrm{Ca}-\mathrm{Mg}-\mathrm{Na}$ sulfates, and possibly $\mathrm{Mg}-\mathrm{Na}+\mathrm{K}-\mathrm{Ca}$ halides [King et al., 2004]. Chlorides imply the lowest $\mathrm{a}_{\mathrm{H} 2 \mathrm{O}}$ at $\leq 0.48$ [Tosca et al., 2008 ] because of their relative solubility in basaltic-weathering-derived waters; modeling predicts that chlorides precipitate after sulfate minerals are precipitated.

[74] Two to five classes of deposits, all of probable Noachian age and containing phyllosilicates and carbonates, appear on the basis of our current knowledge to have formed in environments having $\mathrm{pH}$ and $\mathrm{a}_{\mathrm{H} 2 \mathrm{O}}$ values consistent with habitable conditions. Phyllosilicates in fans lack detectable precipitates, and at Jezero they preserve carbonate of probable detrital origin, suggesting neutral to alkaline $\mathrm{pH}$ and $\mathrm{a}_{\mathrm{H} 2 \mathrm{O}} \geq 0.83$. Carbonate deposits imply alkaline $\mathrm{pH}$ and $\mathrm{a}_{\mathrm{H} 2 \mathrm{O}} 0.83-0.88$ if the carbonates were precipitated, or higher if they formed directly by alteration of olivine in more dilute waters. The phyllosilicate layers in plains sediments also appear to be dominantly detrital and they lack evidence for sulfates or carbonates, allowing the possibility that the water activity may have been high. However, at some localities chlorides apparently precipitated late during the plains sediments' emplacement, indicating that water activities reached values too low $\left(\mathrm{a}_{\mathrm{H} 2 \mathrm{O}} \leq 0.48\right)$ to sustain active metabolism at the time the chlorides formed. These three classes of deposits additionally include phases (e.g., phyllosilicates, carbonates) that can entomb and preserve organic matter and thus are promising to preserve a record of any organic chemistry [Farmer and Des Marais, 1999]. Deep phyllosilicates and layered phyllosilicates probably formed in neutral to mildly acidic $\mathrm{pH}$ conditions, and no mineralogical evidence indicating high salinities has yet been detected from orbit.

[75] In contrast, the late Noachian and younger, sulfatebearing deposits may have formed in water environments that were marginally habitable at best because of low water activity, at least at the time when the sulfates were deposited. Earlier periods of higher water activity are not precluded, but neither are they clearly in evidence. Knoll et al. [2005] and Tosca et al. [2008] showed that the presence of 
sulfates including jarosite in at least parts of the Meridiani layered deposits indicates that they formed in waters that were both acidic and highly saline $\left(\mathrm{a}_{\mathrm{H} 2 \mathrm{O}} \leq 0.78\right.$ for layers containing polyhydrated sulfates, assuming they are epsomite, or up to 0.86 if jarosite was coprecipitated). In the Valles Marineris layered deposits, for a plausible mineral assemblage including epsomite and ferricopiapite, $\mathrm{a}_{\mathrm{H} 2 \mathrm{O}}$ would have been $\sim 0.61$, or less where the sulfates were monohydrated. Mineral identification in the intracrater phyllosilicate deposits is ongoing, but preliminary results indicate the presence of hydrated $\mathrm{Fe}$ and $\mathrm{Mg}$ sulfates including kieserite, plus the acid sulfate alunite, again indicating extreme salinities and low $\mathrm{pH}$. The circumpolar gypsum plains are too poorly understood to allow the habitability of their depositional environment to be assessed, however gypsum is expected to precipitate in waters that are much less saline than those that precipitate magnesium sulfates [Tosca et al., 2005].

[76] The exobiological potential of hydrated silica-bearing deposits is less clear. Some beds exhibit evidence for jarosite [Milliken et al., 2008] which, if precipitated with epsomite, would allow $\mathrm{a}_{\mathrm{H} 2 \mathrm{O}}$ as high as $\sim 0.86$. If the jarosite was detrital or if other hydrated ferric sulfates suggested by Bishop et al. [2009] including copiapite were coprecipitated, $\mathrm{a}_{\mathrm{H} 2 \mathrm{O}}$ could have been as low as $\sim 0.6$. However, the layers containing hydrated silica are segregated and their depositional environments might have been less saline and only mildly acidic, and the silica could have effectively entombed organic chemistry [Farmer and Des Marais, 1999].

[77] Continued acquisition and analysis of orbital data will be critical to resolving among the hypotheses for the origin of aqueous mineral-bearing deposits, and to providing additional constraints on the habitability of their depositional environments. However, landed investigations will provide the best opportunities to characterize these deposits in detail. Techniques including high-resolution imaging to resolve grain-scale relationships and textures, definitive mineralogy, precision chemical analysis, and morphologic data will all be important to clarifying the nature of the processes that led to alteration and deposition of rock formations bearing hydrated minerals. With the new highresolution data from $\mathrm{MRO}$, it is possible to carefully target sites with multiple lithologic units and plan traverses that cross the unit boundaries.

\section{Summary}

[78] MRO has complemented results from earlier orbital investigations of aqueous mineral deposits on Mars by improving the spatial resolution at which both mineralogy and surface morphology can be characterized. When added to earlier results from TES, THEMIS, and OMEGA, new observations from CRISM, HiRISE and CTX reveal great diversity of aqueous mineral-bearing deposits. On the basis of similarities in the deposits' mineral assemblages, morphologies, and geologic settings, 9-10 distinct classes of deposits are recognized, and they outcrop in thousands of locations that are most numerous in the Noachian highlands. As well as they can be determined at present, the deposits' relative ages appear to be consistent with Bibring et al.'s [2006] conceptual framework of distinct phyllosian and theiikian time periods and environments. The implications of these classes of deposits are still being studied and landed investigations ultimately are required to distinguish among competing hypotheses for their origins. The Noachian-aged phyllosilicate- and carbonate-bearing deposits appear, on the basis of data in hand, possibly to have formed in aqueous environments suitable for life.

[79] Acknowledgments. The authors thank the CRISM, HiRISE, CTX, and MRO operations team for collecting the data that made the results in this paper possible. This work was supported by MRO funding through subcontract 852950 from the Jet Propulsion Laboratory.

\section{References}

Allen, C., and J. Conca (1991), Weathering of basaltic rocks under cold, arid conditions: Antarctica and Mars, Proc. Lunar Planet. Sci. Conf., 21, $711-717$.

Andrews-Hanna, J. C., R. J. Phillips, and M. T. Zuber (2007), Meridiani Planum and the global hydrology of Mars, Nature, 446, 163-166, doi:10.1038/nature05594.

Andrews-Hanna, J. C., S. M. Wiseman, and R. E. Arvidson (2008), The role of groundwater in the origin of the indurated layered deposits of Arabia Terra, Mars, Eos Trans. $A G U, 89(53)$, Fall Meet. Suppl., Abstract P44A-01.

Arvidson, R. E., F. P. Seelos IV, K. S. Deal, W. C. Koeppen, N. O. Snider, J. M. Kieniewicz, B. M. Hynek, M. T. Mellon, and J. B. Garvin (2003), Mantled and exhumed terrains in Terra Meridiani, Mars, J. Geophys. Res., 108(E12), 8073, doi:10.1029/2002JE001982.

Arvidson, R. E., F. Poulet, J.-P. Bibring, M. Wolff, A. Gendrin, R. V. Morris, J. J. Freeman, Y. Langevin, N. Mangold, and G. Bellucci (2005), Spectral reflectance and morphologic correlations in eastern Terra Meridiani, Mars, Science, 307, 1591-1594, doi:10.1126/science.1109509.

Arvidson, R. E., et al. (2006), Nature and origin of the hematite-bearing plains of Terra Meridiani based on analyses of orbital and Mars Exploration rover data sets, J. Geophys. Res., 111, E12S08, doi:10.1029/ 2006JE002728.

Arvidson, R. E., et al. (2008), Spirit Mars Rover mission to the Columbia Hills, Gusev Crater: Mission overview and selected results from the Cumberland Ridge to Home Plate, J. Geophys. Res., 113, E12S33, doi:10.1029/2008JE003183.

Baker, V. R., M. H. Carr, V. C. Gulick, C. R. Williams, and M. S. Marley (1992), Channels and valley networks, in Mars, edited by H. H. Kieffer et al., pp. 493-522, Univ. of Ariz. Press, Tucson.

Bandfield, J. L., V. E. Hamilton, and P. R. Christensen (2000), A global view of Martian surface compositions from MGS-TES, Science, 287 1626-1630, doi:10.1126/science.287.5458.1626.

Banfield, J. F., B. F. Jones, and D. R. Veblen (1991), An AEM-TEM study of weathering and diagenesis, Abert Lake, Oregon: I. Weathering reactions in the volcanics, Geochim. Cosmochim. Acta, 55, 2781-2793, doi:10.1016/0016-7037(91)90444-A.

Bibring, J.-P., et al. (2005), Mars surface diversity as revealed by the OMEGA/Mars Express observations, Science, 307, 1576-1581, doi:10.1126/science.1108806.

Bibring, J.-P., et al. (2006), Global mineralogical and aqueous Mars history derived from OMEGA/Mars Express data, Science, 312, 400-404, doi:10.1126/science. 1122659 .

Bibring, J.-P., et al. (2007), Coupled ferric oxides and sulfates on the Martian surface, Science, 317, 1206-1210, doi:10.1126/science. 1144174.

Bigham, J. M., U. Schwertmann, S. J. Traina, R. L. Winland, and M. Wolf (1996), Schwertmannite and the chemical modeling of iron in acid sulfate waters, Geochim. Cosmochim. Acta, 60, 2111-2121, doi:10.1016/00167037(96)00091-9.

Bishop, J. L., E. Murad, M. D. Lane, and R. L. Mancinelli (2004), Multiple techniques for mineral identification on Mars: A study of hydrothermal rocks as potential analogues for astrobiology sites on Mars, Icarus, 169, $311-323$.

Bishop, J. L., et al. (2007), Sulfates and mafic minerals in Juventae Chasma as seen by CRISM in coordination with OMEGA, HIRISE and context images, in Seventh International Conference on Mars, July 9-13, 2007, Pasadena CA, [CD-ROM], LPI Contrib., 1353, Abstract 3350.

Bishop, J. L., et al. (2008), Phyllosilicate diversity and past aqueous activity revealed at Mawrth Vallis, Mars, Science, 321, 830-833, doi:10.1126/ science. 1159699.

Bishop, J. L., et al. (2009), Mineralogy of Juventae Chasma: Sulfates in the light-toned mounds, mafic minerals in the bedrock, and hydrated silica 
and hydroxylated ferric sulfate on the plateau, J. Geophys. Res., doi:10.1029/2009JE003352, in press.

Buczkowski, D. L., S. Murchie, F. Seelos, E. Malaret, C. Hash, and the CRISM Science Team (2008), CRISM analyses of Argyre basin, Lunar Planet. Sci., XXXIX, Abstract 1030

Burns, R. G. (1986), Terrestrial analogs of the surface rocks of Mars, Nature, 320, 55-56, doi:10.1038/320055a0.

Burns, R. G. (1987), Ferric sulfates on Mars, J. Geophys. Res., 92, E570-E574, doi:10.1029/JB092iB04p0E570.

Burns, R. G. (1993), Rates and mechanisms of chemical weathering of ferromagnesian silicate minerals on Mars, Geochim. Cosmochim. Acta, 57, 4555-4574, doi:10.1016/0016-7037(93)90182-V.

Burns, R. G., and D. S. Fisher (1990), Evolution of sulfide mineralization on Mars, J. Geophys. Res., 95, 14,169-14,173, doi:10.1029/ JB095iB09p14169.

Byrne, S., and B. C. Murray (2002), North polar stratigraphy and the paleoerg of Mars, J. Geophys. Res., 107(E6), 5044, doi:10.1029/ 2001JE001615

Calvin, W., L. Roach, F. Seelos, K. Seelos, R. Green, and S. Murchie (2009), CRISM observations of northern Martian latitudes in summer, $J$. Geophys. Res., doi:10.1029/2009JE003348, in press.

Chamley, H. (1989), Clay Sedimentology, 623 pp., Springer, New York.

Christensen, P. R., and H. J. Moore (1992), The Martian surface layer, in Mars, edited by H. H. Kieffer et al., pp. 686-729, Univ. of Ariz. Press, Tucson.

Christensen, P. R., et al. (2000), Detection of crystalline hematite mineralization on Mars by the Thermal Emission Spectrometer: Evidence for near-surface water, J. Geophys. Res., 105, 9623-9642, doi:10.1029/ 1999JE001093.

Christensen, P. R., R. V. Morris, M. D. Lane, J. L. Bandfield, and M. C. Malin (2001a), Global mapping of Martian hematite mineral deposits: Remnants of water-driven processes on early Mars, J. Geophys. Res. 106, 23,873-23,885, doi:10.1029/2000JE001415.

Christensen, P. R., et al. (2001b), Mars Global Surveyor Thermal Emission Spectrometer experiment: Investigation description and surface science results, J. Geophys. Res., 106, 23,823-23,871, doi:10.1029/ 2000JE001370.

Christensen, P. R, et al. (2004), The Thermal Emission Imaging System (THEMIS) for the Mars 2001 Odyssey mission, Space Sci. Rev., 110 85-130, doi:10.1023/B:SPAC.0000021008.16305.94.

Clark, R. N., G. A. Swayze, S. L. Murchie, J. F. Mustard, R. E. Milliken, B. L. Ehlmann, N. K. McKeown, W. M. Calvin, J. J. Wray, and J. L. Bishop (2008), Diversity of mineralogy and occurrences of phyllosilicates on Mars, Eos Trans. AGU, 89(53), Fall Meet. Suppl., Abstract P43D-04.

Edwards, C. S., P. R. Christensen, and V. E. Hamilton (2008), Evidence for extensive olivine-rich basalt bedrock outcrops in Ganges and Eos chasmas, Mars, J. Geophys. Res., 113, E11003, doi:10.1029/2008JE003091.

Ehlmann, B. L., et al. (2007), New secondary minerals detected by MRO CRISM and their geologic settings: Kaolinite, chlorite, illite/muscovite, and the possibility of serpentine or carbonate in Nili Fossae, in Seventh International Conference on Mars, July 9-13, 2007, Pasadena CA, [CD-ROM], LPI Contrib., 1353, Abstract 3270.

Ehlmann, B. L., J. F. Mustard, C. I. Fassett, S. C. Schon, J. W. Head III D. J. Des Marais, J. A. Grant, and S. L. Murchie (2008a), Clay-bearing minerals and organic preservation potential in sediments from a Martian delta environment, Jezero crater, Nili Fossae, Mars, Nat. Geosci., 1, 355-358, doi:10.1038/ngeo207.

Ehlmann, B. L., et al. (2008b), Orbital identification of carbonate-bearing rocks on Mars, Science, 322, 1828-1832, doi:10.1126/science.1164759.

Ehlmann, B. L., J. F. Mustard, J. L. Bishop, G. A. Swayze, L. H. Roach, R. N. Clark, R. E. Milliken, F. Poulet, S. L. Murchie, and the MRO CRISM Team (2008c), Distinct provinces of aqueous alteration in the western Isidis region identified with MRO-CRISM, Lunar Planet. Sci., XXXIX, Abstract 2326.

Ehlmann, B. L., et al. (2009), Identification of hydrated silicate minerals on Mars using MRO-CRISM: Geologic context near Nili Fossae and implications for aqueous alteration, J. Geophys. Res., doi:10.1029/ 2009JE003339, in press.

Fairén, A. G., D. Fernández-Remolar, J. M. Dohm, V. R. Baker, and R. Amils (2004), Inhibition of carbonate synthesis on acidic oceans on early Mars, Nature, 431, 423-426, doi:10.1038/nature02911.

Farmer, J. D., and D. J. Des Marais (1999), Exploring for a record of ancient Martian life, J. Geophys. Res., 104, 26,977-26,995, doi:10.1029/ 1998JE000540.

Fassett, C. I., and J. W. Head III (2005), Fluvial sedimentary deposits on Mars: Ancient deltas in a crater lake in the Nili Fossae region, Geophys. Res. Lett., 32, L14201, doi:10.1029/2005GL023456.

Fassett, C. I., and J. W. Head III (2008), Valley network-fed, open-basin lakes on Mars: Distribution and implications for Noachian surface and subsurface hydrology, Icarus, 198, 37-56, doi:10.1016/j.icarus.2008. 06.016

Feldman, W. C., M. C. Bourke, R. C. Elphic, S. Maurice, J. Bandfield, T. H. Prettyman, B. Diez, and D. J. Lawrence (2008), Hydrogen content of sand dunes within Olympia Undae, Icarus, 196, 422-432, doi:10.1016/j.icarus.2007.08.044.

Fenchel, T., and T. H. Blackburn (1979), Bacteria and Mineral Cycling, Academic, San Diego, Calif.

Fischer, E., and C. Pieters (1993), The continuum slope of Mars: Bidirectional reflectance investigations and applications to Olympus Mons, Icarus, 102, 185-202, doi:10.1006/icar.1993.1043.

Fishbaugh, K. E., and J. W. Head III (2005), Origin and characteristics of the Mars north polar basal unit and implications for polar geologic history, Icarus, 174, 444-474, doi:10.1016/j.icarus.2004.06.021.

Fishbaugh, K. E., F. Poulet, V. Chevrier, Y. Langevin, and J.-P. Bibring (2007), On the origin of gypsum in the Mars north polar region, J. Geophys. Res., 112, E07002, doi:10.1029/2006JE002862.

Fisk, M. R., and S. J. Giovannoni (1999), Sources of nutrients and energy for a deep biosphere on Mars, J. Geophys. Res., 104, 11,805-11,815, doi:10.1029/1999JE900010

Fraeman, A. A., J. F. Mustard, B. L. Elhmann, L. H. Roach, R. E. Milliken, and S. L. Murchie (2009), Evaluating models of crustal cooling using CRISM observations of impact craters in Terra Tyrrhena and Noachis Terra, Lunar Planet. Sci., XL, Abstract 2320.

Frey, H. V. (2006), Impact constraints on the age and origin of the lowlands of Mars, Geophys. Res. Lett., 33, L08S02, doi:10.1029/2005GL024484. Gendrin, A., et al. (2005a), Sulfates in Martian layered terrains: The OMEGA/Mars Express view, Science, 307, 1587-1591, doi:10.1126/ science. 1109087.

Gendrin, A., et al. (2005b), Identification of predominant ferric signatures in association to the Martian sulfate deposits, Lunar Planet. Sci., XXXVI, Abstract 1378.

Grant, J. A., R. P. Irwin III, J. P. Grotzinger, R. E. Milliken, L. L. Tornabene, A. S. McEwen, C. M. Weitz, S. W. Squyres, T. D. Glotch, and B. J. Thomson (2007), Impact and aqeuous stratigraphy in Holden crater as revealed by HiRISE, in Seventh International Conference on Mars, July 9-13, 2007, Pasadena CA, [CD-ROM], LPI Contrib., 1353, Abstract 3229.

Grant, J. A., R. P. Irwin III, J. P. Grotzinger, R. E. Milliken, L. L. Tornabene, A. S. McEwen, C. M. Weitz, S. W. Squyres, T. D. Glotch, and B. J. Thomson (2008), HiRISE imaging of impact megabreccia and sub-meter aqueous strata in Holden Crater, Mars, Geology, 36, 195-198, doi:10.1130/G24340A.1.

Grant, W. D. (2004), Life at low water activity, Philos. Trans. R. Soc London, Ser. B, 359, 1249-1267, doi:10.1098/rstb.2004.1502.

Griffes, J. L., R. E. Arvidson, F. Poulet, and A. Gendrin (2007), Geologic and spectral mapping of etched terrain deposits in northern Meridiani Planum, J. Geophys. Res., 112, E08S09, doi:10.1029/2006JE002811.

Hamilton, V. E., and P. R. Christensen (2005), Evidence for extensive, olivine-rich bedrock on Mars, Geology, 33, 433-436, doi:10.1130/ G21258.1

Herkenhoff, K. E., S. Byrne, P. S. Russell, K. E. Fishbaugh, and A. S. McEwen (2007), Meter-scale morphology of the north polar region of Mars, Science, 317, 1711-1715, doi:10.1126/science.1143544.

Hoefen, T. M., R. N. Clark, J. L. Bandfield, M. D. Smith, J. C. Pearl, and P. R. Christensen (2003), Discovery of olivine in the Nili Fossae region of Mars, Science, 302, 627-630, doi:10.1126/science.1089647.

Horgan, B. H., J. F. Bell III, E. Z. Noe Dobrea, E. A. Cloutis, D. T. Bailey, M. A. Craig, L. H. Roach, and J. F. Mustard (2009), Distribution of hydrated minerals in the north polar region of Mars, J. Geophys. Res., 114, E01005, doi:10.1029/2008JE003187.

King, P. L., and H. Y. McSween Jr. (2005), Effects of $\mathrm{H}_{2} \mathrm{O}, \mathrm{pH}$, and oxidation state on the stability of Fe minerals on Mars, J. Geophys. Res., 110, E12S10, doi:10.1029/2005JE002482.

King, P. L., D. T. Lescinsky, and H. W. Nesbitt (2004), The composition and evolution of primordial solutions on Mars, with application to other planetary bodies, Geochim. Cosmochim. Acta, 68, 4993-5008, doi:10.1016/j.gca.2004.05.036.

Knoll, A. H., et al. (2005), An astrobiological perspective on Meridiani Planum, Earth Planet. Sci. Lett., 240, 179-189, doi:10.1016/ j.eps1.2005.09.045.

Komatsu, G., P. E. Geissler, R. G. Strom, and R. B. Singer (1993), Stratigraphy and erosional landforms of layered deposits in Valles Marineris, Mars, J. Geophys. Res., 98, 11,105-11,121, doi:10.1029/93JE00537.

Langevin, Y., F. Poulet, J.-P. Bibring, and B. Gondet (2005), Sulfates in the north polar region of Mars detected by OMEGA/Mars Express, Science, 307, 1584-1587, doi:10.1126/science.1109091.

Le Deit, L., D. Mège, O. Bourgeois, S. Le Mouélic, C. Sotin, N. Mangold, E. Hauber, A. Gendrin, and J.-P. Bibring (2007), Morphological and mineralogical analysis of east Candor Chasma in Valles Marineris on 
Mars, in Seventh International Conference on Mars, July 9-13, 2007, Pasadena CA, [CD-ROM], LPI Contrib., 1353, Abstract 3227.

Lewis, K. W., and O. Aharonson (2006), Stratigraphic analysis of the distributary fan in Eberswalde crater using stereo imagery, J. Geophys. Res., 111, E06001, doi:10.1029/2005JE002558

Loizeau, D., et al. (2007), Phyllosilicates in the Mawrth Vallis region of Mars, J. Geophys. Res., 112, E08S08, doi:10.1029/2006JE002877.

Lucchitta, B., et al. (1992), The canyon system on Mars, in Mars, edited by H. H. Kieffer et al., pp. 453-492, Univ. of Ariz. Press, Tucson.

Majzlan, J., A. Navrotsky, R. B. McCleskey, and C. N. Alpers (2006), Thermodynamic properties and crystal structure refinement of ferricopiapite, coquimbite, rhomboclase, and $\mathrm{Fe}_{2}\left(\mathrm{SO}_{4}\right)_{3}\left(\mathrm{H}_{2} \mathrm{O}\right)_{5}$, Eur. J. Mineral. 18, 175-186, doi:10.1127/0935-1221/2006/0018-0175

Malin, M. C., and K. S. Edgett (2001), Sedimentary rocks of early Mars, Science, 220, 1927-1937.

Malin, M. C., and K. S. Edgett (2003), Evidence for persistent flow and aqueous sedimentation on early Mars, Science, 302, 1931-1934, doi:10.1126/science.1090544.

Malin, M. C., G. E. Danielson, A. P. Ingersoll, H. Masursky, J. Veverka, M. A. Ravine, and T. A. Soulanille (1992), The Mars Observer camera, J. Geophys. Res., 97, 7699-7718, doi:10.1029/92JE00340.

Malin, M. C., et al. (2007), Context Camera investigation on board the Mars Reconnaissance Orbiter, J. Geophys. Res., 112, E05S04, doi:10.1029/ 2006JE002808.

Mangold, N., C. Quantin, V. Ansan, C. Delacourt, and P. Allemand (2004), Evidence for precipitation on Mars from dendritic valleys in the Valles Marineris area, Science, 305, 78-81, doi:10.1126/science.1097549.

Mangold, N., et al. (2007), Mineralogy of the Nili Fossae region with OMEGA/Mars Express data: 2. Aqueous alteration of the crust, J. Geophys. Res., 112, E08S04, doi:10.1029/2006JE002835.

Mangold, N., A. Gendrin, B. Gondet, S. LeMouelic, C. Quantin, V. Ansan, J.-P. Bibring, Y. Langevin, P. Masson, and G. Neukum (2008), Spectral and geological study of the sulfate-rich region of West Candor Chasma, Mars, Icarus, 194, 519-543, doi:10.1016/j.icarus.2007.10.021.

McEwen, A. S., M. C. Malin, M. H. Carr, and W. K. Hartmann (1999), Voluminous volcanism on early Mars revealed in Valles Marineris, Nature, 397, 584-586, doi:10.1038/17539.

McEwen, A. S., et al. (2007), Mars Reconnaissance Orbiter's High Resolution Imaging Science Experiment (HiRISE), J. Geophys. Res., 112, E05S02, doi:10.1029/2005JE002605.

McEwen, A. S., L. Tornabene, J. Grant, J. Wray, and J. Mustard (2008), Noachian megabreccia on Mars, Eos Trans. AGU, 89(53), Fall Meet. Suppl., Abstract P43D-03.

McEwen, A. S., et al. (2009), The High Resolution Imaging Science Experiment (HiRISE) during MRO's primary science phase (PSP), Icarus, in press.

McGuire, P. C., et al. (2008), CRISM retrieval of surface Lambert albedos for multispectral mapping of Mars with DISORT-based radiative transfer modeling, IEEE Trans. Geosci. Remote Sens., 46, 4020-4040, doi:10.1109/TGRS.2008.2000631.

McKay, C., and S. Nedell (1988), Are there carbonate deposits in the Valles Marineris, Mars?, Icarus, 73, 142-148, doi:10.1016/0019-1035(88) 90088-7.

McKeown, N. K., J. L. Bishop, E. Z. Noe Dobrea, B. L. Ehlmann, M. Parente, J. F. Mustard, S. L. Murchie, G. A. Swayze, J.-P. Bibring, and E. A. Silver (2009), Characterization of phyllosilicates observed in the central Mawrth Vallis region, Mars, their potential formational processes, and implications for past climate, J. Geophys. Res., doi:10.1029/ 2008JE003301, in press.

MEPAG Special Regions-Science Analysis Group (2006), Findings of the Mars Special Regions Science Analysis Group, Astrobiology, 6, $677-732$.

Michalski, J. R., and E. Z. Noe Dobrea (2007), Evidence for a sedimentary origin of clay minerals in the Mawrth Vallis region, Mars, Geology, 35, 951-954, doi:10.1130/G23854A.1.

Milliken, R., et al. (2008), Opaline silica in young deposits on Mars, Geology, 36, 847-850, doi:10.1130/G24967A.1.

Milliken, R. E., et al. (2009), A clay and sulfate stratigraphic sequence in Gale Crater, Lunar Planet. Sci., XL, Abstract 1479.

Murchie, S., et al. (2007a), Compact Reconnaissance Imaging Spectrometer for Mars (CRISM) on Mars Reconnaissance Orbiter (MRO), J. Geophys. Res., 112, E05S03, doi:10.1029/2006JE002682.

Murchie, S., et al. (2007b), CRISM mapping of layered deposits in western Candor Chasma, in Seventh International Conference on Mars, July 913, 2007, Pasadena CA, [CD-ROM], LPI Contrib., 1353, Abstract 3238.

Murchie, S., et al. (2009a), CRISM investigation and data set from the Mars Reconnaissance Orbiter's primary science phase, J. Geophys. Res., doi:10.1029/2009JE003344, in press.

Murchie, S., et al. (2009b), Evidence for the origin of layered deposits in Candor Chasma, Mars, from mineral composition and hydrologic modeling, J. Geophys. Res., doi:10.1029/2009JE003343, in press.
Mustard, J. F., F. Poulet, A. Gendrin, J.-P. Bibring, Y. Langevin, B. Gondet, N. Mangold, G. Bellucci, and F. Altieri (2005), Olivine and pyroxene diversity in the crust of Mars, Science, 307, 1594-1597, doi:10.1126/ science. 1109098

Mustard, J. F., F. Poulet, J. W. Head, N. Mangold, J.-P. Bibring, S. M. Pelkey, C. I. Fassett, Y. Langevin, and G. Neukum (2007), Mineralogy of the Nili Fossae region with OMEGA/Mars Express data: 1. Ancient impact melt in the Isidis Basin and implications for the transition from the Noachian to Hesperian, J. Geophys. Res., 112, E08S03, doi:10.1029/2006JE002834.

Mustard, J., et al. (2008), Hydrated silicate minerals on Mars observed by the CRISM instrument on MRO, Nature, 454, 305-309, doi:10.1038/ nature07097.

Mustard, J. F., B. L. Ehlmann, S. L. Murchie, F. Poulet, N. Mangold, J. W. Head, J.-P. Bibring, and L. H. Roach (2009), Composition, morphology, and stratigraphy of Noachian crust around the Isidis basin, J. Geophys. Res., doi:10.1029/2009JE003349, in press.

Nagy, K. L. (1995), Dissolution and precipitation kinetics of sheet silicates, in Chemical Weathering Rates of Silicate Minerals, edited by A. F. White and S. L. Brantley, pp. 173-233, Mineral. Soc. of Am., Washington, D. C.

Nedell, S. S., S. W. Squyres, and D. W. Andersen (1987), Origin and evolution of the layered deposits in the Valles Marineris, Mars, Icarus, 70, 409-414, doi:10.1016/0019-1035(87)90086-8.

Newsom, H. E., C. A. Barber, T. M. Hare, R. T. Schelble, V. A. Sutherland, and W. C. Feldman (2003), Paleolakes and impact basins in southern Arabia Terra, including Meridiani Planum: Implications for the formation of hematite deposits on Mars, J. Geophys. Res., 108(E12), 8075, doi:10.1029/2002JE001993

Noe Dobrea, E. Z., et al. (2008a), Clay bearing units in the region around Mawrth Vallis: Stratigraphy, extent, and possible alteration fronts, Lunar Planet. Sci., XXXIX, Abstract 1077.

Noe Dobrea, E. Z., J. Moore, A. Howard, D. Catling, and J. Grant (2008b), Spectral and geomorphic evidence for a past inland sea in Eridania basin, Mars, Eos Trans. AGU, 89(53), Fall Meet. Suppl., Abstract P32B-03.

Okubo, C. H., and A. S. McEwen (2007), Fracture-controlled paleo-fluid flow in Candor Chasma, Mars, Science, 315, 983-985, doi:10.1126/ science. 1136855

Okubo, C. H., K. W. Lewis, A. S. McEwen, and R. L. Kirk (2008), Relative age of interior layered deposits in southwest Candor Chasma based on high-resolution structural mapping, J. Geophys. Res., 113, E12002, doi:10.1029/2008JE003181

Osterloo, M. M., V. E. Hamilton, J. L. Bandfield, T. D. Glotch, A. M. Baldridge, P. R. Christensen, L. L. Tornabene, and F. S. Anderson (2008), Chloride-bearing materials in the southern highlands of Mars, Science, 319, 1651-1654, doi:10.1126/science.1150690.

Parente, M. (2008), A new approach to denoising CRISM images, Lunar Planet. Sci., XXXIX, Abstract 2528.

Parmentier, E. M., J. F. Mustard, B. L. Ehlmann, and L. H. Roach (2008), Deep hydrothermal circulation and implications for the early crustal compositional and thermal evolution of Mars, Lunar Planet. Sci., XXXIX, Abstract 1544.

Pelkey, S. M., et al. (2007), CRISM multispectral summary products: Parameterizing mineral diversity on Mars from reflectance, J. Geophys. Res. 112, E08S14, doi:10.1029/2006JE002831.

Peterson, C. (1981), A secondary origin for the central plateau of Hebes Chasma, Proc. Lunar Planet. Sci. Conf., 12, 1459-1471.

Poulet, F., J.-P. Bibring, J. F. Mustard, A. Gendrin, N. Mangold, Y. Langevin, R. E. Arvidson, B. Gondet, C. Gomez, and the OMEGA Team (2005), Phyllosilicates on Mars and implications for early Martian climate, Nature, 438, 623-627, doi:10.1038/nature04274.

Roach, L. H., J. F. Mustard, S. Murchie, C. M. Weitz, B. L. Ehlmann, S. Pelkey, F. P. Seelos, K. Seelos, J.-P. Bibring, and the CRISM Team (2007a), Sulfate identifications in East Candor, Valles Marineris with CRISM visible-infrared spectra, Lunar Planet. Sci., XXXVIII, Abstract 2106

Roach, L. H. (2007b), CRISM spectral signatures of the north polar gypsum dunes, Lunar Planet. Sci., XXXVIII, Abstract 1970.

Roach, L. H., J. F. Mustard, S. L. Murchie, J.-P. Bibring, R. E. Arvidson, J. L. Bishop, R. E. Milliken, F. Seelos, and the CRISM Science Team (2008), Constraints on the rate of sulfate phase changes in Valles Marineris interior layered deposits, Lunar Planet. Sci., XXXIX, Abstract 1823.

Roach, L. H., J. F. Mustard, S. L. Murchie, J.-P. Bibring, F. Forget, K. W. Lewis, O. Aharonson, M. Vincendon, and J. L. Bishop (2009), Testing evidence of recent hydration state change in sulfates on Mars, J. Geophys. Res., 114, E00D02, doi:10.1029/2008JE003245.

Robert, C., and B. Goffé (1993), Zeolitization of basalts in subaqueous freshwater settings: Field observations and experimental study, Geochim. Cosmochim. Acta, 57, 3597-3612, doi:10.1016/0016-7037(93)90142-J. 
Rogers, A. D., and P. R. Christensen (2007), Surface mineralogy of Martian low-albedo regions from MGS-TES data: Implications for upper crustal evolution and surface alteration, J. Geophys. Res., 112, E01003, doi:10.1029/2006JE002727.

Schatz, V., H. Tsoar, K. S. Edgett, E. J. R. Parteli, and H. J. Herrmann (2006), Evidence for indurated sand dunes in the Martian north pola region, J. Geophys. Res., 111, E04006, doi:10.1029/2005JE002514.

Scott, D. H., and K. L. Tanaka (1986), Geologic map of the western equatorial region of Mars, U.S. Geol. Surv. Misc. Geol. Invest. Map, I-1802-A

Solomon, S., et al. (2005), New perspectives on ancient Mars, Science, 307 , 1214-1220, doi:10.1126/science.1101812.

Squyres, S. W., et al. (2004), In situ evidence for an ancient aqueous environment at Meridiani Planum, Mars, Science, 306, 1709-1713, doi:10.1126/science. 1104559 .

Squyres, S. W., et al. (2006), Overview of the Opportunity Mars Exploration Rover mission to Meridiani Planum: Eagle Crater to purgatory ripple, J. Geophys. Res., 111, E12S12, doi:10.1029/2006JE002771.

Squyres, S. W., et al. (2008), Detection of silica-rich deposits on Mars, Science, 320, 1063-1067, doi:10.1126/science.1155429.

Stamnes, K., S.-C. Tsay, K. Jayaweera, and W. Wiscombe (1988), Numerically stable algorithm for discrete-ordinate-method radiative transfer in multiple scattering and emitting layered media, Appl. Opt., 27, 2502-2509, doi:10.1364/AO.27.002502.

Swayze, G. A., et al. (2008), Discovery of the acid-sulfate mineral alunite in Terra Sirenum, Mars, using MRO CRISM: Possible evidence for acidsaline lacustrine deposits?, Eos Trans. AGU, 89(53), Fall Meet. Suppl., Abstract P44A-04.

Tanaka, K. N., D. H. Scott, and R. Greeley (1992), Global stratigraphy, in Mars, edited by H. H. Kiefer et al., pp. 345-383, Univ. of Ariz. Press, Tucson.

Tanaka, K. L., J. A. P. Rodriguez, J. A. Skinner Jr., M. C. Bourke, C. M. Fortezzo, K. E. Herkenhoff, E. J. Kolb, and C. H. Okubo (2008), North polar region of Mars: Advances in stratigraphy, structure, and erosional modification, Icarus, 196, 318-358, doi:10.1016/j.icarus.2008.01.021.

Thomson, B. J., N. T. Bridges, R. Milliken, J. F. Bell III, W. C. Calvin, and C. M. Weitz (2008a), New constraints on the origin and evolution of the layered deposits in Gale crater, Mars, Lunar Planet. Sci., XXXIX, Abstract 1456.

Thomson, B. J., N. T. Bridges, R. Milliken, S. Hook, A. Baldridge, J. Crowley, and G. Marion (2008b), Signs of aqueous activity in Gale Crater, Mars as viewed by Mars Reconnaissance Orbiter, Eos Trans. $A G U, 89(53)$, Fall Meet. Suppl., Abstract P41B-1365.

Tornabene, L. L., A. S. McEwen, G. R. Osinski, P. J. Mouginis-Mark J. M. Boyce, R. M. E. Williams, J. J. Wray, J. A. Grant, and the HiRISE Team (2007), Impact melting and the role of subsurface volatiles: Implications for the formation of valley networks and phyllosilicate-rich lithologies on early Mars, in Seventh International Conference on Mars, July 9-13, 2007, Pasadena CA, [CD-ROM], LPI Contrib. 1353, Abstract 3288 .

Tosca, N. J., S. M. McLennan, B. C. Clark, J. P. Grotzinger, J. A. Hurowitz, A. H. Knoll, C. Schröder, and S. W. Squyres (2005), Geochemical modeling of evaporation processes on Mars: Insight from the sedimentary record at Meridiani Planum, Earth Planet. Sci. Lett., 240, $122-148$, doi:10.1016/j.epsl.2005.09.042.

Tosca, N. J., A. H. Knoll, and S. M. McLennan (2008), Water activity and the challenge for life on early Mars, Science, 320, 1204-1207, doi: $10.1126 /$ science. 1155432 .

Weitz, C. M., R. E. Milliken, J. A. Grant, A. S. McEwen, R. M. E. Williams, and J. L. Bishop (2008), Light-toned strata and inverted channels adjacent to Juventae and Ganges chasmata, Mars, Geophys. Res. Lett., 35, L19202, doi:10.1029/2008GL035317.
Weitz, C. M., R. E. Milliken, J. A. Grant, A. S. McEwen, R. M. E. Williams, J. L. Bishop, and B. J. Thomson (2009), Mars Reconnaissance Orbiter observations of light-toned layered deposits and associated fluvial landforms on the plateaus adjacent to Valles Marineris, Icarus, in press.

Williams, R. E., M. C. Malin, and K. S. Edgett (2005), Remnants of the courses of fine-scale, precipitation-fed runoff streams preserved in the Martian rock record, Lunar Planet. Sci., XXXVI, Abstract 1173.

Wiseman, S. M., J. L. Griffes, R. E. Arvidson, S. Murchie, F. Poulet, A. T. Knudson, F. P. Seelos, N. Tosca, and the CRISM Science Team (2007), New analyses of MRO CRISM, HiRISE, and CTX data over layered sedimentary deposits in Meridiani, in Seventh International Conference on Mars, July 9-13, 2007, Pasadena CA, [CD-ROM], LPI Contrib. 1353, Abstract 3111.

Wiseman, S. M., et al. (2008), Phyllosilicate and sulfate-hematite deposits within Miyamoto crater in southern Sinus Meridiani, Mars, Geophys. Res. Lett., 35, L19204, doi:10.1029/2008GL035363.

Wiseman, S. M., R. E. Arvidson, R. V. Morris, S. L. Murchie, F. P. Seelos, J. C. Andrews-Hanna, and the CRISM Team (2009), Hydrated sulfate deposits detected within Schiaparelli Crater, Mars, Lunar Planet. Sci., XL, Abstract 1798

Wray, J. J., S. W. Squyres, B. L. Ehlmann, J. F. Mustard, and and the HiRISE Team (2007), Meter-scale morphology and stratigraphy of phyllosilicate-rich outcrops in Mawrth Vallis, in Seventh International Conference on Mars, July 9-13, 2007, Pasadena CA, [CD-ROM], LPI Contrib., 1353, Abstract 3119.

Wray, J. J., B. L. Ehlmann, S. W. Squyres, J. F. Mustard, and R. L. Kirk (2008a), Compositional stratigraphy of clay-bearing layered deposits at Mawrth Vallis, Mars, Geophys. Res. Lett., 35, L12202, doi:10.1029/ 2008GL034385.

Wray, J. J., R. E. Milliken, S. L. Murchie, G. A. Swayze, C. M. Dundas, F. P. Seelos, and S. W. Squyres (2008b), Clays and sulfates in a potential lacustrine evaporite sequence at Columbus Crater, Mars, Eos Trans. $A G U, 89(53)$, Fall Meet. Suppl., Abstract P53B-1446.

Wray, J. J., S. L. Murchie, S. W. Squyres, F. P. Seelos, and L. L. Tornabene (2009), Diverse aqueous environments on ancient Mars revealed in the southern highlands, Geology, doi:10.1130/G30331A.1, in press.

R. E. Arvidson and S. M. Wiseman, Department of Earth and Planetary Sciences, Washington University, St. Louis, MO 63130, USA.

J.-P. Bibring, Lunar and Planetary Laboratory, University of Arizona, Tucson, AZ 85721, USA.

J. L. Bishop, SETI Institute, Mountain View, CA 94043, USA.

D. L. Buczkowski, S. L. Murchie, and F. P. Seelos, Applied Physics Laboratory, Laurel, MD 20723, USA. (scott.murchie@jhuapl.edu)

R. N. Clark and G. Swayze, U.S. Geological Survey, Denver, CO 80225 , USA.

D. J. Des Marais, NASA Ames Research Center, Moffett Field, CA 94035, USA.

B. L. Ehlmann and J. F. Mustard, Department of Geological Sciences, Brown University, Providence, RI 02912, USA.

A. S. McEwen, Institut d'Astrophysique Spatiale, Université Paris Sud, F-91405 Orsay, France.

N. K. McKeown, Department of Earth and Planetary Sciences, University of California, Santa Cruz, CA 95064, USA.

R. E. Milliken and E. Z. Noe Dobrea, Jet Propulsion Laboratory, Caltech, Pasadena, CA 91109, USA.

J. J. Wray, Department of Astronomy, Cornell University, Ithaca, NY 14853, USA. 